\title{
Field Test Design Simulations of Pore-Water Extraction for the SX Tank Farm
}

\author{
MJ Truex \\ M Oostrom
}

September 2013

Pacific Northwest

NATIONAL LABORATORY

Proudly Operated by Battelle Since 1965 


\title{
DISCLAIMER
}

This report was prepared as an account of work sponsored by an agency of the United States Government. Neither the United States Government nor any agency thereof, nor Battelle Memorial Institute, nor any of their employees, makes any warranty, express or implied, or assumes any legal liability or responsibility for the accuracy, completeness, or usefulness of any information, apparatus, product, or process disclosed, or represents that its use would not inf ringe privately owned rights. Reference herein to any specific commercial product, process, or service by trade name, trademark, manufacturer, or otherwise does not necessarily constitute or imply its endorsement, recommendation, or favoring by the United States Government or any agency thereof, or Battelle Memorial Institute. The views and opinions of authors expressed herein do not necessarily state or reflect those of the United States Government or any agency thereof.

\author{
PACIFIC NORTHWEST NATIONAL LABORATORY \\ operated by \\ BATTELLE \\ for the \\ UNITED STATES DEPARTMENT OF ENERGY \\ under Contract DE-AC05-76RL01830
}

Printed in the United States of America
Available to DOE and DOE contractors from the
Office of Scientific and Technical Information
P.O. Box 62, Oak Ridge, TN 37831-0062;
ph: (865) 576-8401
fax: $(865) 576-5728$
email: reports@adonis.osti.gov

Available to the public from the National Technical Information Service

5301 Shawnee Rd., Alexandria, VA 22312

ph: (800) 553-NTIS (6847)

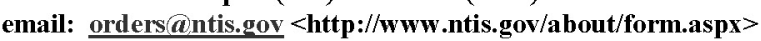

Online ordering: http://www.ntis.gov

This document was printed on recycled paper. 


\title{
Field Test Design Simulations of Pore-Water Extraction for the SX Tank Farm
}

\author{
MJ Truex
}

M Oostrom

September 2013

Prepared for

the U.S. Department of Energy

under Contract DE-AC05-76RL01830

Pacific Northwest National Laboratory

Richland, Washington 99352 


\section{Summary}

A proof-of-principle test of pore-water extraction is being performed by Washington River Protection Solutions for the U.S. Department of Energy, Office of River Protection. The test is being conducted to meet the requirements of Hanford Federal Facility Agreement and Consent Order (Ecology et al. 1989) Milestone M-045-20, and is described in the 200 West Area Tank Farms Interim Measures Investigation Work Plan (RPP-PLAN-53808 2013). To support the design of the test, numerical simulations were conducted to help define equipment and operational parameters. The modeling effort builds from information collected in laboratory studies and from field characterization information collected at the test site near the Hanford Site 241-SX Tank Farm. Numerical simulations were used to evaluate pore-water extraction performance as a function of the test site properties and for the type of extraction well configuration that can be constructed using the direct-push installation technique. Output of simulations included rates of water and soil-gas extraction as a function of operational conditions for use in supporting field equipment design. The simulations also investigated the impact of subsurface heterogeneities in sediment properties and moisture distribution on pore-water extraction performance. Phenomena near the extraction well were also investigated because of their importance to pore-water extraction performance.

Two sets of simulations were conducted to evaluate pore-water extraction under conditions relevant to the SX Tank Farm test site. In the first set, the 10-m-thick Cold Creek Unit silt (CCUz) layer was assumed to be either 1) homogeneous or 2) heterogeneous with a single $0.3-\mathrm{m}$ (1-ft)-thick highconductivity layer (at various locations with respect to the screen interval) in an otherwise homogeneous zone. In these simulations, the extraction rates were computed for relatively simple representations of the CCUz layer, but provided an effective configuration to examine the impact of variations in key hydraulic parameters and subsurface configurations (e.g., the position of hypothetical high-permeability layers with respect to the extraction screen). For the second set of simulations, three model configuration approaches were used to represent the observed vertical distribution of moisture content variations in the CCUz layer at the field test site (data from borehole C8761). In all simulations, extraction was from a $0.3-\mathrm{m}$ (1-ft) screened interval.

For a homogeneous CCUz layer with hydraulic properties obtained in the laboratory (e.g., Base Case simulations), long-term pore-water extraction rates are approximately $15 \mathrm{~L} /$ day. The associated gas extraction rate is about $11.3 \mathrm{~L} / \mathrm{min}\left(0.4 \mathrm{ft}^{3} / \mathrm{min}\right)$. However, the pore-water extraction rate is highly sensitive to the initial water saturation adjacent to the well screen. Increasing the vacuum from 2 to $3 \mathrm{~m}$ $\mathrm{H}_{2} \mathrm{O}$ ( $\sim 20$ to $30 \mathrm{kPa}, 2.8$ to $4.3 \mathrm{psi}$ ) almost triples the water extraction rate. Based on experience from laboratory experiments, care must be used in applying higher vacuum levels to avoid creating preferential gas flow pathways that negatively affect the pore-water extraction rate.

A limited sensitivity analysis of hydraulic properties identified hydraulic conductivity and the van Genuchten parameters $n$ and $\alpha$ as having the most impact on pore-water extraction performance. Changes in hydraulic conductivity have a nearly linear correlation with water extraction rates. An increase in the pore geometry factor $n$ or a decrease in the air entry pressure factor $\alpha$ both resulted in considerably higher extraction rates, with limited effects on the gas extraction rates. The vertical anisotropy ratio, up to a value of 100 , had only a minor effect on the water extraction rate. All the investigated parameter value variations were within the ranges of potential values for the field test site, indicating that a wide range of possible water extraction rates may occur in the field test. 
Of importance for equipment design and test operations, the gas extraction rates of most simulations yielded values of less than $28.3 \mathrm{~L} / \mathrm{min}\left(1 \mathrm{ft}^{3} / \mathrm{min}\right)$. Values considerably higher than $28.3 \mathrm{~L} / \mathrm{min}\left(1 \mathrm{ft}^{3} / \mathrm{min}\right)$ were obtained for simulation cases in which (part of) the well screen was located directly adjacent to a high-permeability zone. These high gas extraction rates correlate with low water extraction rates and delayed water arrival times at the extraction well. At the field test site, the combination of these observations (high gas extraction rate, low water extraction rate, delayed water arrival) would be a strong indication that a high-permeability zone with low moisture content is negatively affecting the water extraction performance. However, if both relatively high water and gas extraction rates are observed, it is likely that the well screen is located adjacent to a high-moisture zone with a relatively high water permeability. Such conditions are most favorable for water removal using the pore-water extraction technique.

Near-well compaction occurring during well installation will reduce both water and gas extraction rates but will not reduce these rates to zero. Field indicators of such conditions are relatively low water extraction rates in combination with low gas extraction rates. Based on testing within boreholes recently installed at the field test site, well development through surging and purging with relatively small volumes of water appears to have the ability to reduce near-well compaction and improve pore-water extraction performance. This testing also included use of a falling-head test approach to verify well development success in decreasing near-well compaction and providing an estimate of subsurface permeability adjacent to the screened interval based on an analytical computation. A series of STOMP simulations was completed as an independent evaluation of the falling-head test analysis applied during well development. The main conclusion from the numerical analysis is that the analytical computation appears to be valid and can be used to interpret falling-head data during well development in these kinds of unsaturated sediments. A more complex numerical simulator is not needed to produce reliable orderof-magnitude-level permeability estimates.

Modeling was also conducted using configurations with more detailed layering of the CCUz that was based on soil moisture data from the field test site (borehole C8761). Simulations with these configurations resulted in pore-water extraction rates between approximately 2 and $5 \mathrm{~L} /$ day and gas extraction rates of less than $56.6 \mathrm{~L} / \mathrm{min}\left(2 \mathrm{ft}^{3} / \mathrm{min}\right)$. The reduced pore-water extraction rates, compared to the Base Case simulation, are related to the limited thickness of high-moisture zones from which water was extracted. The impact of limited thickness moisture zones will need to be considered when evaluating the field test data.

This modeling study provides estimates of pore-water extraction for a variety of potential conditions in the field. The study builds on previous efforts to verify and quantify the pore-water extraction process. The modeling study results can be used to help guide equipment selection, operational strategies, and interpretation of the field test results. The following specific recommendations for the field test configuration are based on these modeling results.

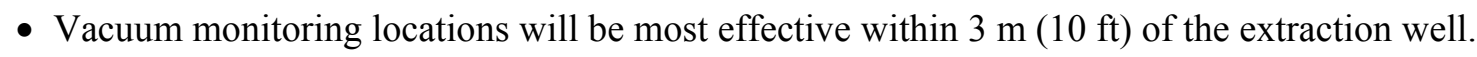

- Test equipment should accommodate pore-water extraction rates of up to $10 \mathrm{~s}$ of $\mathrm{L} /$ day with associated gas extraction rates of between 2.8 and $56.6 \mathrm{~L} / \mathrm{min}\left(0.1\right.$ and $\left.2 \mathrm{ft}^{3} / \mathrm{min}\right)$ for the expected subsurface conditions at the field test site.

- To improve the pore-water extraction rate, extraction well screens should target high-moisture zones and avoid intersecting zones with low moisture content. With the observed variation in 
moisture content at the field test site, a well screen interval of $0.3 \mathrm{~m}(1 \mathrm{ft})$ is expected to enable effective targeting of a high moisture content zone.

- Well development efforts are recommended to loosen the compacted zone of sediment adjacent to the well bore at the screened interval and improve the permeability of this zone using the techniques previously tested in borehole C8761. 


\section{Acknowledgments}

Funding for this work was provided by Washington River Protection Solutions. Pacific Northwest National Laboratory is operated by Battelle Memorial Institute for the U.S. Department of Energy under Contract DE-AC05-76RL01830. 


\section{Acronyms and Abbreviations}

$\begin{array}{ll}{ }^{\circ} \mathrm{C} & \text { degrees Celsius } \\ \alpha & \text { air entry pressure factor } \\ \text { bgs } & \text { below ground surface } \\ \mathrm{CCU} & \text { Cold Creek Unit } \\ \mathrm{CCUc} & \text { Cold Creek Unit caliche } \\ \mathrm{CCUz} & \text { Cold Creek Unit silt } \\ \mathrm{cm} & \text { centimeter(s) } \\ \mathrm{DOE} & \text { U.S. Department of Energy } \\ \mathrm{ft} & \text { foot, feet } \\ \mathrm{ft} / \mathrm{min} & \text { cubic foot (feet) per minute } \\ \mathrm{gal} & \text { gallon(s) } \\ \mathrm{H} 1 & \text { Hanford formation H1 sediments } \\ \mathrm{H} 2 & \text { Hanford formation H2 sediments } \\ \mathrm{kg} / \mathrm{m}^{2} \mathrm{~s} & \text { kilogram(s) per square meter per second } \\ \mathrm{L} & \text { liter(s) } \\ \mathrm{L} / \mathrm{min} & \text { liters per minute } \\ \mathrm{m} & \text { meter(s) } \\ \mathrm{mm} & \text { millimeter(s) } \\ n & \text { pore geometry factor } \\ \mathrm{Pa} & \text { pascal(s) } \\ \mathrm{PNNL} & \text { Pacific Northwest National Laboratory } \\ \mathrm{psi} & \text { pounds per square inch } \\ \mathrm{s} & \text { second(s) } \\ \mathrm{STOMP} & \text { Subsurface Transport Over Multiple Phases } \\ \mathrm{Tc}-99 & \text { technetium-99 } \\ & \\ \mathrm{Pa} & \end{array}$




\section{Contents}

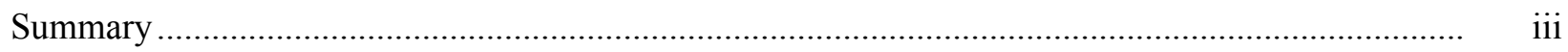

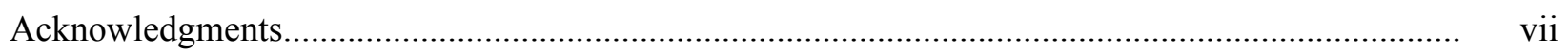

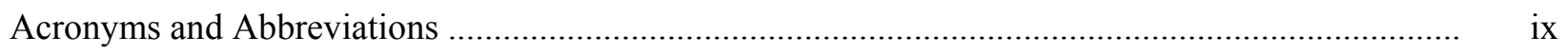

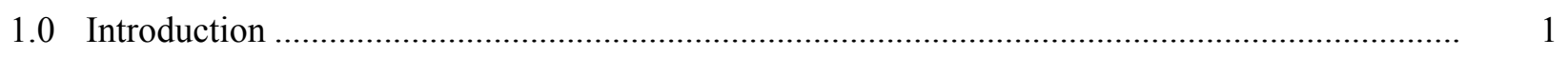

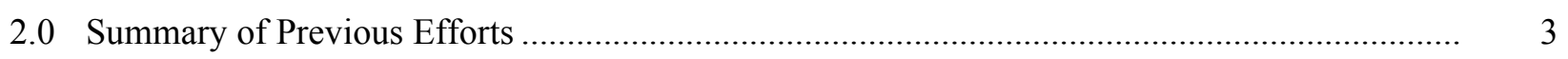

2.1 Pore-Water Extraction Phenomena ............................................................................ 3

2.2 Pore-Water Extraction Scale-Up for SX Tank Farms Application .................................... 4

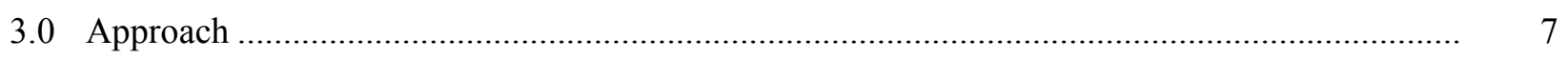

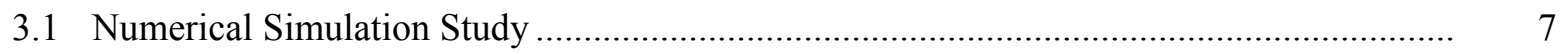

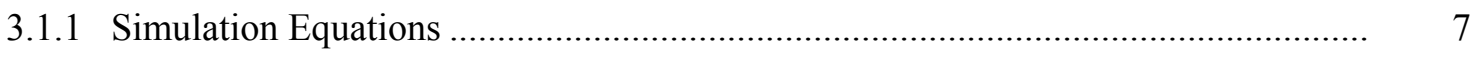

3.1.2 Seepage Face Boundary Condition ............................................................. 8

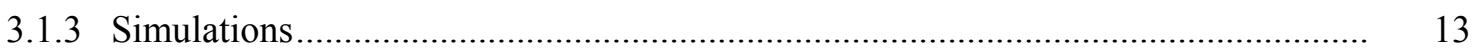

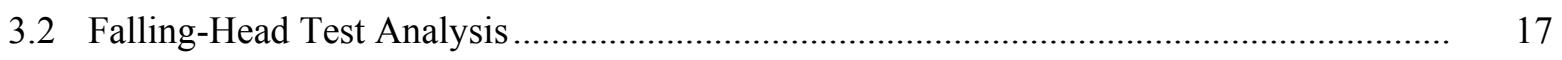

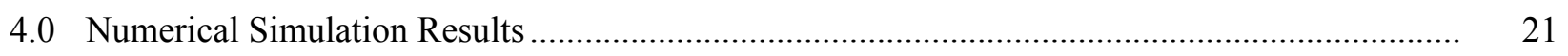

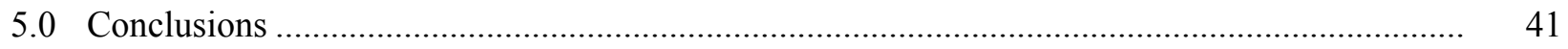

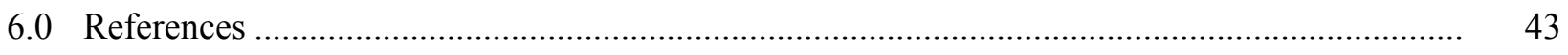

Attachment - Vadose Zone Falling-Head Test Evaluation........................................................ A.1

\section{Figures}

1 Gas and water pressures at $t=0,1$, and 60 seconds after imposing a Seepage Face boundary condition at the left-hand side of a 1-m-long horizontal column filled with unsaturated silt

2 Gas and water pressures at $t=60$ seconds, 1 day, and 3 days after imposing a Seepage Face boundary condition at the left-hand side of a 1-m-long horizontal column filled with unsaturated silt

3 Water saturations at $t=0$ seconds, 1 hour, 1 day, and 3 days after imposing a Seepage Face boundary condition at the left-hand side of a 1-m-long horizontal column filled with unsaturated silt.

4 Cumulative water extraction after imposing a Seepage Face boundary condition at the left-hand side of a 1-m-long horizontal column filled with unsaturated silt

5 Gas and water pressures at $t=0,1$, and 60 seconds after imposing a Seepage Face boundary condition at the left-hand side of a 1-m-long horizontal column filled with unsaturated silt.....

6 Gas and water pressures at $t=60$ seconds, 10 days, and 30 days after imposing a Seepage Face boundary condition at the left-hand side of a 1-m-long horizontal column filled with unsaturated silt 
7 Water saturations at $t=0$ seconds, 1 day, 10 days, and 30 days after imposing a Seepage Face boundary condition at the left-hand side of a 1-m-long horizontal column filled with unsaturated silt

8 Computational domain for pore-water extraction simulations listed in Table 1

9 Volumetric moisture contents as a function of depth at borehole C8761 in the SX area

10 Initial moisture contents for simulation of pore-water extraction from layered system using Method 1

11 Layer porosities for simulation of pore-water extraction from layered system using Method 2

12 Falling head test hydrographs obtained with STOMP simulations

13 Falling head test hydrographs for three near-well saturations obtained with STOMP simulations .....

14 Water and gas extraction rates as a function of time for the Base Case simulation.

15 Water and gas extraction rates as a function of time for the Base Case simulation during the initial stages of the vacuum application.

16 Near-well water saturations and velocities for the Base Case simulation during steadystate conditions

17 Gas pressures for the Base Case simulation during steady-state conditions.

18 Water and gas extraction rates as a function of time for the simulation with an initial nearwell water saturation of 0.9 .

19 Water and gas extraction rates as a function of time for the simulation with an initial nearwell water saturation of 0.7

20 Water and gas extraction rates as a function of time for the simulation with an imposed vacuum of $3 \mathrm{~m} \mathrm{H}_{2} \mathrm{O}$

21 Water and gas extraction rates as a function of time for the simulation with an increased hydraulic conductivity

22 Water and gas extraction rates as a function of time for the simulation with a decreased hydraulic conductivity

23 Steady-state gas pressure for the simulation with an increased hydraulic conductivity

24 Water and gas extraction rates as a function of time for the simulation with an anisotropy ratio of $10: 1$

25 Water and gas extraction rates as a function of time for the simulation with an anisotropy ratio of 100:1

26 Near-well water saturations and velocities for the simulation with an anisotropy ratio of $10: 1$

27 Water and gas extraction rates as a function of time for the simulation with an increased van Genuchten $n$ value

28 Water and gas extraction rates as a function of time for the simulation with a decreased van Genuchten $n$ value.

29 Water and gas extraction rates as a function of time for the simulation with a decreased van Genuchten $\alpha$ value

30 Water and gas extraction rates as a function of time for the simulation with an increased van Genuchten $\alpha$ value 
31 Water and gas extraction rates as a function of time for the simulation with a highpermeability sand layer between 123 and $124 \mathrm{ft}$ bgs

32 Water and gas extraction rates as a function of time for the simulation with a highpermeability sand layer between 122.5 and $123.5 \mathrm{ft}$ bgs

33 Water and gas extraction rates as a function of time for the simulation with a highpermeability sand layer between 122.25 and $123.25 \mathrm{ft}$ bgs

34 Water and gas extraction rates as a function of time for the simulation with a highpermeability sand layer between 122 and $123 \mathrm{ft} \mathrm{bgs}$

35 Steady-state water saturations and velocities for the simulation with a high-permeability sand layer between 123 and $124 \mathrm{ft}$ bgs

36 Water and gas extraction rates as a function of time for the simulation with a highpermeability sand layer between 123.25 and $123.75 \mathrm{ft}$ bgs

37 Water and gas extraction rates as a function of time for the simulation with a compaction zone with a 10 -times-reduced $K_{\text {sat }}$ value

38 Water and gas extraction rates as a function of time for the simulation with a compaction zone with a 100 -times-reduced $K_{\text {sat }}$ value

39 Steady-state water saturation and velocities for the simulation with a compaction zone with a 10 -times-reduced $K_{\text {sat }}$ value

40 Water and gas extraction rates as a function of time for the simulation with a layered system created using Method 1

41 Steady-state gas pressure for the simulation with a layered system created using Method 1.......

42 Water and gas extraction rates as a function of time for the simulation with a layered system created using Method 2

43 Steady-state gas pressure for the simulation with a layered system created using Method $2 \ldots . .$.

44 Water and gas extraction rates as a function of time for the simulation with a layered system created using Method 3

45 Steady-state gas pressure for the simulation with a layered system created using Method $3 \ldots \ldots .$.

\section{Tables}

1 Overview of simulations using the layered system depicted in Figure 8.................................. 14

2 Hydraulic properties of the sediments used in the STOMP simulations ................................... 15

3 Water and gas extraction rates after 90 days of vacuum extraction and arrival time of water at the extraction well for the simulations listed in Table 1 


\subsection{Introduction}

A proof-of-principle test of pore-water extraction is being performed by Washington River Protection Solutions for the U.S. Department of Energy, Office of River Protection. The test is being conducted to meet the requirements of Hanford Federal Facility Agreement and Consent Order (Ecology et al. 1989) Milestone M-045-20, and is described in the 200 West Area Tank Farms Interim Measures Investigation Work Plan (RPP-PLAN-53808 2013). The test will use the application of negative pressure (vacuum) via soil-gas extraction at a well to induce coincident pore-water extraction. Previous laboratory and modeling efforts have included quantification of pore-water extraction by application of negative pressure (vacuum) via soil-gas extraction at a well to induce coincident pore-water extraction (Oostrom et al. 2011; Truex et al. 2012).

The test design is centered on using tank-farm-deployable equipment to address the constraints of working within a tank farm. Because of radioactive soil contamination and limitations in drilling near tanks, small-diameter direct-push drilling techniques applicable to tank farms are being used for well placement. To address space and weight limitations in working around tanks and obstacles within tank farms, the above-ground portions of the test system have been constructed to allow deployment flexibility.

To support design of this test, Pacific Northwest National Laboratory (PNNL) conducted numerical simulations to help define equipment and operational parameters. The modeling effort builds from information collected in laboratory studies and from field characterization information collected at the test site near the Hanford Site's 241-SX Tank Farm. Numerical simulations were used to evaluate pore-water extraction performance as a function of the test site properties and for the type of extraction well configuration that can be constructed using the direct-push installation technique. The output of the simulations included rates of water and soil-gas extraction as a function of operational conditions for use in supporting field equipment design. The simulations also investigated the impact of subsurface heterogeneities in sediment properties and moisture distribution on pore-water extraction performance. Phenomena near the extraction well were also investigated because of their importance for pore-water extraction performance.

The ensuing sections of this report present a summary of previous laboratory and modeling evaluations of pore-water extraction (Section 2.0), the study approach (Section 3.0), and the results of the numerical simulation study (Section 4.0). Section 5.0 presents conclusions of the study. Sources cited in

the text are listed in Section 6.0. A memorandum reporting on a vadose zone falling-head test evaluation is included as an attachment. 


\subsection{Summary of Previous Efforts}

Previous laboratory and modeling efforts conducted by PNNL to examine pore-water extraction are summarized in this section. Details are available in the cited references.

\subsection{Pore-Water Extraction Phenomena}

Both numerical simulations and laboratory experiments have been applied to investigate the process of pore-water extraction by inducing a vacuum with soil-gas extraction. Initially, a series of numerical simulations was used to evaluate the potential conditions for pore-water extraction and the temporal pattern of the pore-water extraction rate. Based on these simulations, a set of laboratory experiments was designed and conducted to measure pore-water extraction under controlled conditions. The simulation model was revisited to model the laboratory experiments and confirm that the numerical model properly reproduced the experimental results.

Numerical simulations were used to examine the phenomena of pore-water extraction for selected sand, silt, and clay sediment properties. Simulations were configured with a negative pressure (suction) applied at an extraction well, creating a pressure gradient toward the extraction well. From these simulations, it was concluded that the induced pressure gradient across the sediment could result in porewater migration to the well; the most movement occurred in silt-type sediments (versus sand- or clay-type sediments). In the simulations, not all pore water could be extracted. Only a portion of water above a threshold moisture content (a function of the sediment properties and imposed vacuum) could be extracted. The simulation results also suggested that the pore-water extraction process can potentially be sustained for as long as water content conditions remain above the threshold for pore-water movement.

An additional set of flow cell tests and associated numerical simulations were conducted to further demonstrate the phenomena of pore-water extraction (Oostrom et al. 2011) and are summarized in the remainder of this section. A series of six flow cell experiments was conducted to demonstrate the process of pore-water extraction in unsaturated systems as a result of induced vacuum. An intermediate-scale flow cell was designed and constructed specifically for this purpose. The experimental configurations consisted of homogeneous packings that represent, in terms of particle-size distribution, targeted subsurface sediments at the Hanford Site SX Tank Farm that contain high moisture contents and high contaminant concentrations. The porous media used in the actual experiments were mixtures of several classes of other Hanford Site sediments to arrive at the selected particle-size distribution. The water in the flow cell experiments did not contain contaminants.

In the six experiments conducted, the variables considered were the imposed negative pressure ( $1 \mathrm{~m} \mathrm{H}_{2} \mathrm{O}$ and $2 \mathrm{~m} \mathrm{H}_{2} \mathrm{O}$ [1.4 and $\left.2.8 \mathrm{psi}\right]$ ), initial volumetric moisture content (0.11 and

$0.18 \mathrm{~m}^{3}{ }_{\text {water }} / \mathrm{m}^{3}$ total), water supply (no flow boundary condition and a condition in which extracted water was replenished), and the inclusion of fine-grained sand to represent a filter pack around the extraction well. The experiments without the fine-grained filter pack sand were conducted for 7 days, while the experiments with the fine-grained filter pack sand lasted for 10 days. Temporal data included water content distribution and measurement of water pressure at four locations in the flow cell. For the experiments with the fine-grained filter pack sand, gas pressures were also obtained at the same locations as the water pressures. 
In experiments where a zero-flux water boundary condition was imposed, the application of a negative pressure (vacuum) in a controlled manner resulted in pore-water extraction until the water pressure gradients toward the extraction boundary approached zero. A few scoping tests indicated that when the extraction vacuum was applied instantaneously, virtually no water outflow was obtained, likely because of the formation of larger conduits through which air could easily be conducted without associated movement of water. For field applications, it is recommended that the imposed vacuum be slowly increased to avoid the water continuity problems observed in the laboratory.

Although the experimental matrix was not sufficiently large to reach conclusions regarding maximizing cumulative pore-water extraction, several general trends were observed. Increased cumulative pore-water extraction was obtained with an increase in initial moisture content or applied negative pressure (suction) and when the water supply was not limited.

The experiments demonstrated that pore-water extraction from unsaturated porous media is, in principle, possible under the highly controlled conditions in the laboratory. The design was such that the moving air was forced to travel through sediment containing the pore water available for extraction. More complex systems with porous media heterogeneities were not investigated.

The pore-water extraction performance and pressure predictions of the simulations were similar to the experimental observations for all six experiments. This result demonstrates that numerical simulations can be used as a design tool for field-scale applications of pore-water extraction. Some of the reasons good agreement between numerical and experimental results were obtained include the independent determination of hydraulic properties and the control of experimental boundary and initial conditions.

\subsection{Pore-Water Extraction Scale-Up for SX Tank Farms Application}

Laboratory experiments and numerical modeling were conducted to specifically examine pore-water extraction for sediment conditions relevant to the vadose zone beneath the SX Tank Farm at the Hanford Site (Truex et al. 2012). Available SX Tank Farm data were evaluated to generate a conceptual model of the subsurface in areas with elevated moisture and Tc-99 concentration. This conceptual model formed the basis for selecting materials for subsequent laboratory hydraulic property analyses and for conducting numerical modeling to simulate a field application of pore-water extraction.

Hydraulic properties of the types of sediment in the targeted zone of the SX Tank Farm subsurface were determined in the laboratory. Sediment mixtures were prepared in the laboratory based on borehole sediment particle-size data for each type of sediment. Measurements quantified the sediment porosity, hydraulic conductivity, and the nature of pressure-saturation relationships, thereby extending the available sediment characterization data. These sediment characterization data were used to estimate the pore-water extraction potential for each sediment type as a function of initial moisture content and applied suction. In summary, study results showed that pore-water extraction through application of vacuum or absorbent polymers can extract water from SX Tank Farm sediments primarily when initial volumetric moisture content is above $25 \%\left(\mathrm{~m}^{3}\right.$ water $/ \mathrm{m}^{3}$ total $)$ and applied suction is greater than $2 \mathrm{~m} \mathrm{H}_{2} \mathrm{O}(2.8 \mathrm{psi})$. Another important finding was that the hydraulic properties of the sediments in the targeted pore-water extraction area are similar. Thus, inefficiencies in pore-water extraction caused by hydraulic property heterogeneity may not be extreme for the targeted vadose zone depth intervals at the SX Tank Farm. Future laboratory flow cell tests will provide more specific information for evaluating the impact of 
sediment property differences on pore-water extraction performance and are also required to select appropriate well filter-pack materials to ensure efficient pore-water extraction.

Numerical modeling was used as an evaluation tool to examine scale-up of pore-water extraction. In numerical simulations, the pore-water extraction rate declined rapidly from initial extraction rates to a steady-state rate under conditions with an infinite water supply (e.g., a laterally extensive high-moisture zone). Although not simulated, a finite water supply would result in a continued decline of pore-water extraction rates over time. The rate of pore-water extraction is relatively slow for the simulated SX Tank Farm conditions because water content reduction near the extraction well resulted in a decreased water relative permeability. In general, unless the hydraulic conductivity encountered in the field is significantly different (higher or lower) than the values determined in the laboratory, pore-water extraction rates are expected to be approximately 5 to $15 \mathrm{~L} /$ day. As an example, these pore-water extraction rates translate to remediation time frames on the order of decades for the goal of decreasing volumetric moisture content by $5 \%\left(\mathrm{~m}^{3}{ }_{\text {water }} / \mathrm{m}^{3}\right.$ total $)$ in a $10-\mathrm{m}$ radius around an extraction well. Thus, the remedy must be applied over a relatively long time frame to meet objectives, much like other contaminant extraction technologies (e.g., pump-and-treat of groundwater). These estimates of pore-water extraction rates (and corresponding remediation time frames) should be considered approximations. Additional data from planned laboratory flow cell experiments and field testing will provide more specific remedy performance information. 


\subsection{Approach}

This study included two components - numerical simulation and falling-head test analysis. Each is described in this section.

\subsection{Numerical Simulation Study}

Numerical modeling was used as an evaluation tool for scale-up, including simulations to assess the impact of heterogeneities and extraction well configuration on pore-water extraction performance for targeted field applications. Simulations included three-dimensional configurations with appropriate variations in porous media properties and heterogeneities and with imposed vacuum/pressure conditions for selected scenarios. These simulations evaluated overall extraction performance in terms of water removal rate, water removal extent (i.e., percentage of initial moisture content), and lateral influence as a function of time. Simulations were conducted using an approach similar to that applied for previous porewater extraction efforts (Oostrom et al. 2011).

\subsubsection{Simulation Equations}

The vacuum-induced, pore-water extraction simulations were conducted with the water-air-energy mode of the Subsurface Transport Over Multiple Phases (STOMP) simulator (White and Oostrom 2006). This fully implicit integrated finite difference mode of the simulator has been used to simulate a variety of water-air systems (e.g., Oostrom et al. 2009). For the simulations, constant temperature boundary conditions $\left(20^{\circ} \mathrm{C}\right)$ were assumed. The applicable governing equations ( 1 through 5$)$ are the component mass-conservation equations for water and air:

$$
\begin{gathered}
\frac{\partial}{\partial t}\left[n_{D} \omega_{l}^{w} \rho_{l} s_{l}\right]=-\nabla F_{l}^{w}+\dot{m}^{w} \\
\frac{\partial}{\partial t}\left[\sum_{\gamma=l, g}\left(n_{D} \omega_{\gamma}^{a} \rho_{\gamma} s_{\gamma}\right)\right]=-\sum_{\gamma=l, g}\left\{\nabla F_{\gamma}^{a}+\nabla J_{\gamma}^{a}\right\}+\dot{m}^{a}
\end{gathered}
$$

where

$$
\begin{array}{cc}
F_{\gamma}^{w}=-\frac{\omega_{\gamma}^{w} \rho_{\gamma} k_{r l} k}{\mu_{\gamma}}\left(\nabla P_{\gamma}+\rho_{\gamma} g z\right) & \text { for } \gamma=l, g, \\
F_{\gamma}^{a}=-\frac{\omega_{\gamma}^{a} \rho_{\gamma} k_{r \gamma} k}{\mu_{\gamma}}\left(\nabla P_{\gamma}+\rho_{\gamma} g z\right) & \text { for } \gamma=l, g \\
J_{\gamma}^{a}=-\tau_{\gamma} n_{D} \rho_{\gamma} s_{\gamma} \frac{M^{a}}{M_{\gamma}} D_{\gamma}^{a} \nabla \chi_{\gamma}^{a} & \text { for } \gamma=l, g
\end{array}
$$


The subscripts $l$ and $g$ denote aqueous and gas phases, respectively; the superscripts $w$ and $a$ denote water and air components, respectively; $t$ is time (s); $n_{D}$ is the diffusive porosity; $n_{T}$ is the total porosity; $\omega$ is the component mass fraction; $\rho$ is the density $\left(\mathrm{kg} / \mathrm{m}^{3}\right) ; s$ is the actual liquid saturation

$\left(\mathrm{m}^{3}{ }_{\text {liquid }} / \mathrm{m}^{3}\right.$ pore space); $\mathrm{V}$ is the volumetric flux $(\mathrm{m} / \mathrm{s}) ; J$ is the diffusive-dispersive mass flux vector $\left(\mathrm{kg} / \mathrm{m}^{2} \mathrm{~s}\right)$; $m$ is the component mass source rate $\left(\mathrm{kg} / \mathrm{m}^{3} \mathrm{~s}\right) ; k$ is the intrinsic permeability $\left(\mathrm{m}^{2}\right) ; \mathrm{k}_{\mathrm{r \gamma}}$ is the relative permeability of phase $\gamma ; \mu$ is the viscosity $(\mathrm{Pa} \mathrm{s}) ; P$ is the pressure $(\mathrm{Pa}) ; g_{z}$ is the gravitational vector $\left(\mathrm{m} / \mathrm{s}^{2}\right) ; \tau$ is the tortuosity; $M$ is the molecular weight $(\mathrm{kg} / \mathrm{mole}) ; D$ is the diffusive-dispersive tensor $\left(\mathrm{m}^{2} / \mathrm{s}\right)$; and $\chi$ is the component mole fraction. The governing partial differential equations (Equations 1 and 2) are discretized with the integrated-volume finite difference method by integrating over a control volume. Using Euler backward time differencing, yielding a fully implicit scheme, a series of nonlinear algebraic expressions is derived. The algebraic forms of the nonlinear governing equations are solved with a multivariable, residual-based Newton-Raphson iterative technique in which the Jacobian coefficient matrix is composed of the partial derivatives of the governing equations with respect to the primary variables.

Assuming the aqueous phase never disappears, the primary variable for the water equation is always the aqueous pressure. For the air equation, the primary variable is $P_{a}$. The algebraic expressions are evaluated using upwind interfacial averaging for fluid density, mass fractions, and relative permeability. Specified weights (i.e., arithmetic, harmonic, geometric, upwind) are applied to the remaining terms of the flux equations. For the simulations described in this report, harmonic averages were used and the maximum number of Newton-Raphson iterations was eight, with a convergence factor of $10^{-6}$.

Secondary variables - those parameters not directly computed from the solution of the governing equations - are computed from the primary variable set through the constitutive relations. In this section, only the relations between relative permeability, fluid saturation $\left(\mathrm{m}^{3}\right.$ liquid $/ \mathrm{m}^{3}$ pore space $)$, and capillary pressure $(k-S-P)$ pertinent to the conducted simulations are described. The $k-S-P$ relations consist of the van Genuchten (1980) $S$ - $P$ relations in combination with the $k-S$ relations derived from the Mualem (1976) model. The $k-S-P$ relations distinguish between actual and effective saturations. Actual saturations are defined as the ratio of fluid volume to diffusive pore volume. Effective saturations represent normalized actual saturations based on the pore volumes above the irreducible or minimum saturation of the wetting fluid (i.e., aqueous-phase liquid).

\subsubsection{Seepage Face Boundary Condition}

Pore-water extraction from unsaturated media is simulated using a Seepage Face boundary condition. This boundary condition is unique because it compares an imposed gas-phase pressure at a domain boundary with a computed aqueous-phase pressure at the adjacent porous medium grid block. After a gas vacuum is imposed at the boundary, water moves toward the boundary, resulting in pressure changes. The saturation and pressure changes are a strong function of the initial conditions and the imposed gas vacuum. Pore-water extraction occurs only when the aqueous-phase pressure of the adjacent porous medium node is equal to or higher than the imposed gas-phase pressure at the domain boundary. Such a scheme is necessary to accurately simulate pore-water extraction because the STOMP simulator does not explicitly compute boundary values for the fluid phases.

The Seepage Face boundary condition is illustrated using two examples describing pressure changes and water flow as a result of an imposed $2-\mathrm{m} \mathrm{H}_{2} \mathrm{O}(2.8 \mathrm{psi})$ gas vacuum on a 1-m-long horizontal column 
containing unsaturated silt. In the first example, a vacuum is imposed on the silt with an initial capillary pressure (i.e., gas pressure minus water pressure) of 9,753 $\mathrm{Pa}$, which is equivalent to $1 \mathrm{~m}$ of water pressure. The initial water saturation is approximately 0.73 for the entire column. Figure 1 and Figure 2 show the changes in gas and aqueous pressure as function of time over the column. Figure 1 indicates that only a short amount of time passes before a linear gradient is established in both phases after the vacuum is imposed because the water pressure is able to follow the gas pressure changes quickly. The distance between the two lines denotes the capillary pressure and therefore the water saturation. The pressure lines indicate that both water and gas are moving toward the boundary where the vacuum is imposed. Water will move toward the boundary until the water pressure at the boundary equals the imposed vacuum. Figure 2 shows that for this configuration, pore-water extraction starts to occur after approximately 1 day. The saturation distributions at various times are shown in Figure 3 . The plots show the considerable differences in saturation over the column as water migrates toward the boundary and is ultimately extracted. As can be seen in Figure 4, the extraction rate diminishes over time because of water depletion in the finite column. Consistent with what is shown in Figure 3, Figure 4 also shows that it takes some time before water is actually produced.

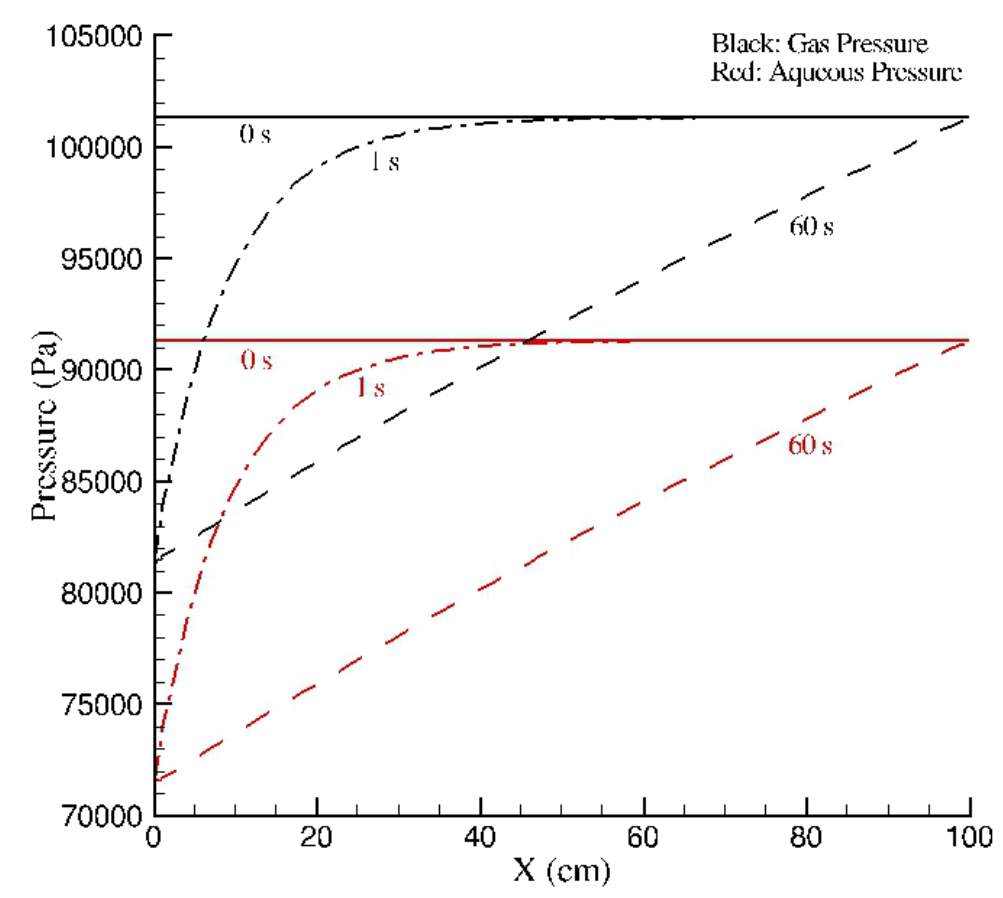

Figure 1. Gas and water pressures at $t=0,1$, and 60 seconds after imposing a Seepage Face boundary condition at the left-hand side of a 1-m-long horizontal column filled with unsaturated silt. The initial capillary pressure is $9,793 \mathrm{~Pa}\left(1 \mathrm{~m} \mathrm{H}_{2} \mathrm{O}\right)$. 


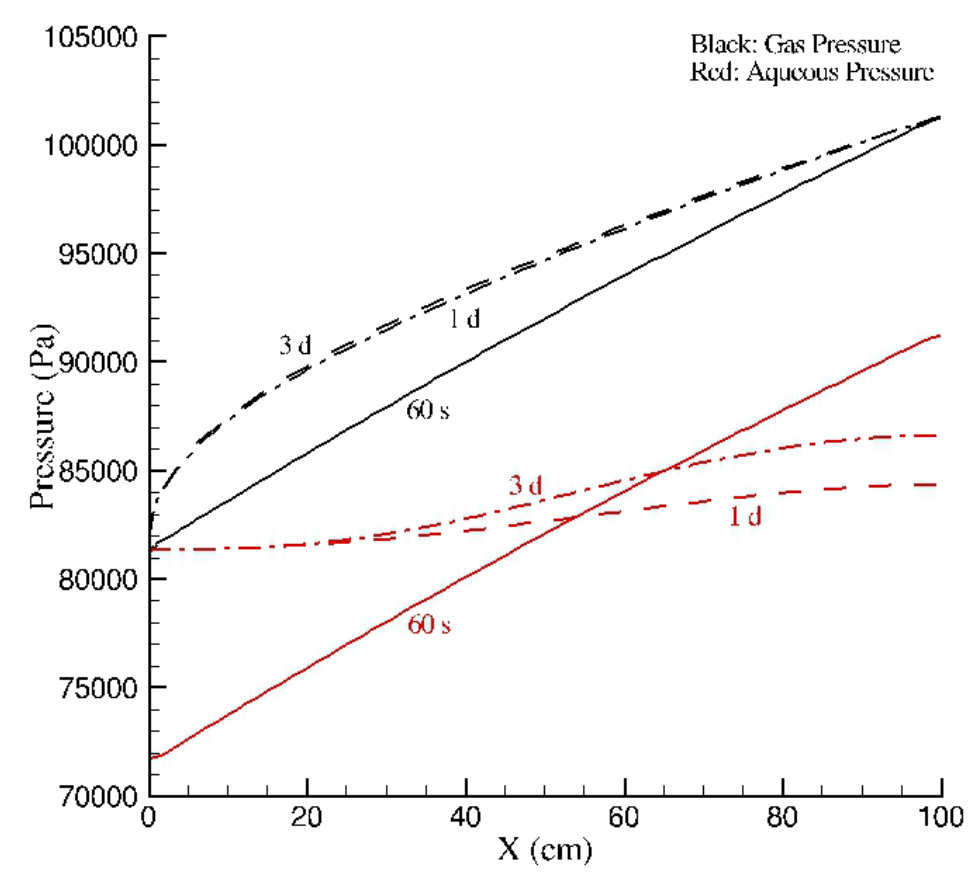

Figure 2. Gas and water pressures at $t=60$ seconds, 1 day, and 3 days after imposing a Seepage Face boundary condition at the left-hand side of a 1-m-long horizontal column filled with unsaturated silt. The initial capillary pressure is $9,793 \mathrm{~Pa}\left(1 \mathrm{~m} \mathrm{H}_{2} \mathrm{O}\right)$.

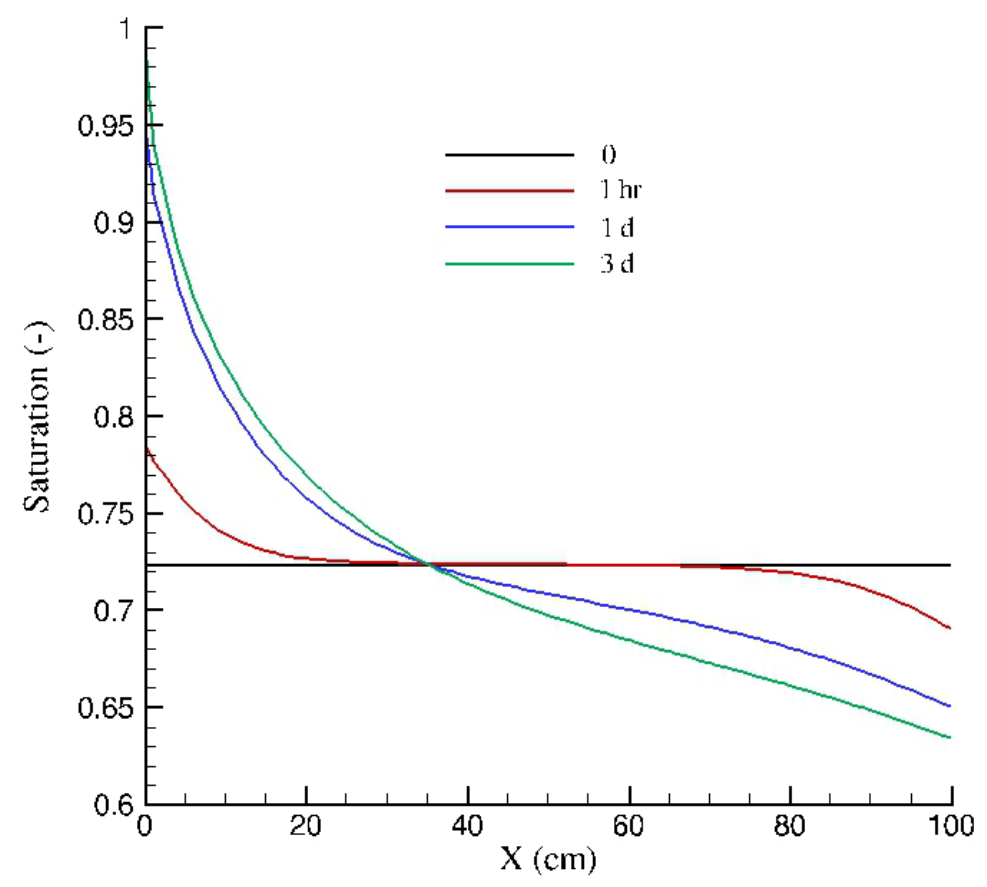

Figure 3. Water saturations at $t=0$ seconds, 1 hour, 1 day, and 3 days after imposing a Seepage Face boundary condition at the left-hand side of a 1-m-long horizontal column filled with unsaturated silt. The initial capillary pressure is $9,793 \mathrm{~Pa}\left(1 \mathrm{~m} \mathrm{H}_{2} \mathrm{O}\right)$. 


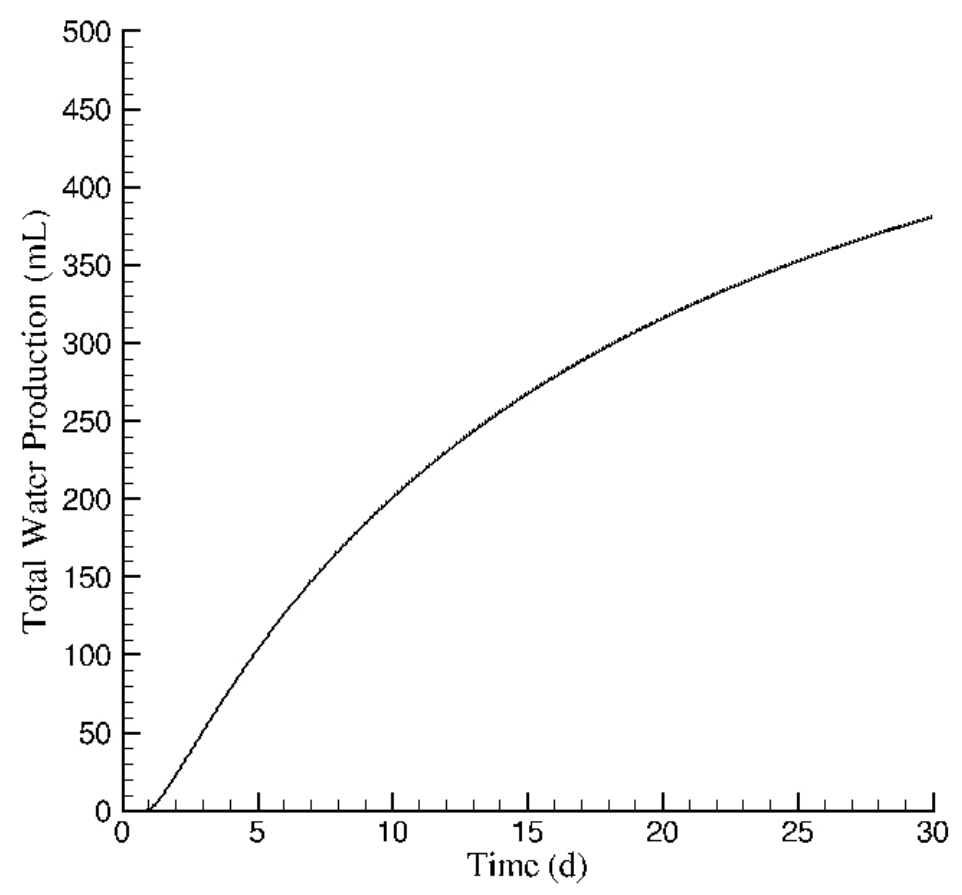

Figure 4. Cumulative water extraction after imposing a Seepage Face boundary condition at the left-hand side of a 1-m-long horizontal column filled with unsaturated silt. The initial capillary pressure is $9,793 \mathrm{~Pa}\left(1 \mathrm{~m} \mathrm{H}_{2} \mathrm{O}\right)$.

To illustrate the limitations of the method, the computations were repeated for a column filled with silt at an initial capillary pressure of $19,584 \mathrm{~Pa}\left(2 \mathrm{~m} \mathrm{H}_{2} \mathrm{O}\right)$. This silt is considerably drier than in the first example, with an initial water saturation of about 0.5 . After the $2-\mathrm{m}$ vacuum is imposed, gas and water pressure gradients are again rapidly established (Figure 5). However, because the initial water saturation is considerably lower than for the first example, water movement to the boundary is slower. For this case, the water pressure at the boundary increases somewhat over time (Figure 6), but the increase is not sufficient to exceed the gas pressure maintained at the boundary. Figure 7 shows that the water saturation at the boundary increases to only 0.55 over 30 days of imposing the vacuum. As a result, no water was extracted from the sediment in this example. 


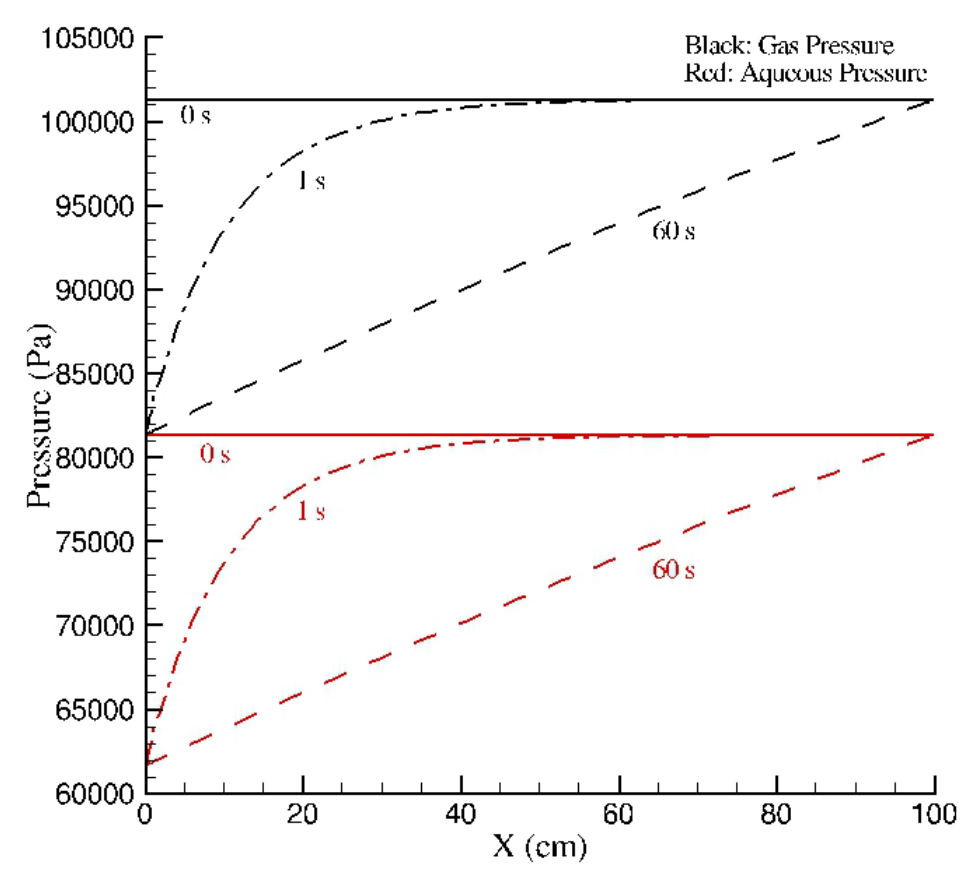

Figure 5. Gas and water pressures at $t=0,1$, and 60 seconds after imposing a Seepage Face boundary condition at the left-hand side of a 1-m-long horizontal column filled with unsaturated silt. The initial capillary pressure is $19,586 \mathrm{~Pa}\left(2 \mathrm{~m} \mathrm{H}_{2} \mathrm{O}\right)$.

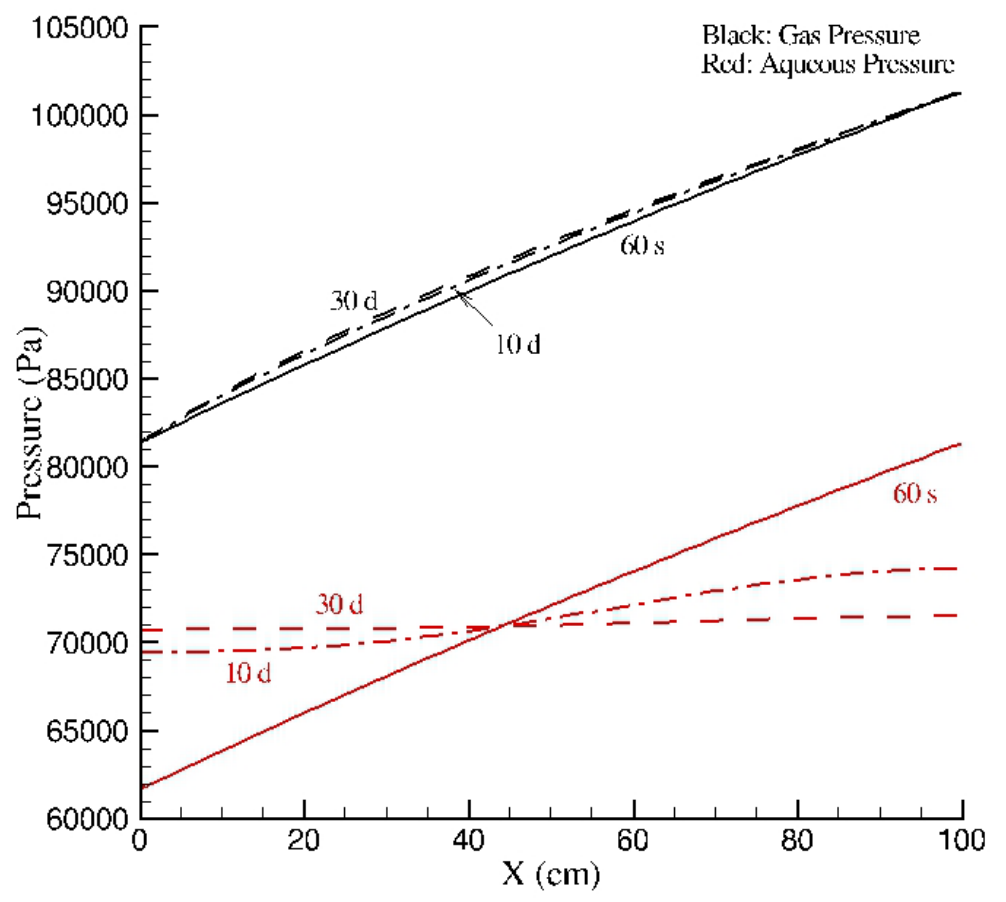

Figure 6. Gas and water pressures at $t=60$ seconds, 10 days, and 30 days after imposing a Seepage Face boundary condition at the left-hand side of a 1-m-long horizontal column filled with unsaturated silt. The initial capillary pressure is $19,586 \mathrm{~Pa}\left(2 \mathrm{~m} \mathrm{H}_{2} \mathrm{O}\right)$. 


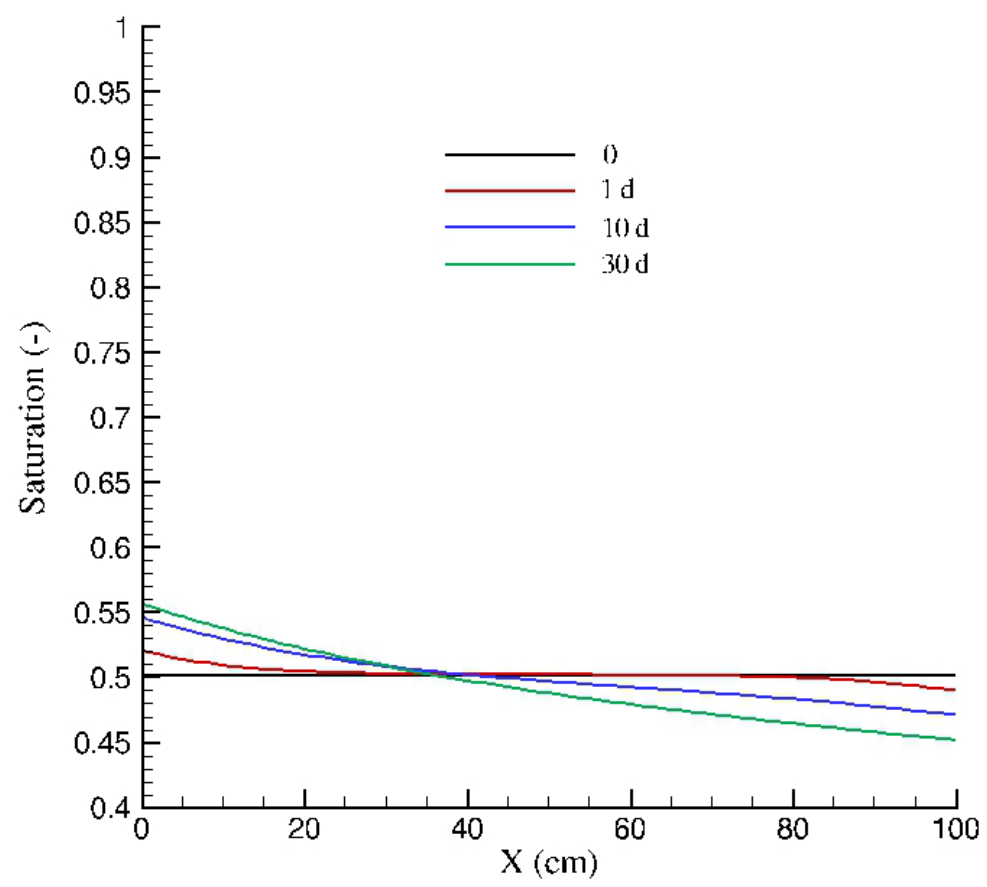

Figure 7. Water saturations at $t=0$ seconds, 1 day, 10 days, and 30 days after imposing a Seepage Face boundary condition at the left-hand side of a 1-m-long horizontal column filled with unsaturated silt. The initial capillary pressure is $19,586 \mathrm{~Pa}\left(2 \mathrm{~m} \mathrm{H}_{2} \mathrm{O}\right)$.

The two examples illustrate that pore-water extraction might be useful only when the initial water pressure in the porous medium is higher than the boundary gas pressure after imposing the vacuum. For the first example, the initial water pressure in the column was higher than the boundary gas pressure during vacuum application, and sufficient water could move to the extraction boundary to ensure the occurrence of seepage. In the second example, the initial water pressure was equal to the gas pressure at the boundary during vacuum application, and there was not sufficient water in the column to result in water seepage out of the column. This observation also translates to field conditions-pore-water extraction is possible only when the initial water pressure of the porous medium adjacent to the extraction well exceeds the boundary gas pressures after a vacuum is imposed. If the dimensions of the system are limited, the initial water pressure most likely has to be considerably higher than the gas pressure at the well to result in meaningful extraction rates.

\subsubsection{Simulations}

Two sets of simulations were conducted to evaluate pore-water extraction under conditions relevant to the SX Tank Farm test site. In the first set, the 10-m-thick Cold Creek Unit silt (CCUz) layer was assumed to be either 1) homogeneous or 2) heterogeneous with a single $0.3-\mathrm{m}$ (1-ft)-thick highconductivity sand layer (at various locations with respect to the screen interval) in an otherwise homogeneous zone. The hydraulic properties of the sand porous medium in Carsel and Parrish (1988) were assigned to the high conductivity layer in the CCUz (Table 2). Although it is not likely that a layer with these hydraulic properties will be present in the CCUz at the SX Tank Farm site, lower soil moisture content zones in the CCUz may contain more sand and may have hydraulic properties similar to those for the hypothetical sand layer. A description of the simulation sensitivities is presented in Table 1. The hydraulic sediment properties used in the simulations are listed in Table 2. The base case computational 
domain for this set of simulations is shown in Figure 8. The two-dimensional cylindrical domain (45 degrees) extends from the surface to the water table and consists of five layers (H1, H2, CCUz, CCUc, and Ringold). The reader is referred to Truex et al. (2012) for a justification for this computation domain and descriptions of the hydraulic layers. The well diameter was assumed to be $2.54 \mathrm{~cm}(1 \mathrm{in}$.). The domain was discretized in 5-cm $\times 5$-cm grid cells in the $x$ and $z$ directions except for the first meter adjacent to the boundary nearest the extraction well $(x=0)$, where the cells were $2.5 \mathrm{~cm} \times 2.5 \mathrm{~cm}$. The simulations consisted of two parts. In the first part, a steady-state system with a constant recharge rate was established. In the second part, a gas-phase vacuum of $2 \mathrm{~m}$ was imposed over a $0.3-\mathrm{m}(1-\mathrm{ft})$ screen length ranging from 123 to $124 \mathrm{ft}$ below ground surface (bgs) for a simulation period of 3 months. For each simulation, water and gas extraction rates were computed as a function of time.

Table 1. Overview of simulations using the layered system depicted in Figure 8. The hydraulic parameters of the Base Case simulation are listed in Table 2. For the Base Case, the near-well aqueous saturation $(S)$ equals 0.8 . The hydraulic properties for the simulations with the sand layers are taken from Carsel and Parrish (1988; Table 2). A vacuum of $2 \mathrm{~m} \mathrm{H}_{2} \mathrm{O}$ (2.8 psi) is imposed over a $0.3-\mathrm{m}$ (1-ft) zone ranging from 123 to $124 \mathrm{ft}$ below ground surface (bgs).

\begin{tabular}{|c|c|}
\hline Simulation Name & Modification with Respect to Base Simulation \\
\hline Base Case & - \\
\hline $\operatorname{High} S$ & Average near-well $S=0.9$ \\
\hline Low $S$ & Average near-well $S=0.7$ \\
\hline 3-m Vacuum & Well vacuum: $3 \mathrm{~m} \mathrm{H}_{2} \mathrm{O}$ \\
\hline High $K_{\text {sat }}$ & Base Case $K_{\text {sat }}$ CCUz x 10 \\
\hline Low $K_{\text {sat }}$ & Base Case $K_{\text {sat }} \mathrm{CCUz} / 10$ \\
\hline Anisotropy 10:1 & Horizontal CCUz $K_{\text {sat }}:$ Vertical CCUz $K_{\text {sat }}=10$ \\
\hline Anisotropy 100:1 & Horizontal CCUz $K_{\text {sat }}$ : Vertical CCUz $K_{\text {sat }}=100$ \\
\hline High van Genuchten $n$ & Base Case CCUz $n+1$ \\
\hline Low van Genuchten $n$ & Base Case CCUz $n-1$ \\
\hline High van Genuchten $\alpha(1 / \mathrm{cm})$ & Base Case CCUz $\alpha$ x 2 \\
\hline High van Genuchten $\alpha(1 / \mathrm{cm})$ & Base Case CCUz $\alpha / 2$ \\
\hline Sand Layer 1 & Sand layer between 123 and $124 \mathrm{ft}$ bgs \\
\hline Sand Layer 2 & Sand layer between 122.5 and $123.5 \mathrm{ft}$ bgs \\
\hline Sand Layer 3 & Sand layer between 122.25 and $123.25 \mathrm{ft}$ bgs \\
\hline Sand Layer 4 & Sand layer between 122 and $123 \mathrm{ft}$ bgs \\
\hline Sand Layer 5 & Sand layer between 123.25 and $123.75 \mathrm{ft}$ bgs \\
\hline Compacted Zone 1 & $K_{\text {sat }}$ of $5 \mathrm{~cm}$ adjacent to well is $0.1 \mathrm{x}$ Base Case $K_{\text {sat }} \mathrm{CCUz}$ \\
\hline Compacted Zone 2 & $K_{\text {sat }}$ of $5 \mathrm{~cm}$ adjacent to well is $0.01 \times$ Base Case $K_{\text {sat }} \mathrm{CCUz}$ \\
\hline
\end{tabular}


Table 2. Hydraulic properties of the sediments used in the STOMP simulations. The values for the H2 unit and CCUz are the averages of the experimental data reported by Truex et al. (2012, Table 9). The values for the other sediments were obtained from Last et al. (2006). The Carsel and Parrish Sand was used in the Sand Layer simulations listed in Table 1.

\begin{tabular}{lccccc}
\hline & Residual & \multicolumn{2}{c}{$\begin{array}{c}\text { Rydraulic } \\
\text { Saturation } \\
\left(\mathrm{m}^{3} \text { liquid }\right. \\
\left.\mathrm{m}_{\text {pore space }}\right)\end{array}$} & $\begin{array}{c}\text { vonductivity, } K_{\text {sat }} \\
(\mathrm{cm} / \mathrm{s})\end{array}$ & $\begin{array}{c}\text { Porosity } \\
(-)\end{array}$ \\
\hline $\mathrm{H} 1$ & $\alpha(1 / \mathrm{cm})$ & $n$ & 0.118 & $3.67 \times 10^{-5}$ & 0.356 \\
$\mathrm{H} 2$ & $1.00 \times 10^{-2}$ & 2.177 & 0.121 & $8.19 \times 10^{-4}$ & 0.393 \\
$\mathrm{CCUz}$ & $7.87 \times 10^{-3}$ & 2.372 & 0.086 & $1.29 \times 10^{-3}$ & 0.389 \\
$\mathrm{CCUc}$ & $6.30 \times 10^{-3}$ & 2.172 & 0.214 & $5.04 \times 10^{-4}$ & 0.306 \\
Ringold & $1.80 \times 10^{-2}$ & 1.727 & 0.334 & $1.06 \times 10^{-4}$ & 0.297 \\
Carsel and Parrish & $1.32 \times 10^{-2}$ & 1.753 & 0.105 & $8.25 \times 10^{-3}$ & 0.430 \\
Sand & $1.45 \times 10^{-1}$ & 2.680 & & & \\
\hline
\end{tabular}

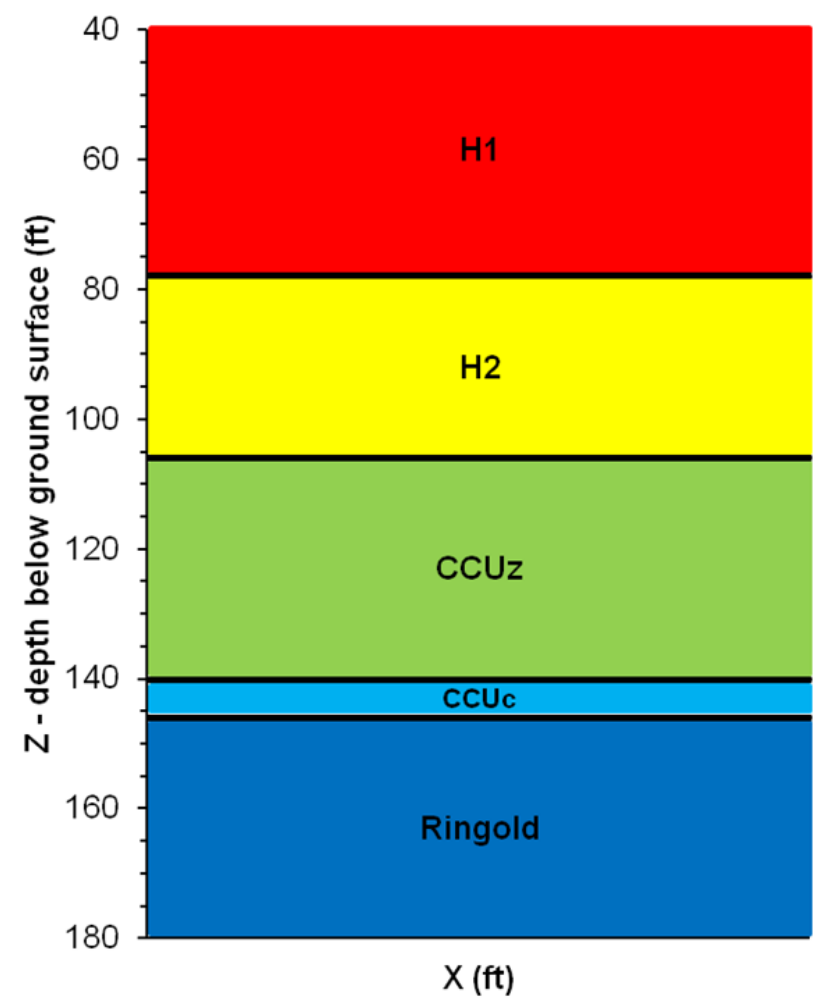

Figure 8. Computational domain for pore-water extraction simulations listed in Table 1.

In the first set of simulations, the extraction rates were computed for relatively simple representations of the CCUz layer. However, in reality, the CCUz layer is considerably more complex than what is shown in Figure 8 and has a large variation in properties between sub-layers. An example of the variability in volumetric water contents as a function of elevation is shown in Figure 9 for borehole C8761. Unfortunately, it is impossible to replicate these water content distributions using a numerical flow model because several pieces of information are not known, including, for instance, the 
detailed subsurface geology. To investigate the effect of a more heterogeneous CCUz layer on fluid extraction, the water content information as provided in Figure 9 was converted into initial conditions for the STOMP simulator using three methods:

- Method 1 - The volumetric moisture contents shown in Figure 9, averaged per foot, were converted to aqueous-phase pressures using the hydraulic properties for CCUz displayed in Table 2. The resulting moisture content distribution is shown in Figure 10.

- Method 2 - Assuming that the varying moisture contents are the result of CCUz porosity only, a modified porosity was computed for each $0.3-\mathrm{m}$ (1-ft) layer in the model. The computed porosities are shown in Figure 11.

- Method 3 - Assuming a steady-state recharge of $4 \mathrm{~mm} / \mathrm{yr}$, aqueous-phase pressures were first computed for each $0.3-\mathrm{m}$ (1-ft) layer while assuming that the entire zone consisted of CCUz sediments as listed in Table 2. Next, for each pair of volumetric water content (Figure 9) and aqueous pressure data, the sediment was selected from the Carsel and Parrish (1988) database that best described the data pair. The selected sediment and associated hydraulic properties then were used to represent the $0.3-\mathrm{m}(1-\mathrm{ft})$ layer. The sequence was repeated over the entire domain represented by Figure 9.

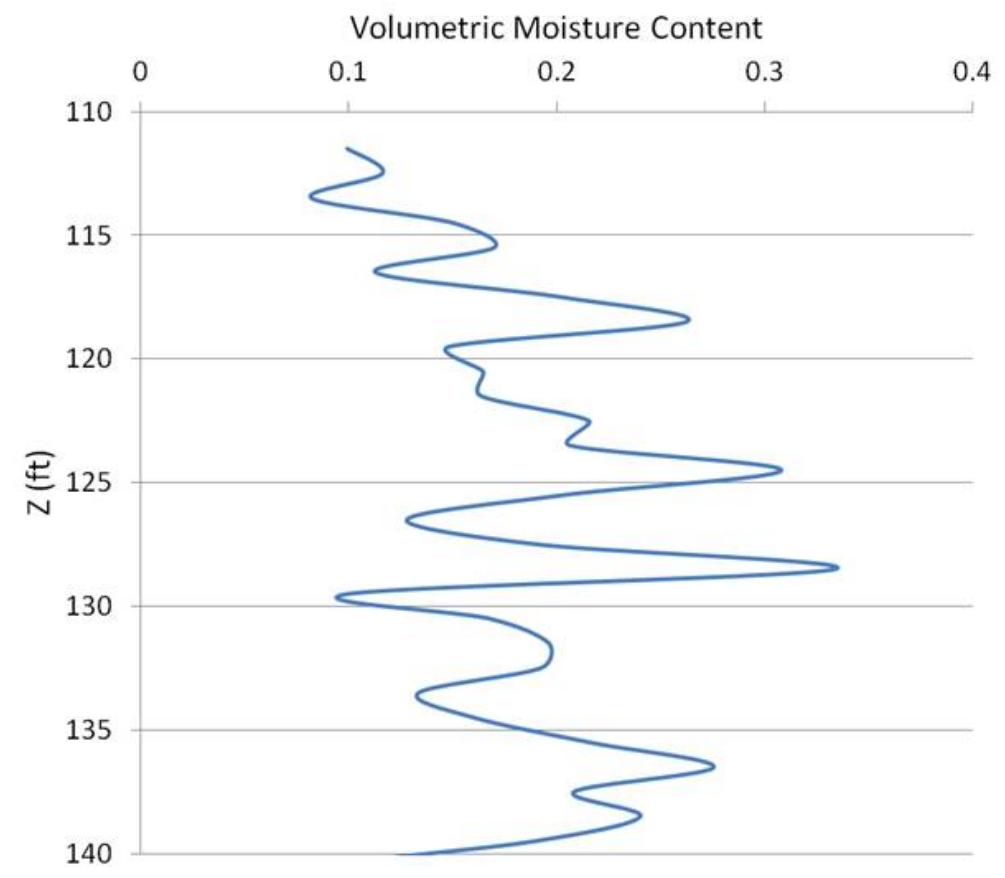

Figure 9. Volumetric moisture contents as a function of depth at borehole C8761 near the SX Tank Farm field test site. 


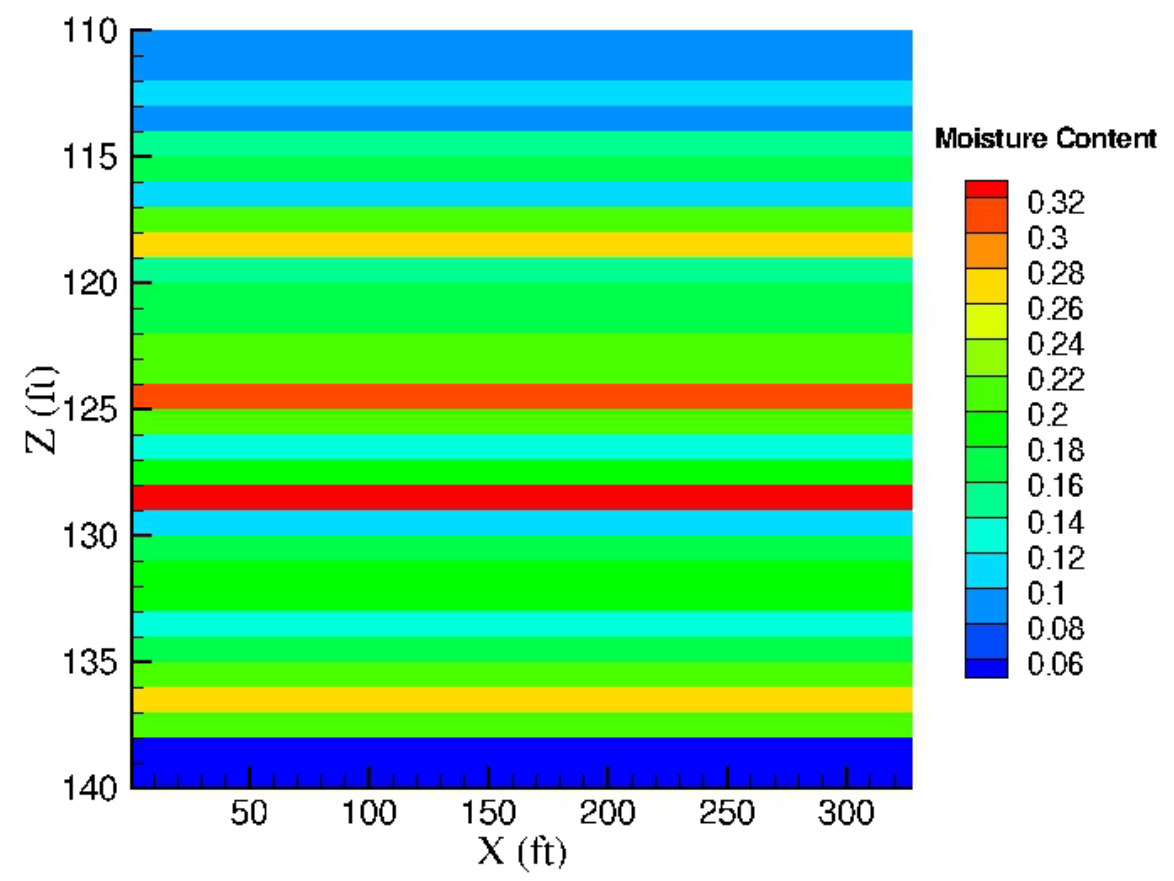

Figure 10. Initial moisture contents for simulation of pore-water extraction from layered system using Method 1.

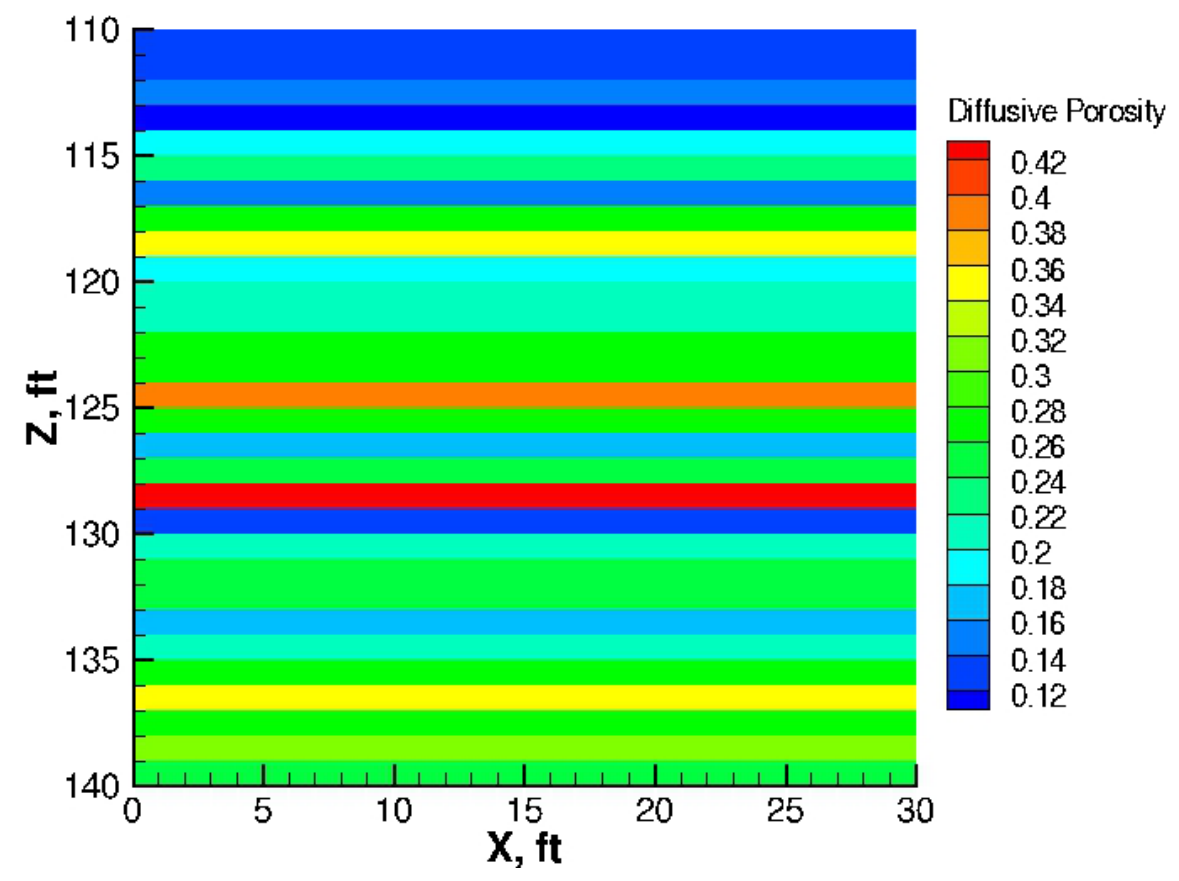

Figure 11. Layer porosities for simulation of pore-water extraction from layered system using Method 2.

\subsection{Falling-Head Test Analysis}

An analysis was conducted by K. Lindsey (GSI Water Solutions, Inc.) to review and evaluate data collected from a number of vadose zone falling-head tests conducted in a borehole near the SX Tank 
Farm. The analysis was reported in a technical memorandum to K. Reynolds on March 29, 2013 (Attachment). The purpose of the field test was to collect data to evaluate the effectiveness of well development techniques. The tests consisted primarily of surging and purging the boring, filling the borehole with a known amount of water ( 2 gal), and then measuring the water pressure response over time with a transducer located near the bottom of the boring. The data reported in the memorandum consist of head (feet) versus elapsed time plots. A simple analysis using a saturated-zone approach yielded estimates of near-well permeability on the order of $1.0 \times 10^{-8} \mathrm{~cm}^{2}$. To test if such an analysis, based on saturated flow and several other simplifying assumptions, can be used to estimate unsaturated sediment permeability in the SX Tank Farm subsurface, PNNL developed a numerical model to compare the field data with simulation results from unsaturated zone computations.

The numerical model was developed to evaluate the 2-gal falling-head tests (Tests $2-5$ in the Lindsey memorandum). This volume of water was assumed to be instantaneously emplaced in the well bore, yielding a water head height of approximately $18 \mathrm{ft}$. The height is consistent with the data presented by Lindsey in the memorandum. After emplacement, the water was allowed to enter saturated sediments through a screen length of $1.5 \mathrm{ft}$, using various permeability values. Examples of the results for three permeabilities are shown Figure 12. A comparison with the field data in the memorandum indicates that a simulated effective permeability of $1.0 \times 10^{-8} \mathrm{~cm}^{2}$ matches the data well, which is consistent with the values estimated by Lindsey using a simple analytical approach. The other plotted values in Figure 12 yielded hydrographs that were off by an order of magnitude compared to the field data.

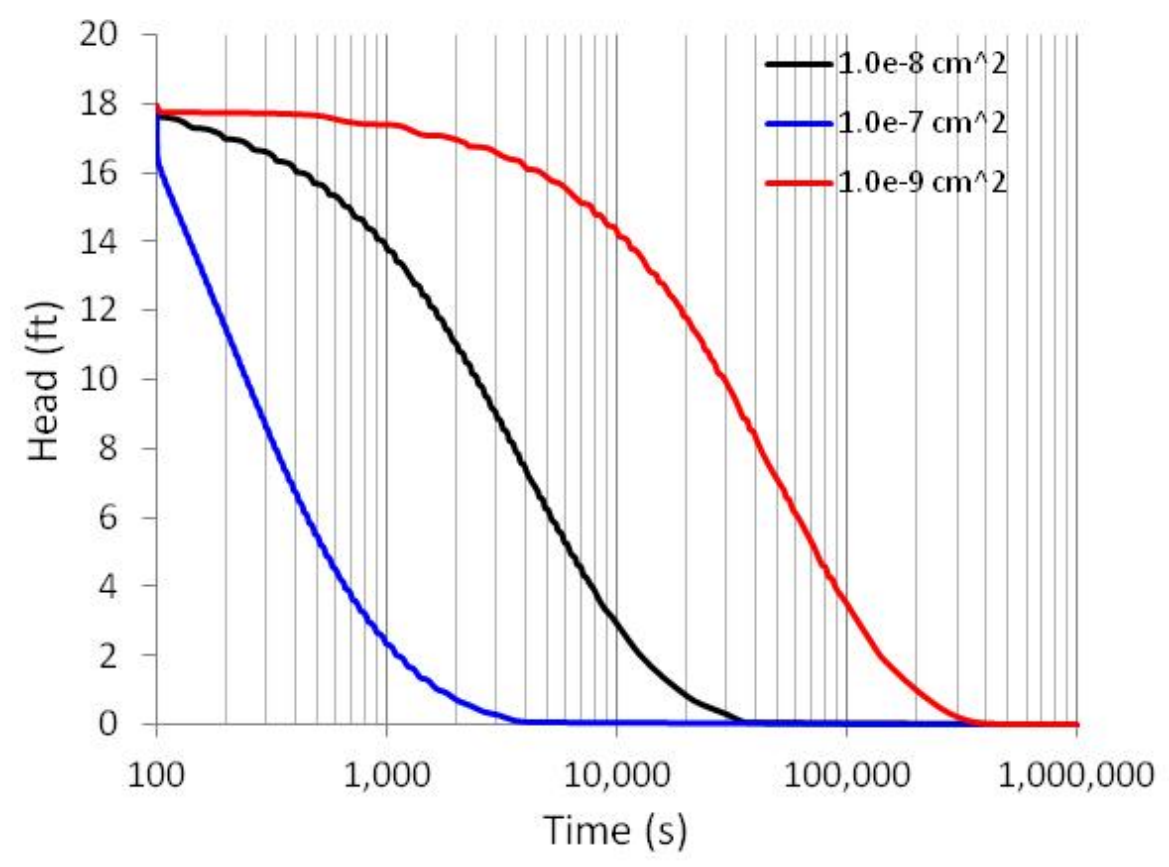

Figure 12. Falling-head test hydrographs obtained with STOMP simulations.

In the next step, the sediment was assumed to be unsaturated by manipulating the lower boundary condition of the domain. A permeability of $1.0 \times 10^{-8} \mathrm{~cm}^{2}$ was used for the sediment to evaluate the effect of near-well saturations on hydrograph behavior. Examples for water saturations of 0.6 and 0.8 are shown in Figure 13 and compared with the saturated case. The numerical results show that a decrease in 
water saturation had a limited effect on water infiltration during a falling-head test in these kinds of sediments. Infiltration under these unsaturated conditions was more rapid for the sediments, indicating that increased water movement due to capillary action was more important than a reduction in effective permeability due to unsaturated flow.

The primary conclusion from this limited analysis using the STOMP simulator is that the analytical approach used by Lindsey appears to be valid and can be used to interpret falling-head data in these kinds of unsaturated sediments for order-of-magnitude-level estimates. A more complex numerical simulator such as STOMP is not needed to produce reliable order-of-magnitude-level permeability estimates.

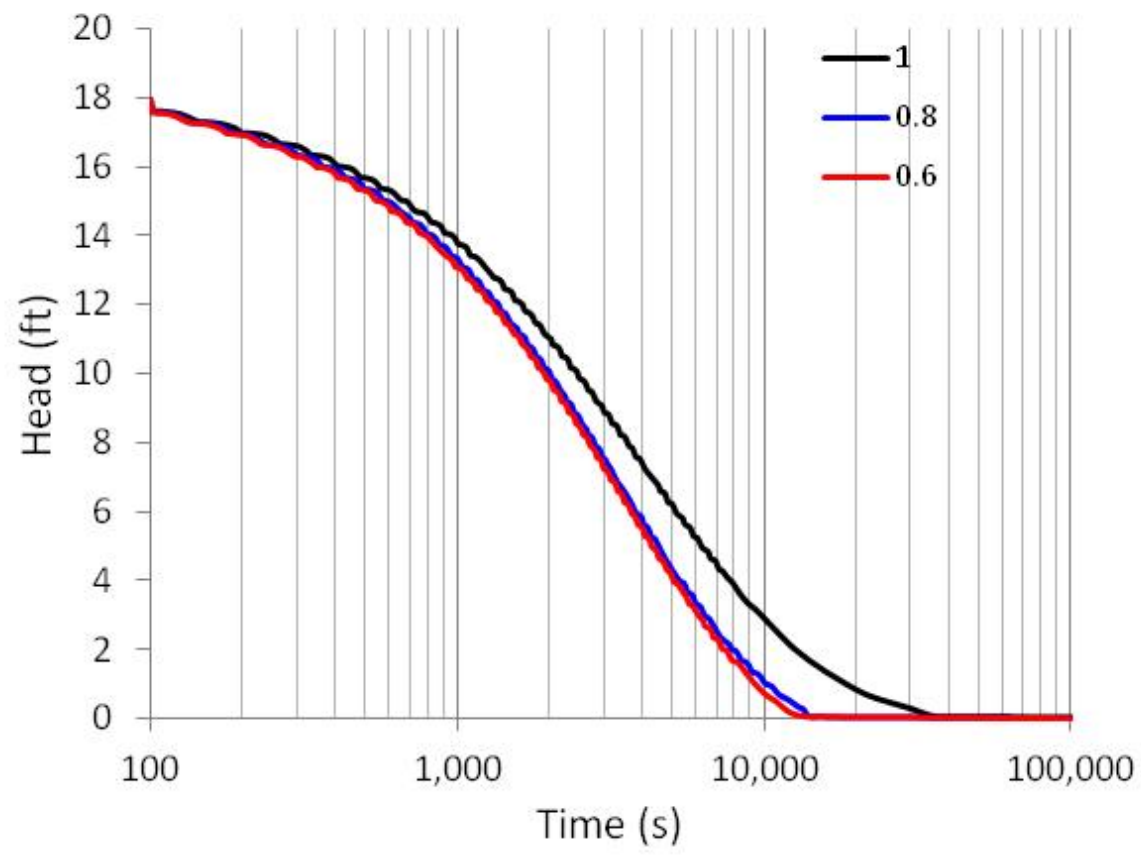

Figure 13. Falling-head test hydrographs for three near-well saturations obtained with STOMP simulations. 


\subsection{Numerical Simulation Results}

The water and gas extraction rates after 90 days of water extraction, as well as the time when water is first being produced, are reported in Table 3 for all of the simulations listed in Table 1. These simulation results are for the simplified CCUz layering depicted in Figure 8 and associated sensitivity cases. The water-extraction rates range from $0 \mathrm{~L} /$ day for the Sand Layer 1 simulation to approximately $165 \mathrm{~L} /$ day for the High $K_{\text {sat }}$ simulation. All simulations showed gas extraction; values ranged from $0.28 \mathrm{~L} / \mathrm{min}$ $\left(0.01 \mathrm{ft}^{3} / \mathrm{min}\right)$ for the Compacted Zone 1 simulation, to about $2200 \mathrm{~L} / \mathrm{min}\left(78 \mathrm{ft}^{3} / \mathrm{min}\right)$ for the Sand Layer 1 simulation. Most of the simulations demonstrate water extraction shortly $(<0.1$ day) after the vacuum was imposed in the well. The reasons for the delayed arrivals times for the other simulations will be discussed later in this section.

Table 3. Water and gas extraction rates after 90 days of vacuum extraction and arrival time of water at the extraction well for the simulations listed in Table 1.

\begin{tabular}{lccc}
\hline \multicolumn{1}{c}{ Simulation Name } & $\begin{array}{c}\text { Water Extraction Rate } \\
(\text { L/day) }\end{array}$ & $\begin{array}{c}\text { Gas Extraction Rate } \\
\left(\mathrm{ft}^{3} / \mathrm{min}\right)\end{array}$ & $\begin{array}{c}\text { First Water Extraction } \\
\text { (days) }\end{array}$ \\
\hline Base & 14.75 & 0.38 & $<0.1$ \\
High $S$ & 39.38 & 0.31 & $<0.1$ \\
Low $S$ & 1.33 & 0.44 & 6.8 \\
3-m Vacuum & 50.50 & 0.67 & $<0.1$ \\
High $K_{\text {sat }}$ & 165.01 & 3.67 & $<0.1$ \\
Low $K_{\text {sat }}$ & 1.03 & 0.39 & $<0.1$ \\
Anisotropy 10:1 & 11.17 & 0.29 & $<0.1$ \\
Anisotropy 100:1 & 9.33 & 0.24 & $<0.1$ \\
High van Genuchten $n$ & 32.99 & 0.29 & $<0.1$ \\
Low van Genuchten $n$ & 3.77 & 0.39 & $<0.1$ \\
High van Genuchten $\alpha(1 / \mathrm{cm})$ & 2.71 & 0.72 & $<0.1$ \\
Low van Genuchten $\alpha(1 / \mathrm{cm})$ & 41.72 & 0.15 & $<0.1$ \\
Sand Layer 1 & 0 & 78.14 & $>90$ \\
Sand Layer 2 & 3.34 & 64.73 & 7.2 \\
Sand Layer 3 & 4.96 & 48.02 & 1.4 \\
Sand Layer 4 & 11.86 & 0.87 & $<0.1$ \\
Sand Layer 5 & 2.51 & 39.12 & 19.4 \\
Compacted Zone 1 & 2.82 & 0.09 & $<0.1$ \\
Compacted Zone 2 & 0.32 & 0.01 & $<0.1$ \\
\hline
\end{tabular}

Results for the Base Case simulations are shown in Figure 14 through Figure 17. The gas extraction plots in Figure 14 and Figure 15 indicate that gas extraction is fairly stable over time with only a minor reduction during the first few days when water saturations increase in the near-well zone. Water extraction rates (Figure 14 and Figure 15) slowly increase to almost $15 \mathrm{~L} /$ day after 90 days of imposing the $2-\mathrm{m} \mathrm{H}_{2} \mathrm{O}(2.8 \mathrm{psi})$ vacuum. The water extraction plot in Figure 15 shows that, similar to what was found for the silt column in Figure 4, extraction does not occur instantaneously. For this case, it takes about 0.01 day before the near-well water saturation at the lowest part of the screen is high enough so that water can move into the borehole. Water saturations and velocities at the end of the simulation are shown in Figure 16 for a $1.5-\mathrm{m} \times 1.5-\mathrm{m}(5-\mathrm{ft} \times 5-\mathrm{ft})$ area adjacent to the borehole. In this area, the water 
saturation ranged from 0.76 to 0.82 , with higher values directly adjacent to the extraction screen. The water velocity vectors clearly demonstrate that below the well screen, no water is moving downward, meaning that for the conditions covered by this simulation, no potentially contaminated water is able to migrate below the zone of influence of the pore-water extraction zone. The gas pressure plot for this case (Figure 17) shows that the gas pressure increases from $2 \mathrm{~m} \mathrm{H}_{2} \mathrm{O}(2.8 \mathrm{psi})$ at the well to atmospheric conditions over a zone of approximately $3 \mathrm{~m}(10 \mathrm{ft})$.

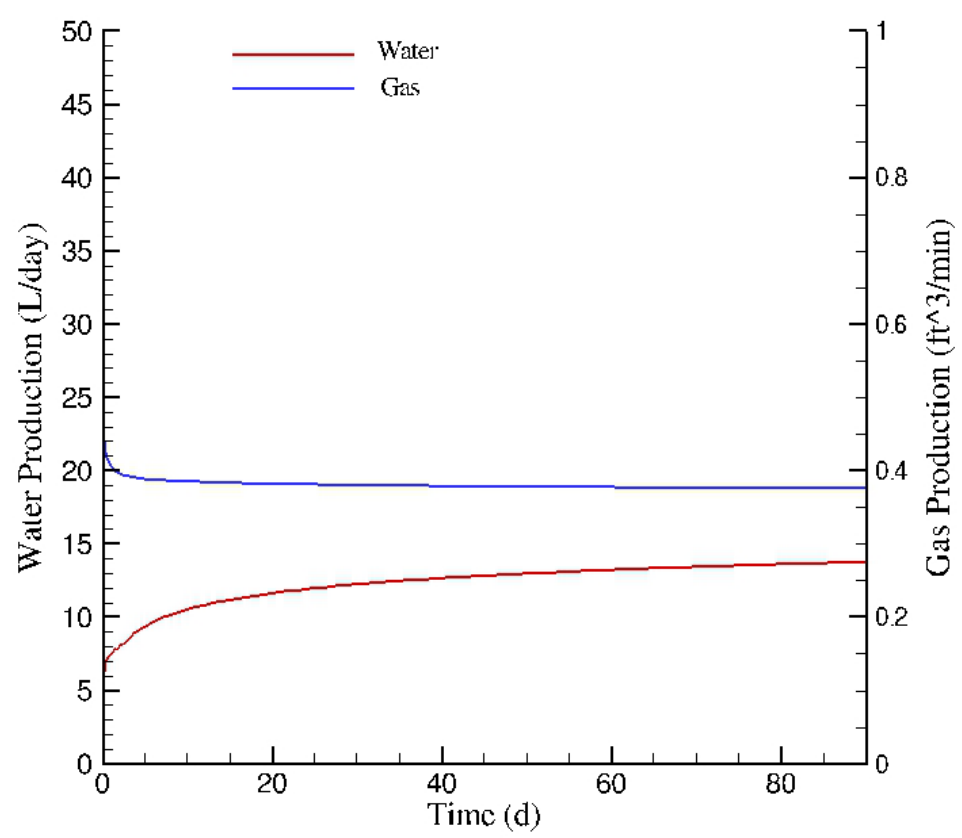

Figure 14. Water and gas extraction rates as a function of time for the Base Case simulation.

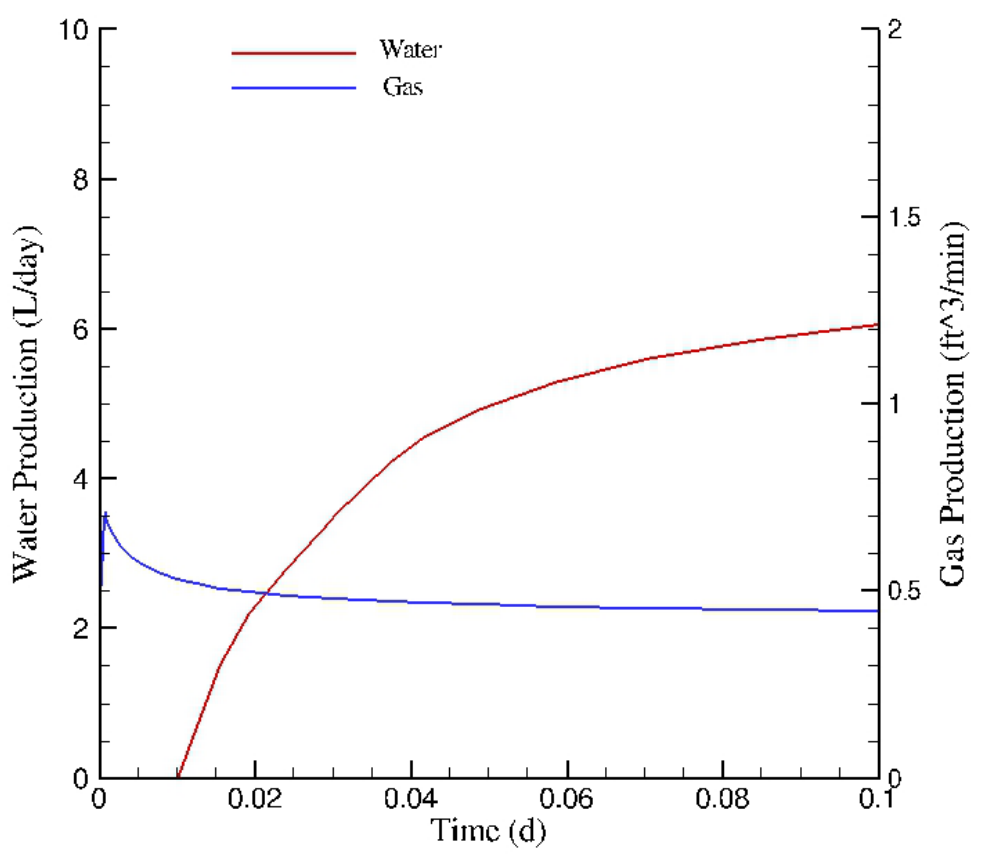

Figure 15. Water and gas extraction rates as a function of time for the Base Case simulation during the initial stages of the vacuum application. 


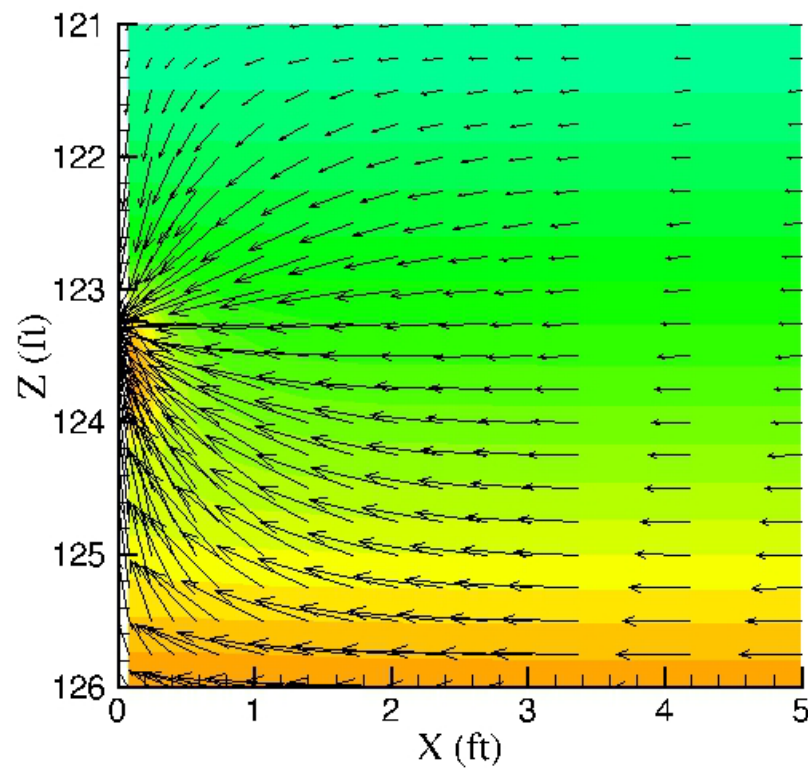

\section{Aqueous Saturation}

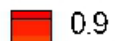

0.88

0.86

0.84

0.82

0.8

0.76

0.74

0.72

0.68

0.66

0.64

0.62

0.6

Figure 16. Near-well water saturations and velocities for the Base Case simulation during steady-state conditions.

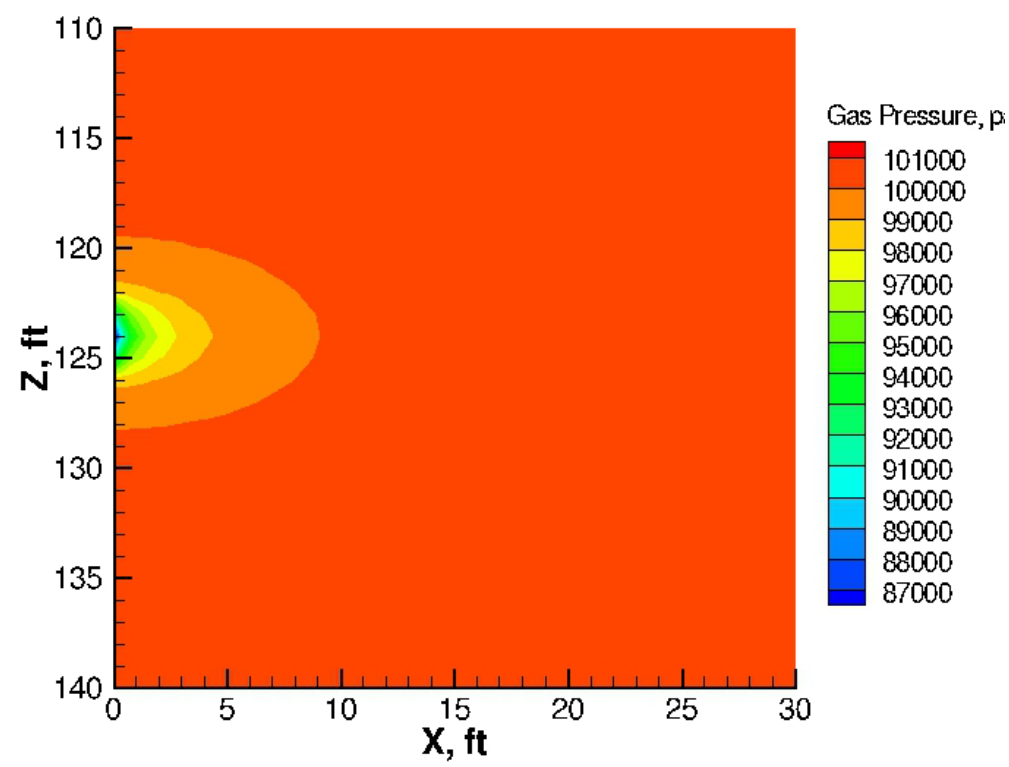

Figure 17. Gas pressures $(\mathrm{Pa})$ for the Base Case simulation during steady-state conditions.

The High $S$ simulation (Table 1), representing a higher initial saturation (0.9) than the Base Case, increases the water extraction by a factor of 3 (Figure 18). The gas extraction rate, however, is only slightly lower than for the Base Case. Reducing the initial saturation to 0.7 (Low $S$ simulation; Table 1) results in a tenfold decrease in water extraction with only a minor increase in the gas extraction rate (Figure 19). The results for the Base Case and the High $S$ and Low $S$ simulations show a high sensitivity of the water extraction rate to initial water saturation because the rate increases from about $1 \mathrm{~L} /$ day to around $40 \mathrm{~L}$ /day for a change in water saturation of only 0.2 . Based on recent borehole data obtained at the site (e.g., the C8761 borehole), such variations in water saturation are not uncommon in 
the targeted CCUz zone. The simulation data also suggest that below water saturations of 0.7, extraction rates will be very low. For each sediment type at a specified imposed vacuum, there is a water saturation at which pore-water extraction rate becomes zero (Truex et al. 2012). In addition, simulation results show a reduction of the initial saturation delays the arrival time of the first water in the extraction well (Table 1); almost 7 days are required for water to be produced for the Low $S$ simulation compared to $<0.1$ day for the Base Case and High S simulations.

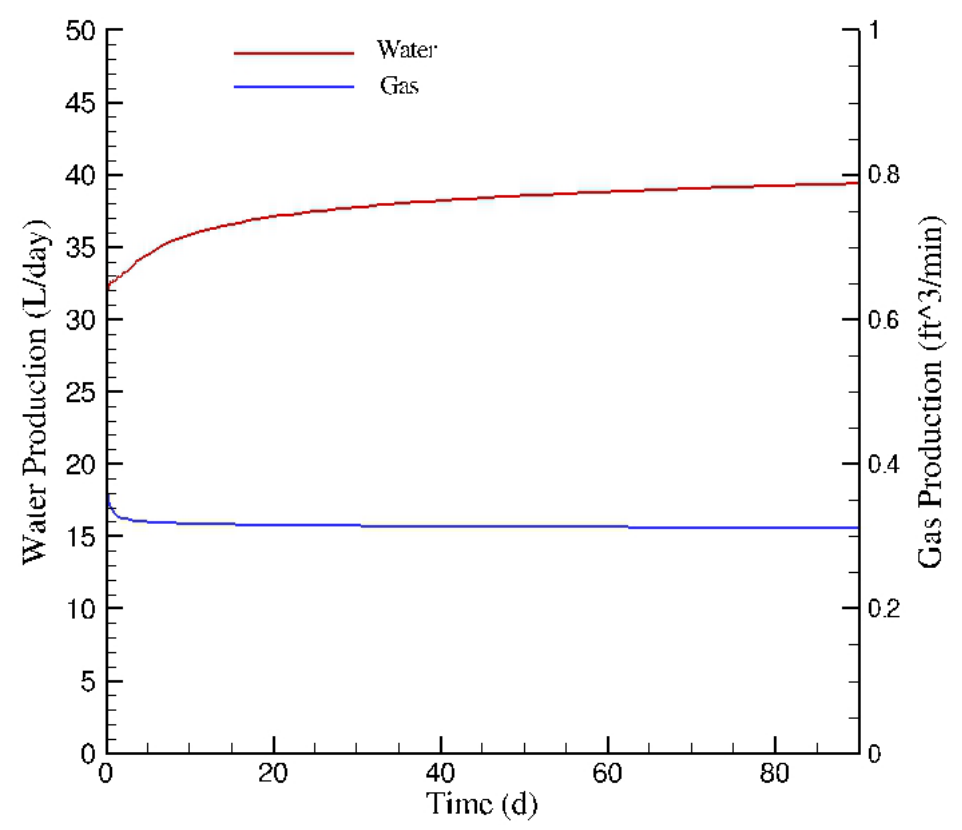

Figure 18. Water and gas extraction rates as a function of time for the simulation with an initial nearwell water saturation of 0.9 (Simulation: High $S$; Table 1).

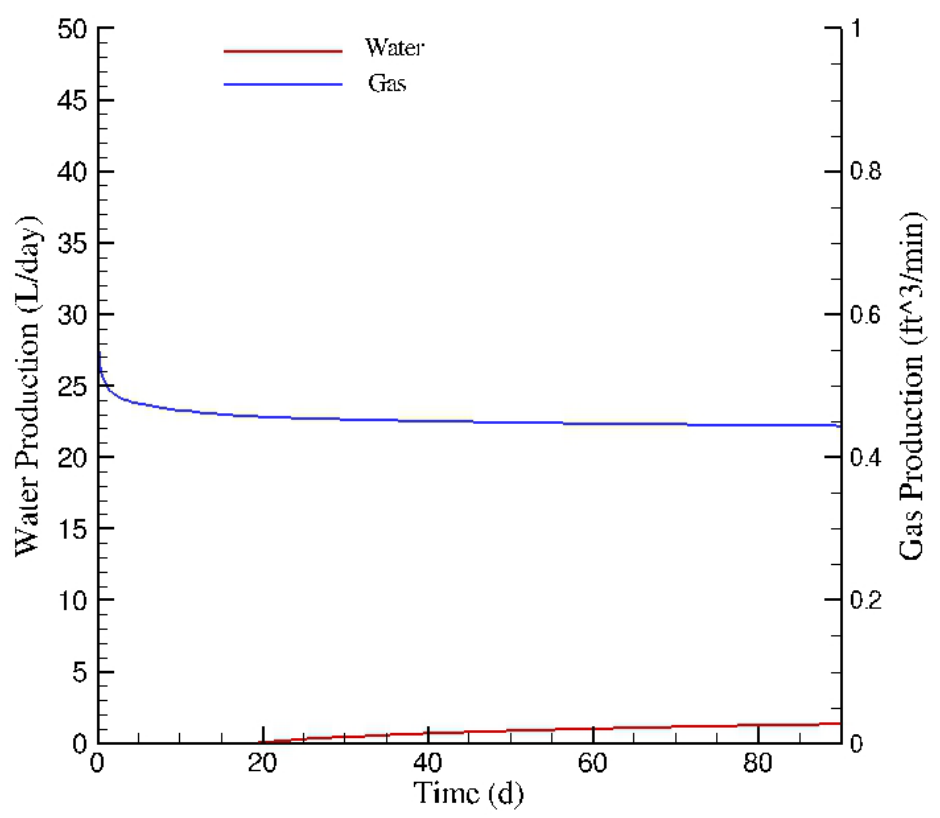

Figure 19. Water and gas extraction rates as a function of time for the simulation with an initial nearwell water saturation of 0.7 (Simulation: Low $S$; Table 1). 
Increasing the vacuum to $3 \mathrm{~m} \mathrm{H}_{2} \mathrm{O}$ (4.3 psi) (Figure 20) leads to a simulated water extraction rate of more than $50 \mathrm{~L} /$ day and a doubling of the gas extraction rate. Although this might seem attractive at first glance, laboratory studies (Oostrom et al. 2011) have shown that maintaining good hydraulic contact between the well screen and sediments might be difficult for relatively high extraction vacuum values.

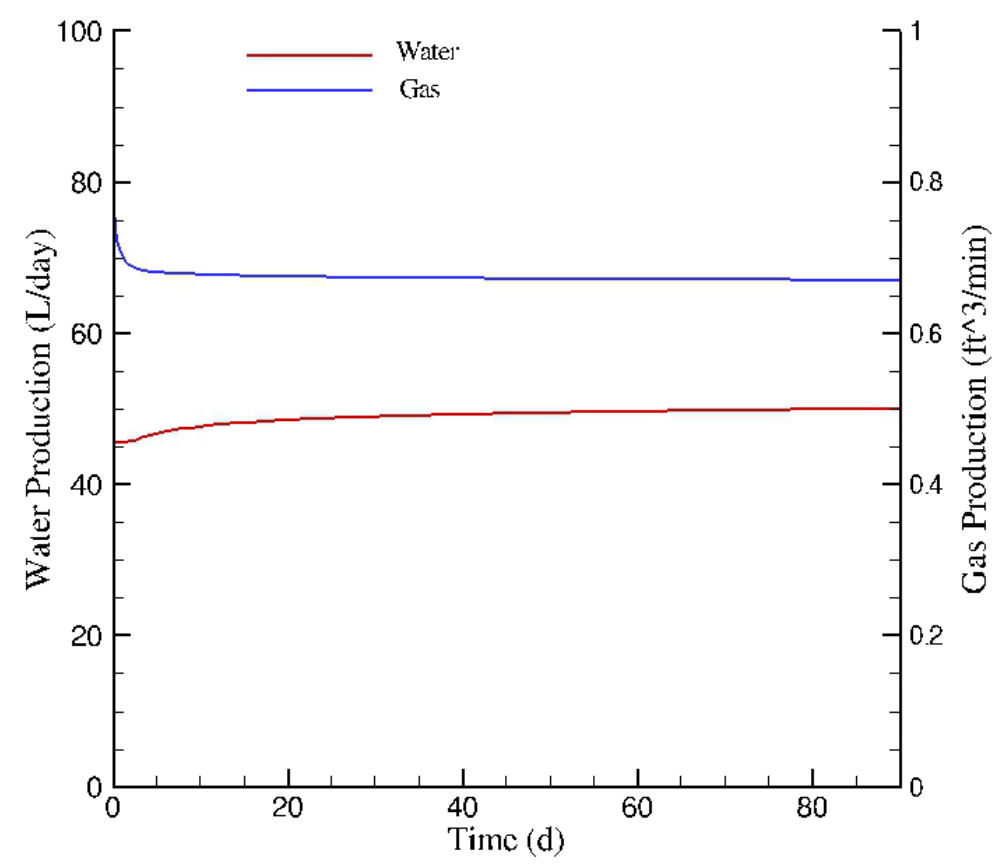

Figure 20. Water and gas extraction rates as a function of time for the simulation with an imposed vacuum of $3 \mathrm{~m} \mathrm{H}_{2} \mathrm{O}$ (4.3 psi) (Simulation: 3-m Vacuum; Table 1).

The effects of hydraulic conductivity changes on extraction are shown in Figure 21 and Figure 22 for the High $K_{\text {sat }}$ and Low $K_{\text {sat }}$ simulations, respectively. The effects on the water extraction are nearly linear, with almost tenfold increases and decreases in rate, respectively, compared to the Base Case. Arrival times of the first water in the extraction wells for both cases are relatively fast $(<0.1$ day). As is shown in data sets for related sediments (e.g., Last et al. 2006; Khaleel and Freeman 1995), a two-order-ofmagnitude range in hydraulic conductivity is not uncommon for CCUz sediments. These results indicate that, in addition to the initial water saturation, hydraulic conductivity is another sensitive parameter in relation to pore-water extraction. As an example, Figure 23 shows that the gas pressure response is also strongly influenced by the hydraulic conductivity. Compared to Figure 17 for the Base Case, a tenfold increase in hydraulic conductivity compresses the zone of influence by several feet. 


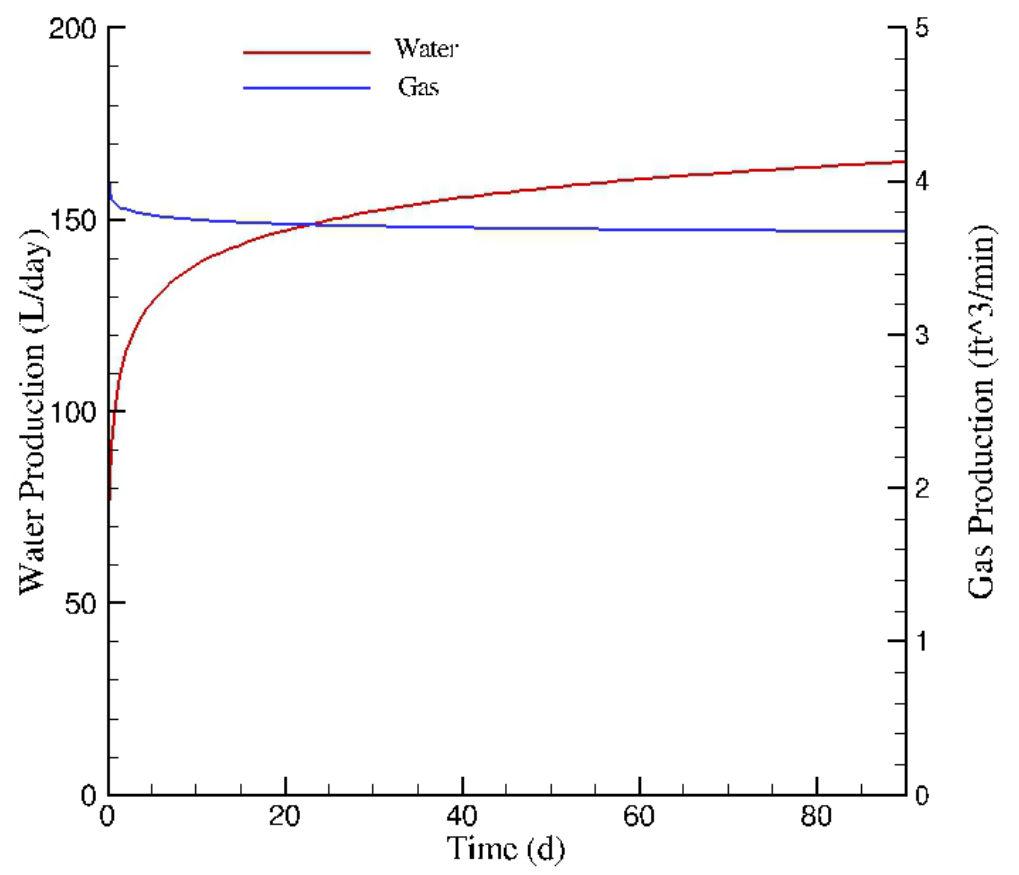

Figure 21. Water and gas extraction rates as a function of time for the simulation with an increased hydraulic conductivity (Simulation: High $K_{\text {sat }}$; Table 1 ).

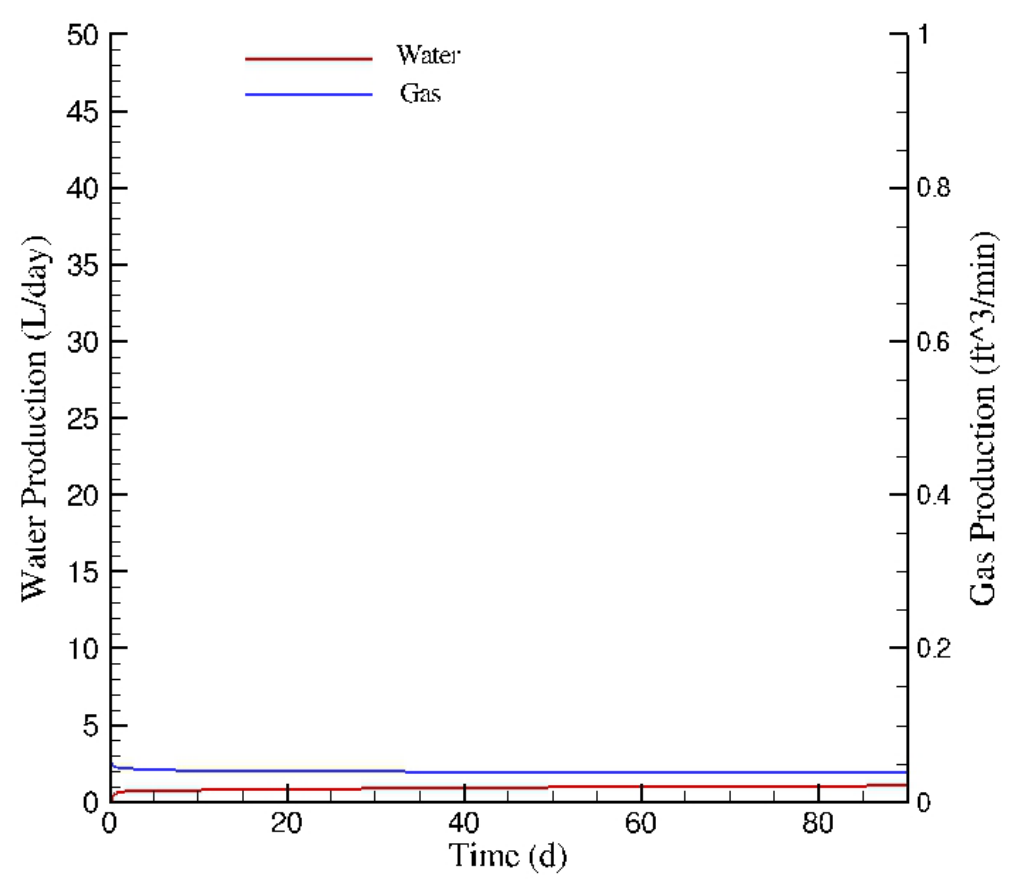

Figure 22. Water and gas extraction rates as a function of time for the simulation with a decreased hydraulic conductivity (Simulation: Low $K_{\text {sat }}$; Table 1 ). 


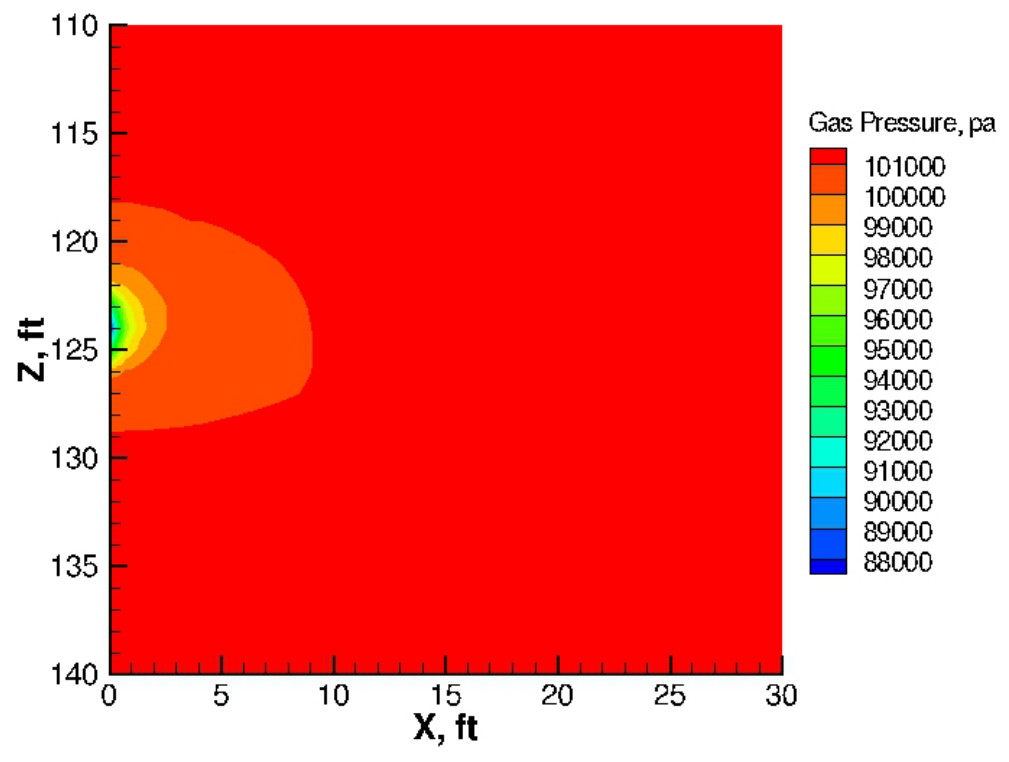

Figure 23. Steady-state gas pressure (Pa) for the simulation with an increased hydraulic conductivity (Simulation: High $K_{\text {sat }}$, Table 1).

Vertical anisotropy effects on extraction rates are shown in Figure 24 and Figure 25 for the 10:1 and 100:1 anisotropy cases, respectively. In these simulations, the horizontal hydraulic conductivity value was kept constant and the vertical value was reduced by a factor 10 or 100 . The plots show that the effects of anisotropy on extraction rates are limited, even for a two-orders-of-magnitude decrease in the vertical hydraulic conductivity value. However, the results suggest that horizontal water migration becomes more predominant with an increasing anisotropy ratio. The increase in horizontal flow compared to the Base Case is obvious when comparing Figure 26 for the Anisotropy 10:1 case with the Base Case water flow vectors in Figure 17.

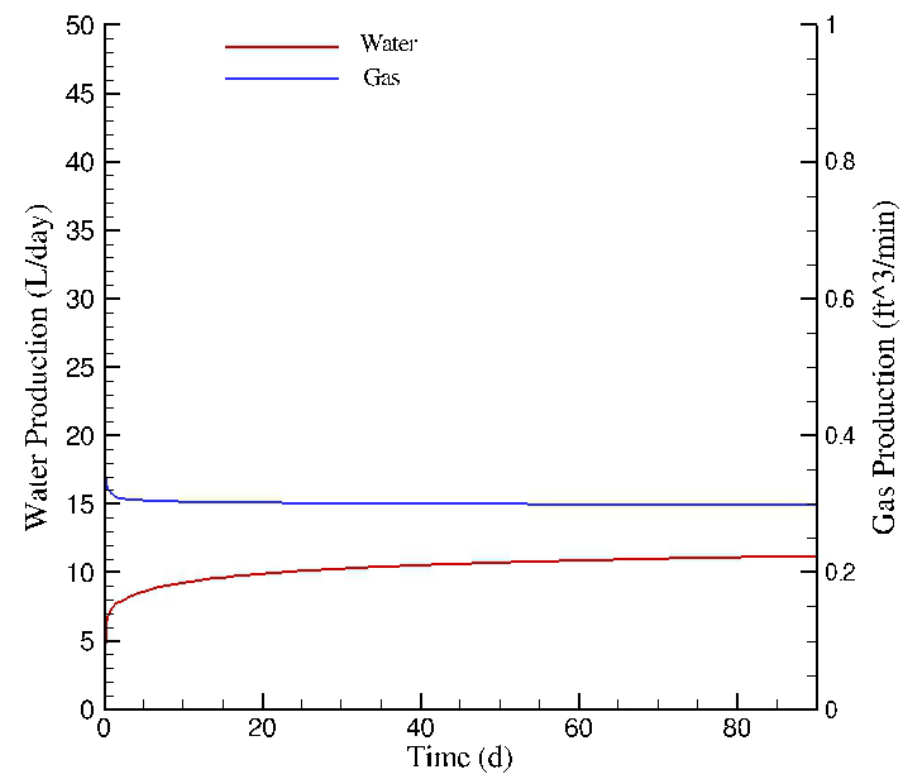

Figure 24. Water and gas extraction rates as a function of time for the simulation with an anisotropy ratio of 10:1 (Simulation: Anisotropy 10:1; Table 1). 


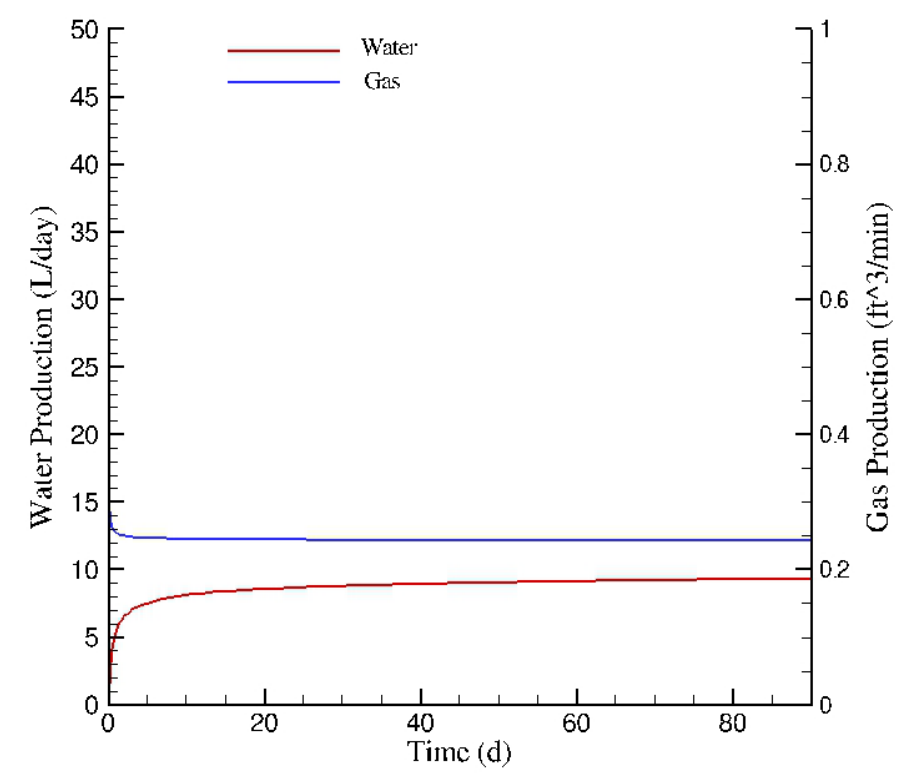

Figure 25. Water and gas extraction rates as a function of time for the simulation with an anisotropy ratio of 100:1 (Simulation: Anisotropy 100:1; Table 1).

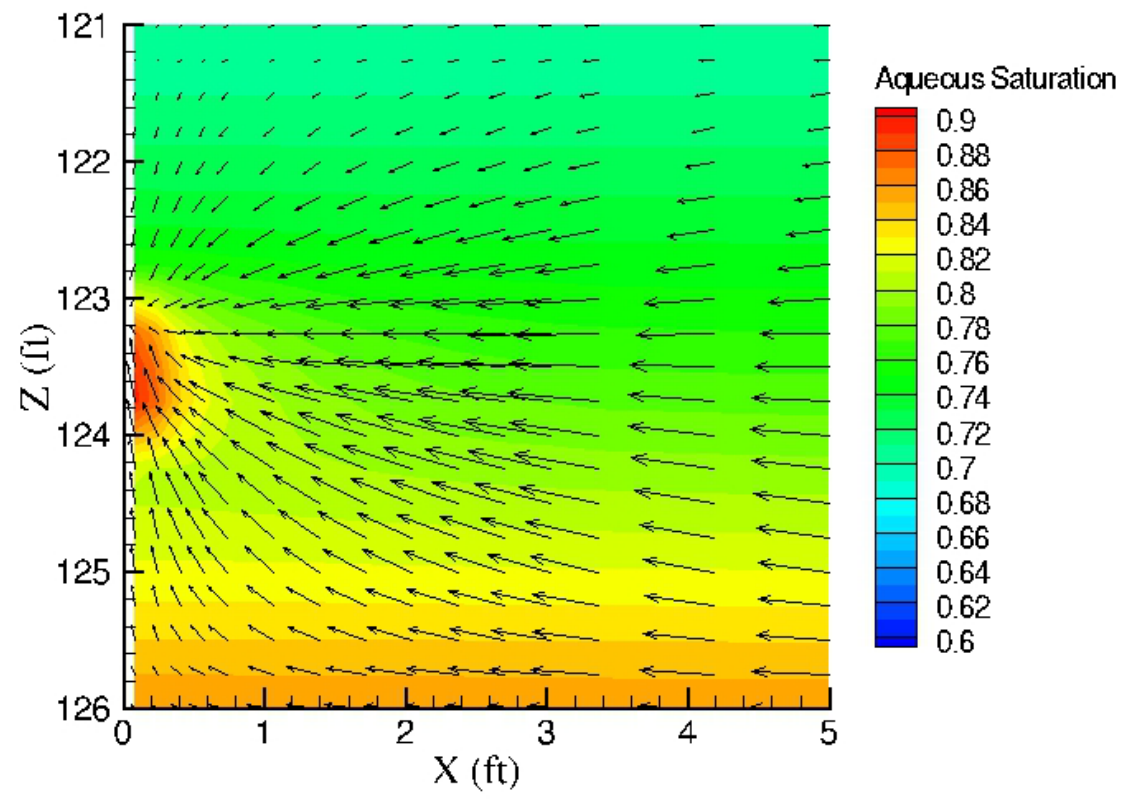

Figure 26. Near-well water saturations and velocities for the simulation with an anisotropy ratio of 10:1 (Simulation: Anisotropy 10:1; Table 1).

The influence of pore-geometry effects on extraction rates are shown in Figure 27 and Figure 28. An increased uniformity (High van Genuchten $n$ simulation; Table 1) yields considerably more water because the relative water permeability increases. The opposite effect causes a reduction in water extraction when the sediment pore-geometry is assumed to be less homogeneous. The range in tested pore-geometry values represents what can be expected for a CCUz sediment (Last et al. 2006). The van Genuchten $\alpha$ is an indication of the largest pore sizes for the sediment and $1 / \alpha$ may be considered to be equivalent to the 
air-entry pressure. A reduction of the $\alpha$ increases the entry pressure and yields a more uniform water saturation around the average of 0.8 compared to the Base Case. As a result, the observed water extraction rate increases (Figure 29). The opposite is true for the higher $\alpha$ value (Figure 30). Based on the simulated results, both van Genuchten parameters ( $n$ and $\alpha$ ) are considered to be sensitive parameters for water extraction. Both parameters have a much smaller influence on the gas extraction rates; their values are far less than $28.3 \mathrm{~L} / \mathrm{min}\left(1 \mathrm{ft}^{3} / \mathrm{min}\right)$ for all considered cases.

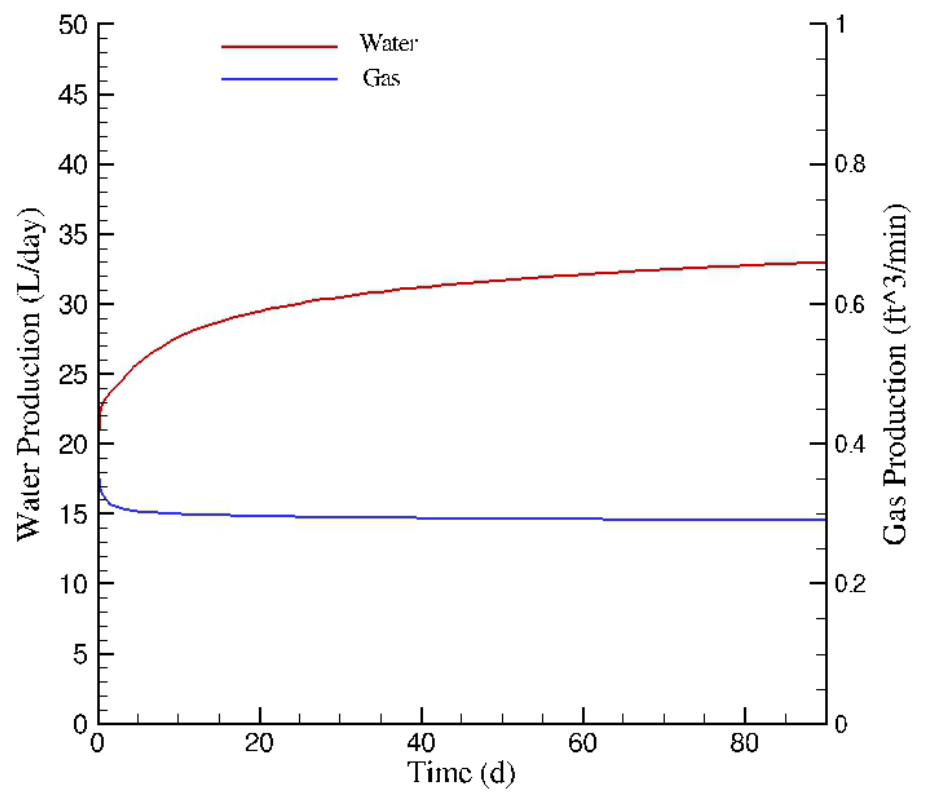

Figure 27. Water and gas extraction rates as a function of time for the simulation with an increased van Genuchten $n$ value (Simulation: High van Genuchten $n$; Table 1).

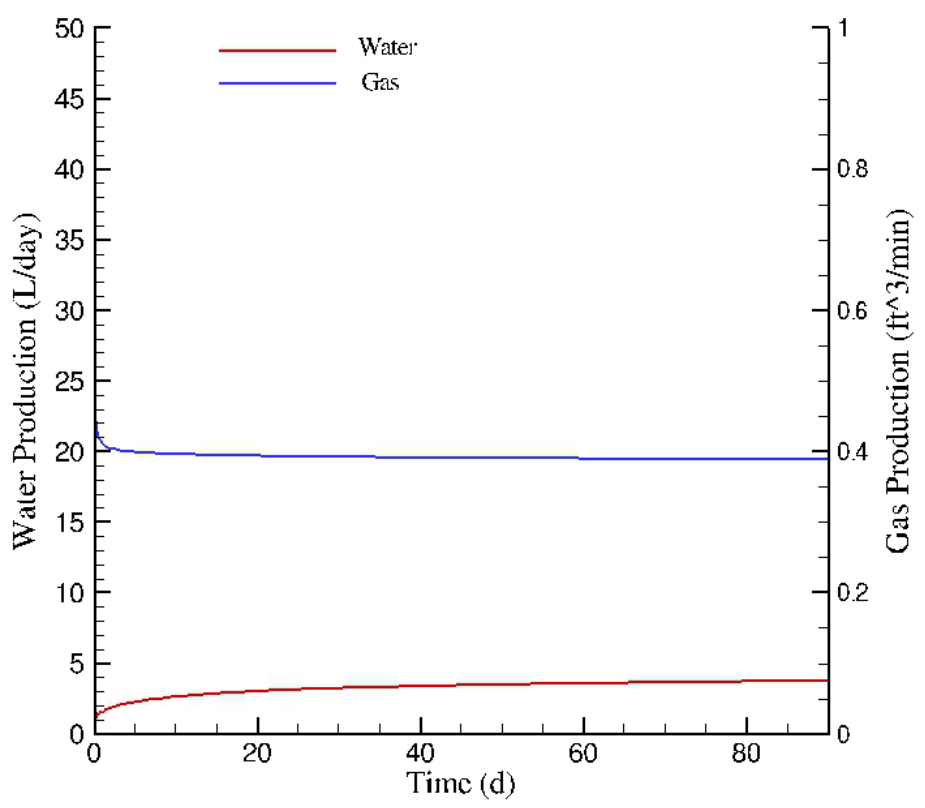

Figure 28. Water and gas extraction rates as a function of time for the simulation with a decreased van Genuchten $n$ value (Simulation: Low van Genuchten $n$; Table 1). 


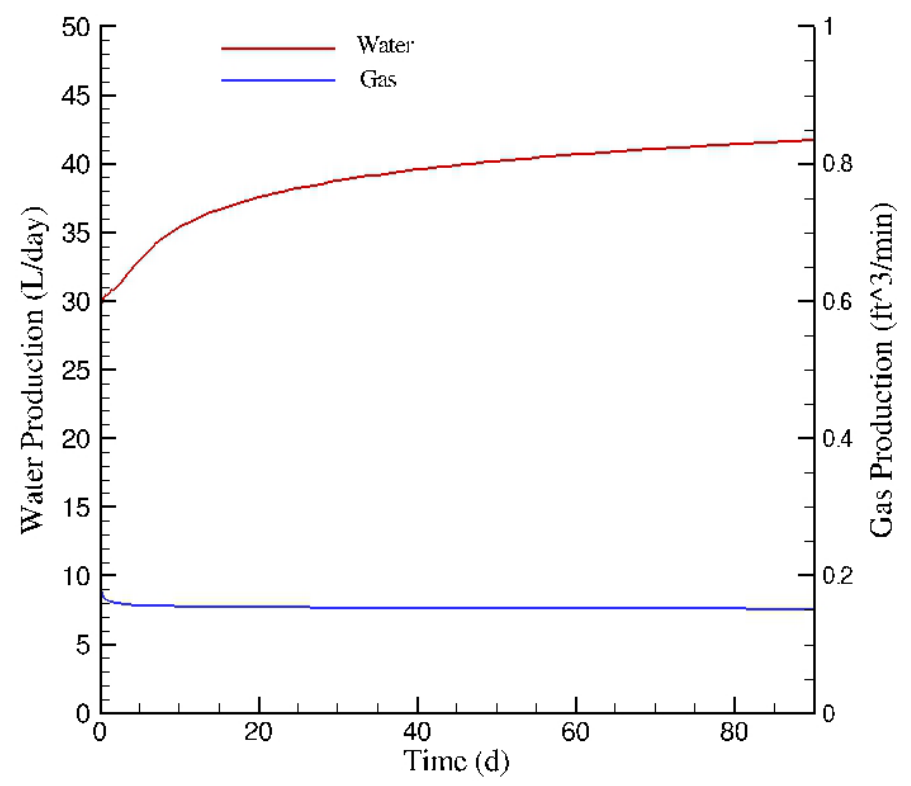

Figure 29. Water and gas extraction rates as a function of time for the simulation with a decreased van Genuchten $\alpha$ value (Simulation: Low van Genuchten $\alpha$, Table 1).

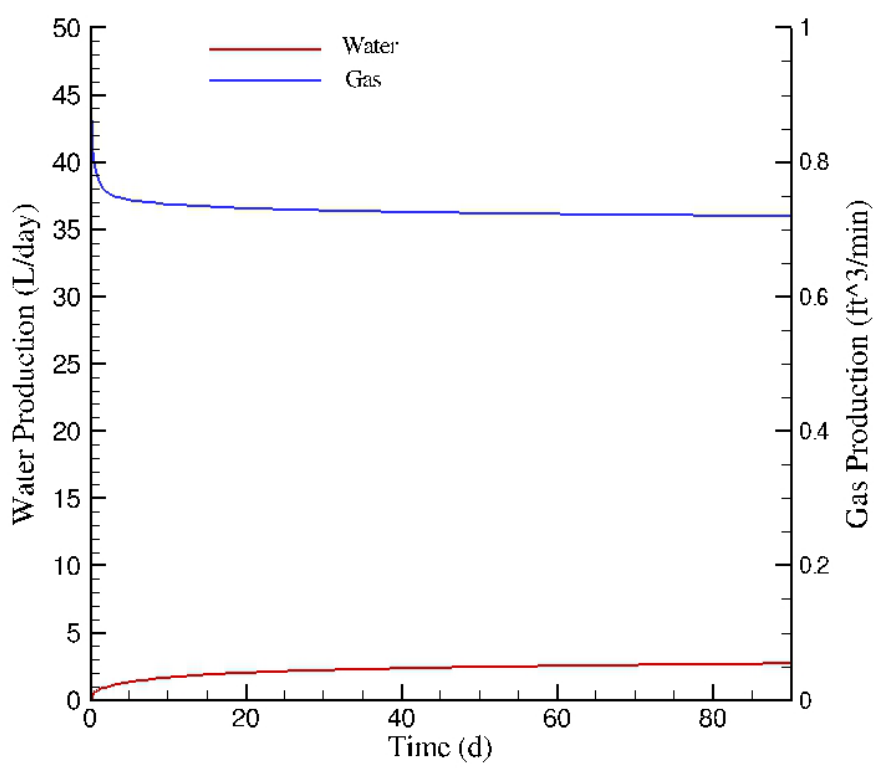

Figure 30. Water and gas extraction rates as a function of time for the simulation with an increased van Genuchten $\alpha$ value (Simulation: High van Genuchten $\alpha$, Table 1).

The simulations Sand Layer 1 through Sand Layer 4 investigate the effect of the location of a horizontal $0.3-\mathrm{m}$-high (1-ft) permeability sand layer with respect to the extraction well screen. Although it is not likely that a layer with these specific hydraulic properties will be present in the CCUz at the SX Tank Farm site, lower soil moisture content zones intersecting the well's screened interval may cause a similar impact on pore-water and gas extraction rates as observed in simulations with the hypothetical sand layer. For instance, the measured lower soil moisture values of about 0.1 (Figure 9) are larger than the residual water content of 0.045 for the Carsel and Parrish (1988) sand, but are still consistent with low 
capillary pressure (dry) conditions. However, the results of these simulations should be considered to yield conservative (low) pore-water extraction rates and conservative (high) gas extraction rates compared to expected actual conditions at the SX Tank Farm field test site. The extraction rates of those four simulations are shown in Figure 31 through Figure 34. If the sand layer is directly adjacent to the screen, no water is produced during the simulation time. The gas extraction rate, on the other hand, approaches $2200 \mathrm{~L} / \mathrm{min}\left(78 \mathrm{ft}^{3} / \mathrm{min}\right)$. When the location of this high-permeability zone is moved up compared to the screen location, the water extraction rate increases as a function of the contact area between the screen and the CCUz (Table 3). When the sand layer is fully above the screen (Sand Layer 4), the water extraction rate starts to approach the rate obtained for the Base Case. The water saturation distribution and velocities for the Sand Layer 4case are shown in Figure 35. The trend in the gas extraction rates is opposite to what happens to the water rates. The data in Table 3 show that gas extraction rates are considerably higher than for the Base Case as long as some part of the screen is in direct contact with the high-permeability sand layer. The location of such a layer also has a large impact on the arrival times of the water at the extraction well. Only when the layer is located fully above the screen (Sand Layer 4) is the water arrival time near instantaneous $(<0.1$ day). For all other cases, the delays in arrival are substantial. Of interest also is the case in which the sand layer is $0.15-\mathrm{m}(0.5-\mathrm{ft})$ thick located at the center of the extraction well screen ("Sand Layer 5" simulation, Table 1). The extraction rates for this case are shown in Figure 36. For this case, the water extraction is close to what was obtained for the Sand Layer 2 simulation where the sand layer is $0.3-\mathrm{m}(1-\mathrm{ft})$ thick but also contacts the screen over a $0.15 \mathrm{~m}$ $(0.5 \mathrm{ft})$ length. However, the gas extraction rate is almost double for the Sand Layer $20.3-\mathrm{m}$ (1-ft)-thick sand-layer simulation. The results for these five simulations show that the location and thickness of highpermeability zones might have a large effect on extraction rates. As long as such a layer is not in direct contact with the extraction screen, the effects on both water and gas extraction are relatively minimal. However, when the screen is completed directly adjacent to a high-permeability zone, the water extraction rates are expected to decrease rapidly with concurrent large increases in gas extraction rates. These kinds of configurations are therefore not favorable for field testing of the methodology.

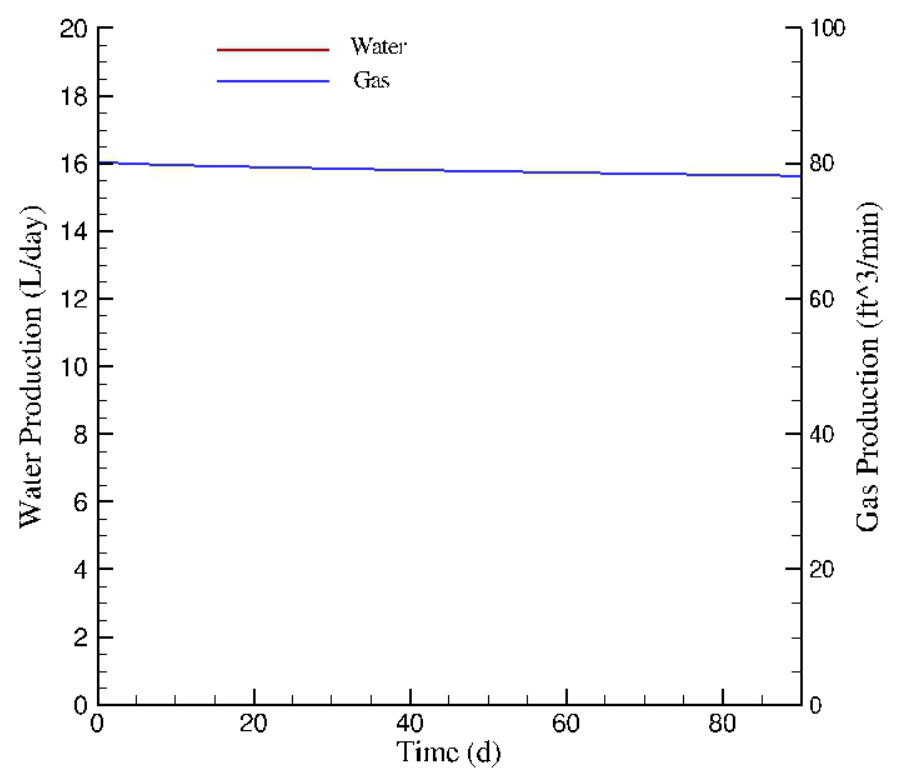

Figure 31. Water and gas extraction rates as a function of time for the simulation with a highpermeability sand layer between 123 and $124 \mathrm{ft}$ bgs (Simulation: Sand Layer 1; Table 1). 


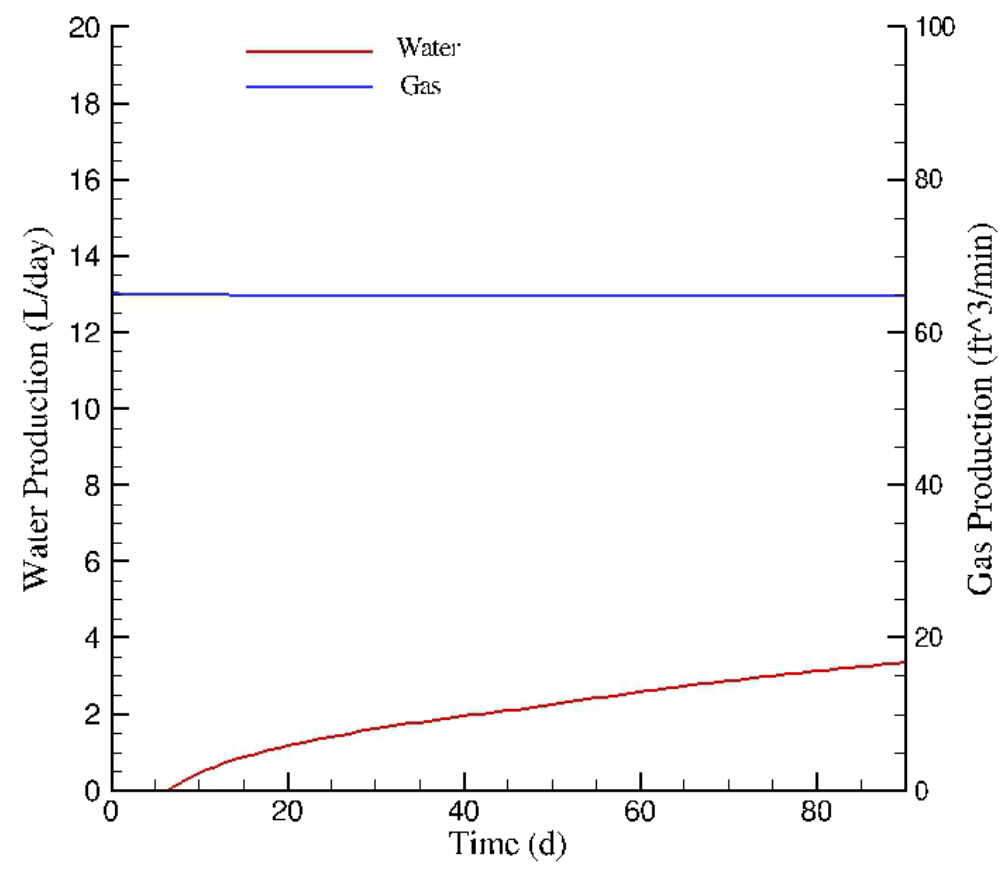

Figure 32. Water and gas extraction rates as a function of time for the simulation with a highpermeability sand layer between 122.5 and $123.5 \mathrm{ft}$ bgs (Simulation: Sand Layer 2; Table 1).

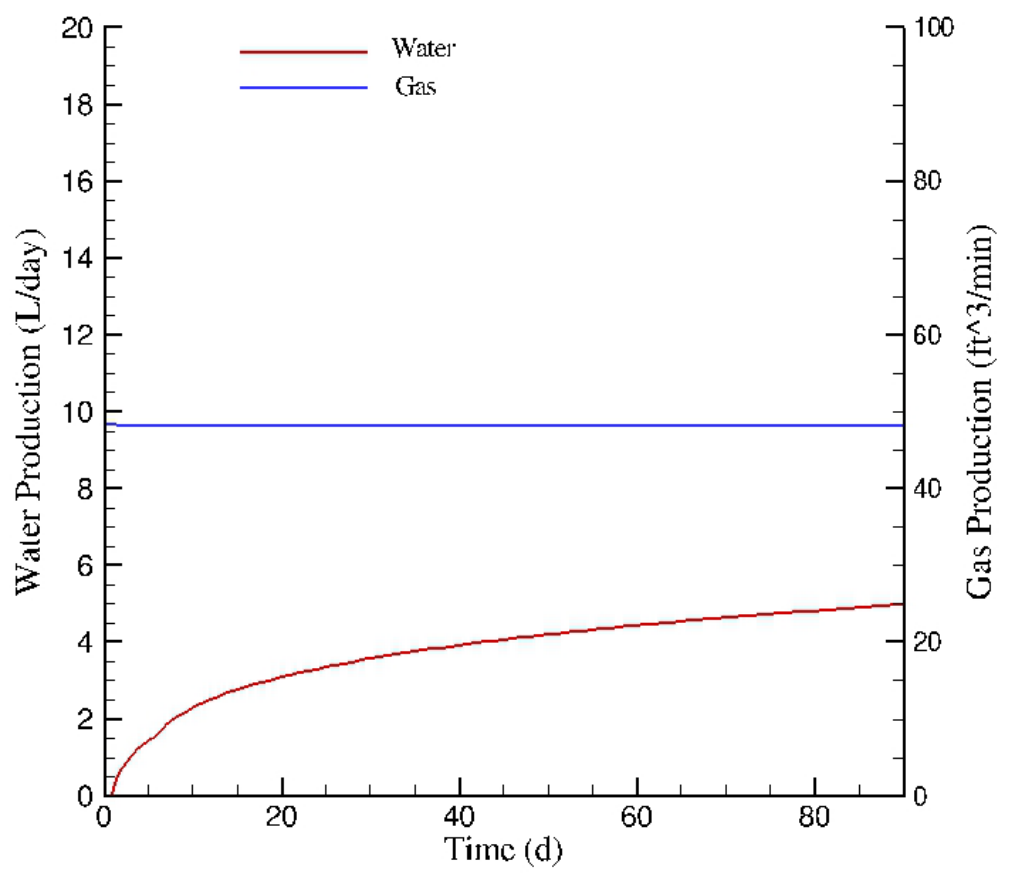

Figure 33. Water and gas extraction rates as a function of time for the simulation with a highpermeability sand layer between 122.25 and $123.25 \mathrm{ft}$ bgs (Simulation: Sand Layer 3; Table 1). 


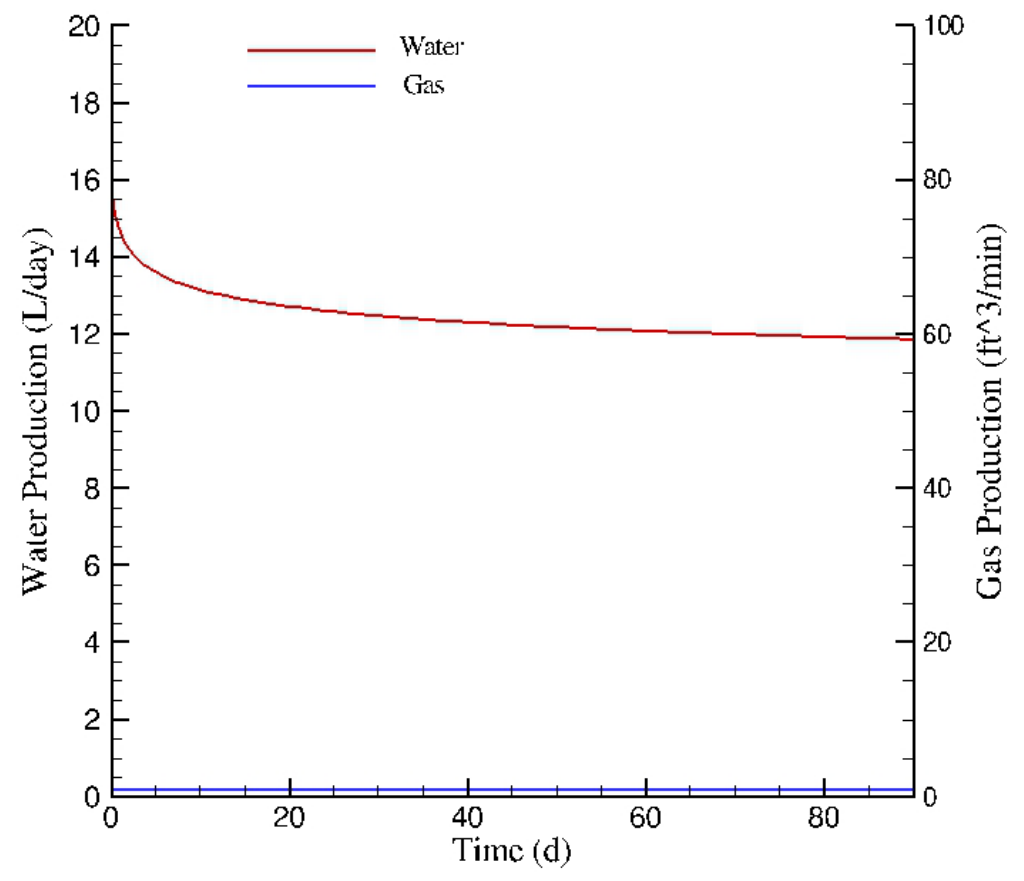

Figure 34. Water and gas extraction rates as a function of time for the simulation with a highpermeability sand layer between 122 and $123 \mathrm{ft} \mathrm{bgs} \mathrm{(Simulation:} \mathrm{Sand} \mathrm{Layer} \mathrm{4;} \mathrm{Table} \mathrm{1).}$

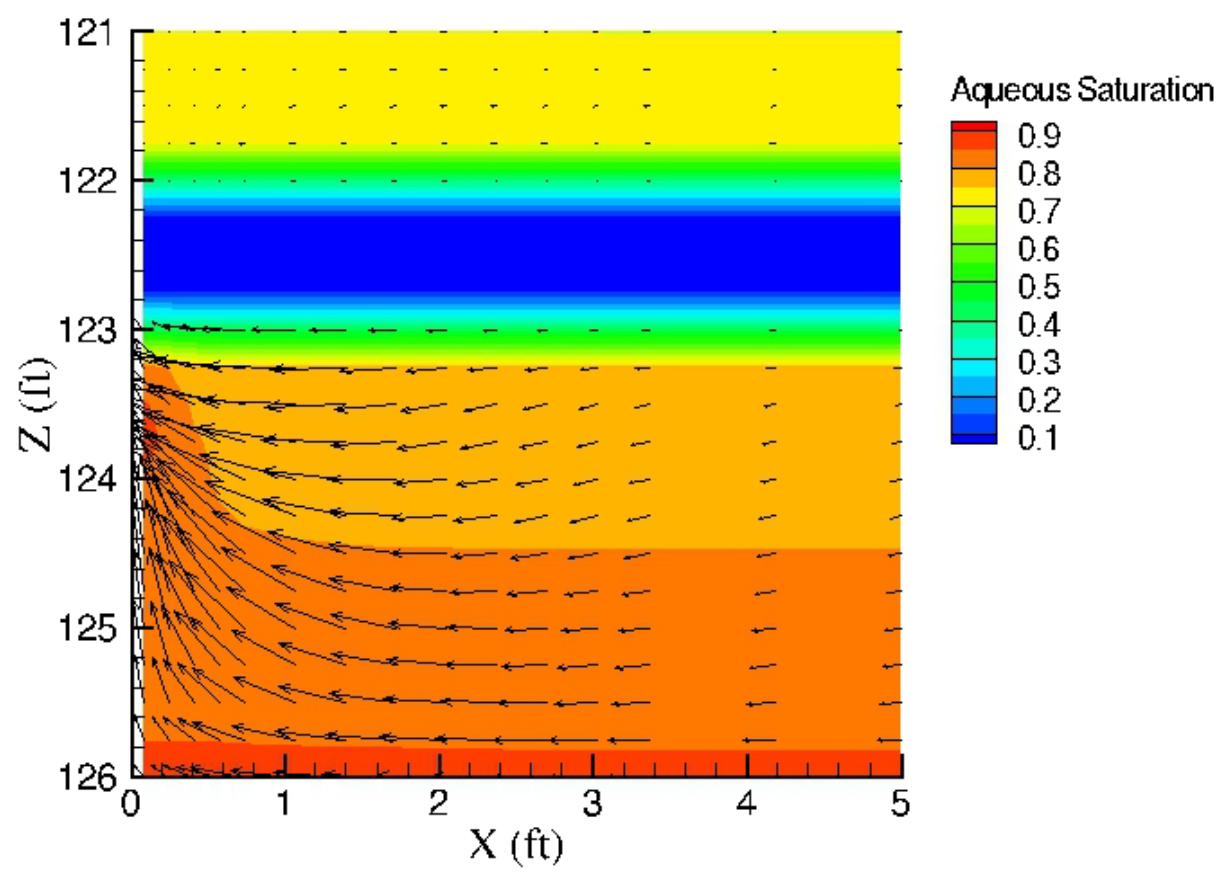

Figure 35. Steady-state water saturations and velocities for the simulation with a high-permeability sand layer between 123 and $124 \mathrm{ft}$ bgs (Simulation: Sand Layer 4; Table 1). 


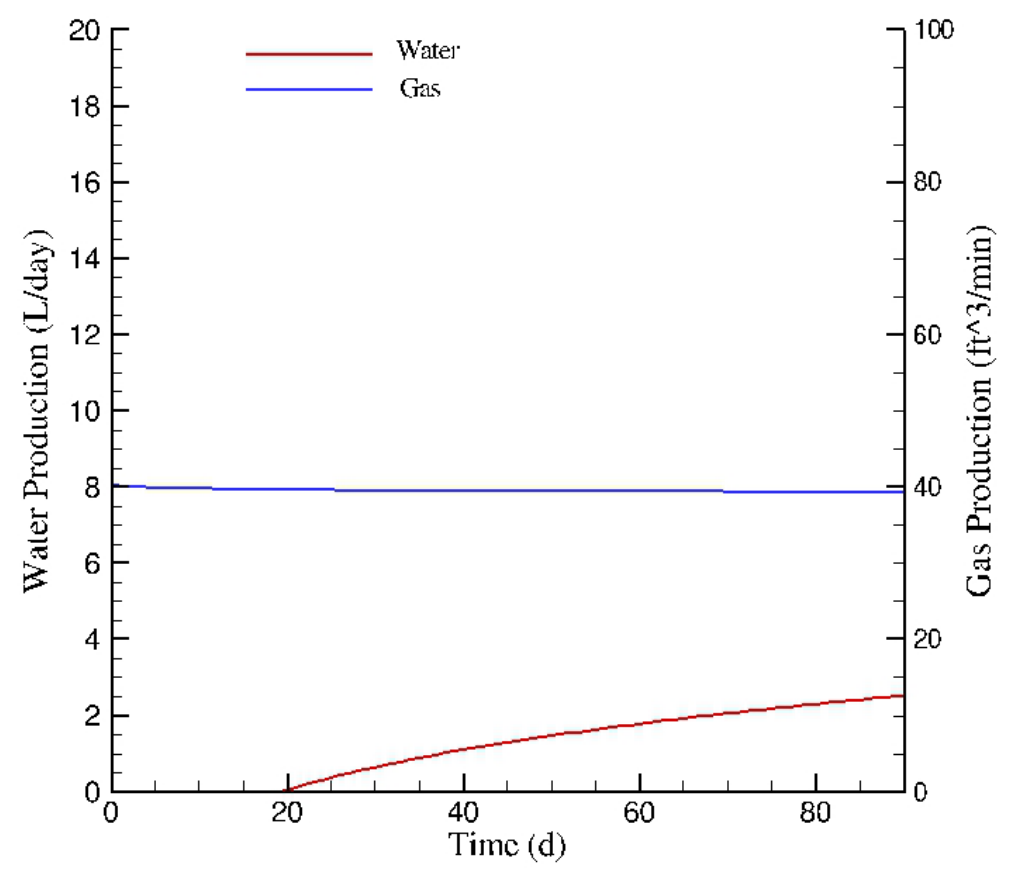

Figure 36. Water and gas extraction rates as a function of time for the simulation with a highpermeability sand layer between 123.25 and $123.75 \mathrm{ft}$ bgs (Simulation: Sand Layer 5; Table 1).

The final two simulations listed in Table 1 considered the effects of compaction near the screen. Due to the nature of direct-push well installation, some compaction is expected, resulting in a zone with a lower effective hydraulic conductivity. In the two simulation scenarios, it was assumed that the hydraulic conductivity was reduced over a 5-cm zone adjacent to the screen. Both simulations (Figure 37 and Figure 38) show a considerable impact for this modification; water extraction rates were reduced by a factor of about 5 for the Compacted Zone 1 simulation (Table 1) and a factor of approximately 50 for the more compacted near-well zone in the Compacted Zone 2 simulation. An example plot showing the nearwell saturations and flow velocity field for the Compacted Zone 1 simulation is shown in Figure 39. Although water extraction was strongly reduced by compaction in both simulations, the rates did not reduce to negligible values. For both of these compacted zone simulations, gas extraction is much lower than for the Base Case; a reduced rate of only $0.28 \mathrm{~L} / \mathrm{min}\left(0.01 \mathrm{ft}^{3} / \mathrm{min}\right)$ was estimated for the highly compacted zone simulation.

For field applications, methods to reduce the compaction effects should be considered to keep fluid permeability as high as possible. For example, the well development method described in the fallinghead test memorandum (Attachment) seems to be effective in achieving some reduction in compaction because the assumed hydraulic conductivity of the CCUz of $1.39 \times 10^{-3} \mathrm{~cm} / \mathrm{s}$ is close to the value of $\sim 1.0 \times 10^{-3} \mathrm{~cm} / \mathrm{s}$ (equivalent to $1.0 \mathrm{e} \times 10^{-8} \mathrm{~cm}^{2}$ ) obtained in the falling-head analysis. 


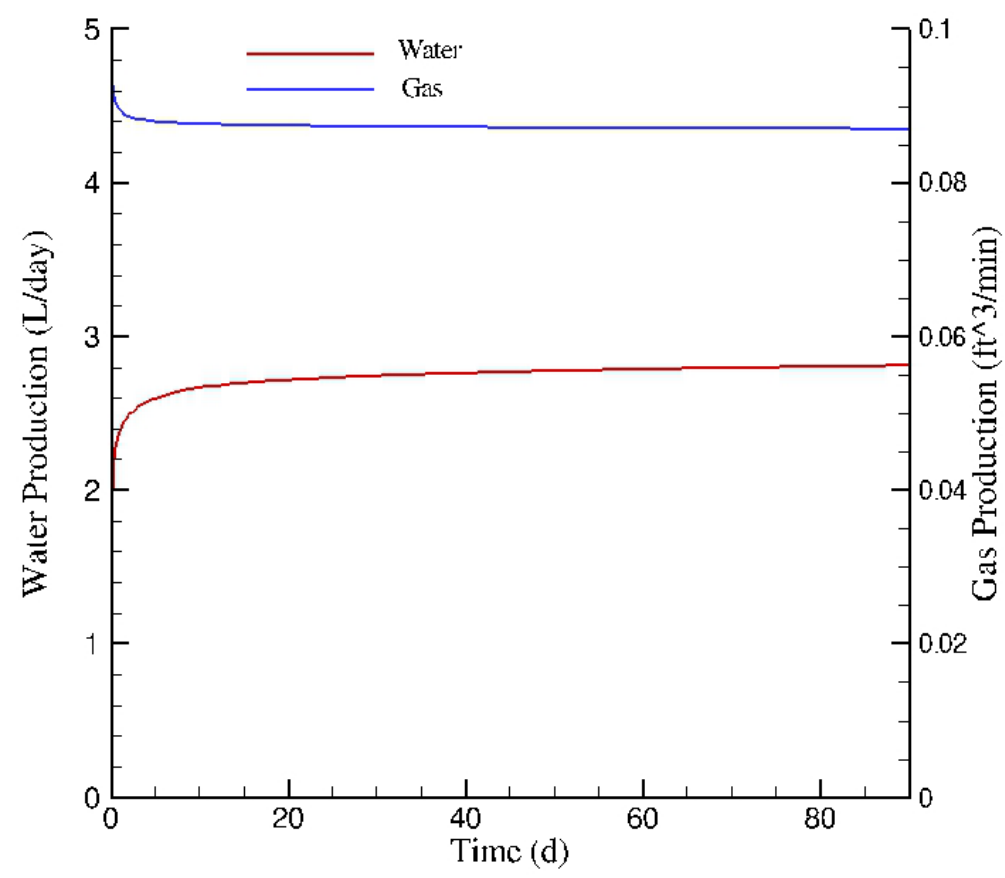

Figure 37. Water and gas extraction rates as a function of time for the simulation with a compaction zone with a 10-times-reduced $K_{\text {sat }}$ value (Simulation: Compaction Zone 1; Table 1).

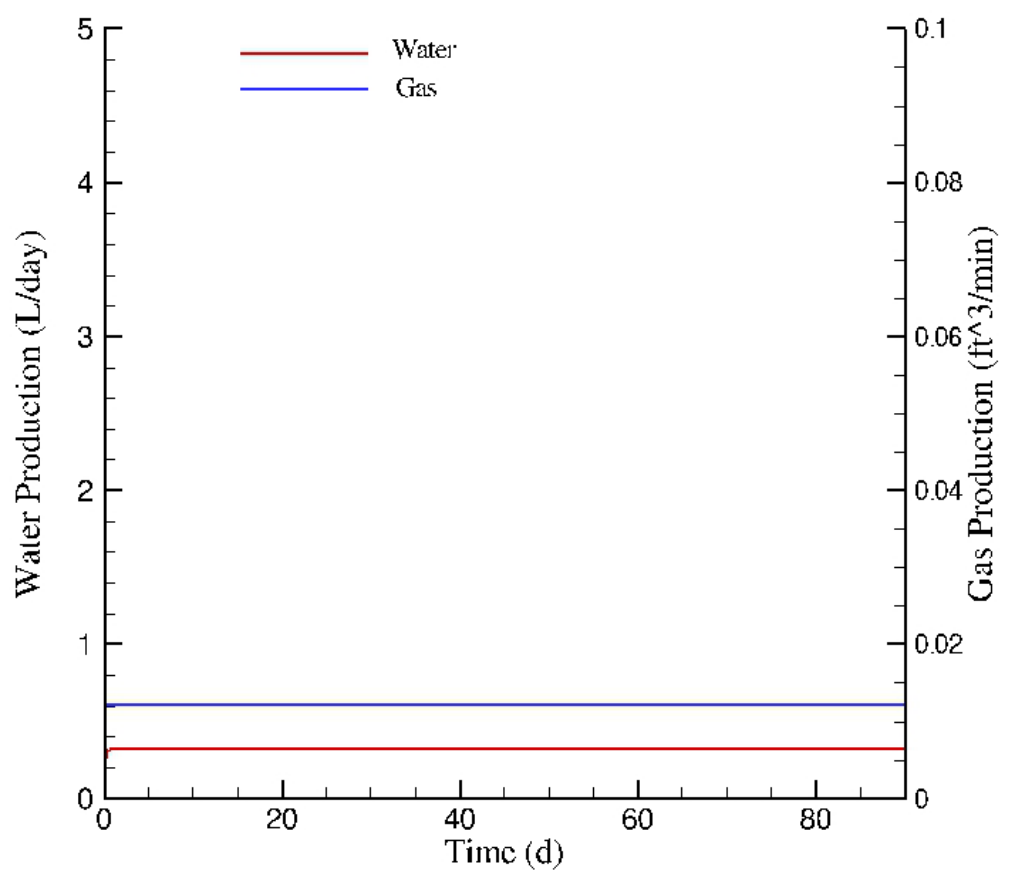

Figure 38. Water and gas extraction rates as a function of time for the simulation with a compaction zone with a 100-times-reduced $K_{\text {sat }}$ value (Simulation: Compaction Zone 2; Table 1). 


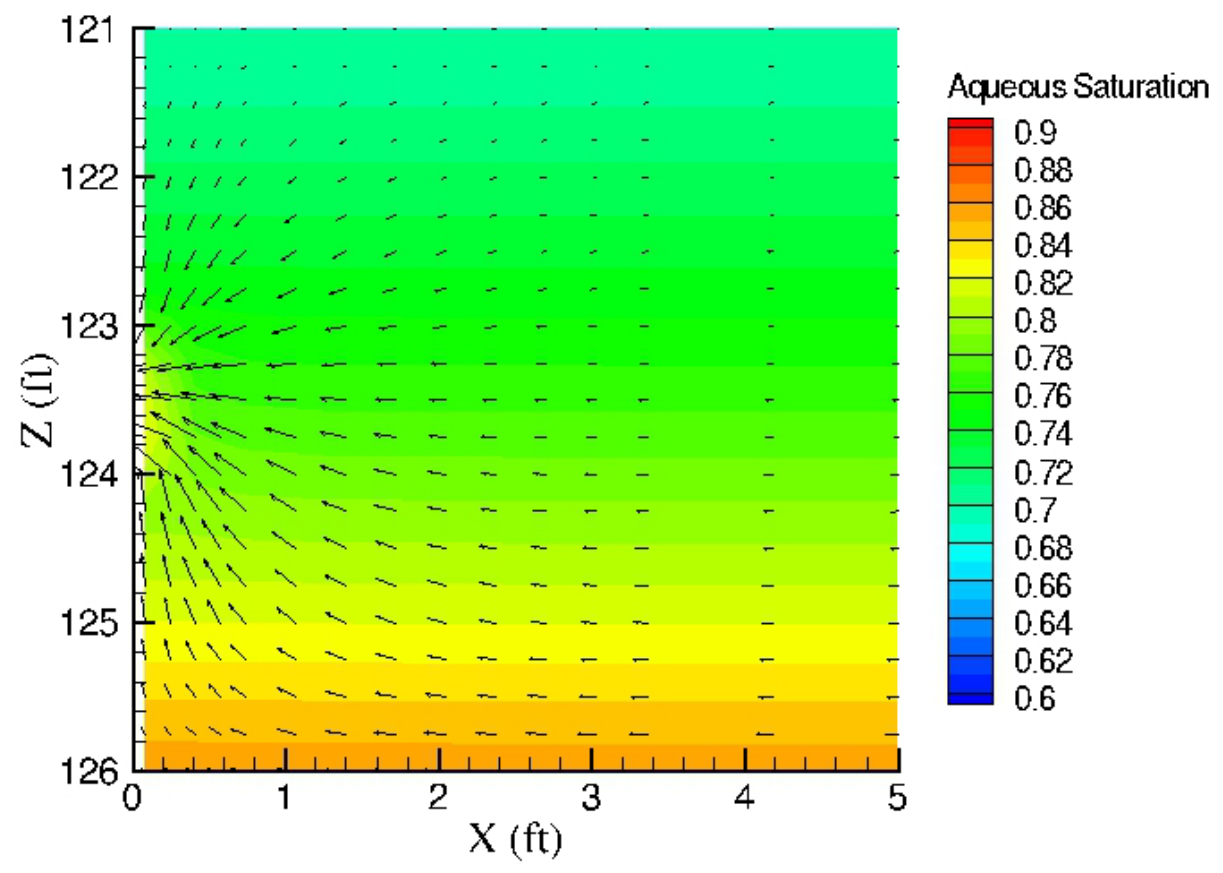

Figure 39. Steady-state water saturation and velocities for the simulation with a compaction zone with a 10-times-reduced $K_{\text {sat }}$ value (Simulation: Compaction Zone 1; Table 1).

Results of the detailed layered simulations for the three methods outlined in Section 3.0 are shown in Figure 40 and Figure 41 for Method 1, Figure 42 and Figure 43 for Method 2, and Figure 44 and Figure 45 for Method 3. The extraction plots show that the differences among the three methods for both water and gas are limited. Final water extraction rates of 2.7, 5.2, and 1.9 L/day result for Methods 1, 2, and 3, respectively. Final gas extraction rates are $21.2,37.7$, and $15.6 \mathrm{~L} / \mathrm{min}\left(0.75,1.33\right.$, and $\left.0.55 \mathrm{ft}^{3} / \mathrm{min}\right)$ for Methods 1, 2, and 3, respectively. For all three simulations, the water extraction rates are lower than for the Base Case, while the gas extraction rates are higher. The reduction in water extraction rates for the three detailed simulations is directly related to the limited thickness of the layers with high moisture content, as can be seen in Figure 10. The gas extraction rates are higher for all three methods than for the Base Case but not nearly as high as for the simulations with a single sand layer (partly) adjacent to the well screen. The primary reason for the limited gas extraction is that the screen does not intersect a highpermeability zone in any of the three simulations. The computed gas pressure distributions are also rather similar to the Base Case, indicating a limited influence of layering on gas pressure. In all cases, negative gas pressures (i.e., gas pressures less than atmospheric) of $0.35 \mathrm{~m} \mathrm{H}_{2} \mathrm{O}(0.5 \mathrm{psi})$ are located within $1.5 \mathrm{~m}$ $(5 \mathrm{ft})$ of the well. 


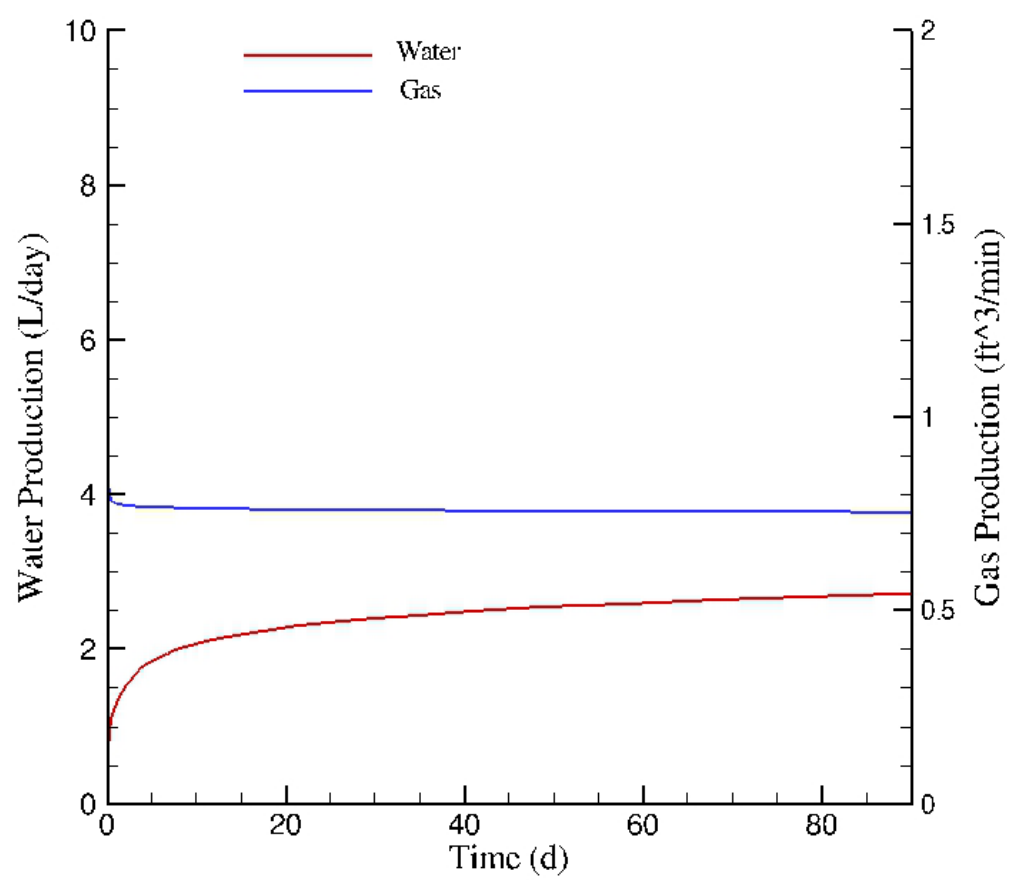

Figure 40. Water and gas extraction rates as a function of time for the simulation with a layered system created using Method 1.

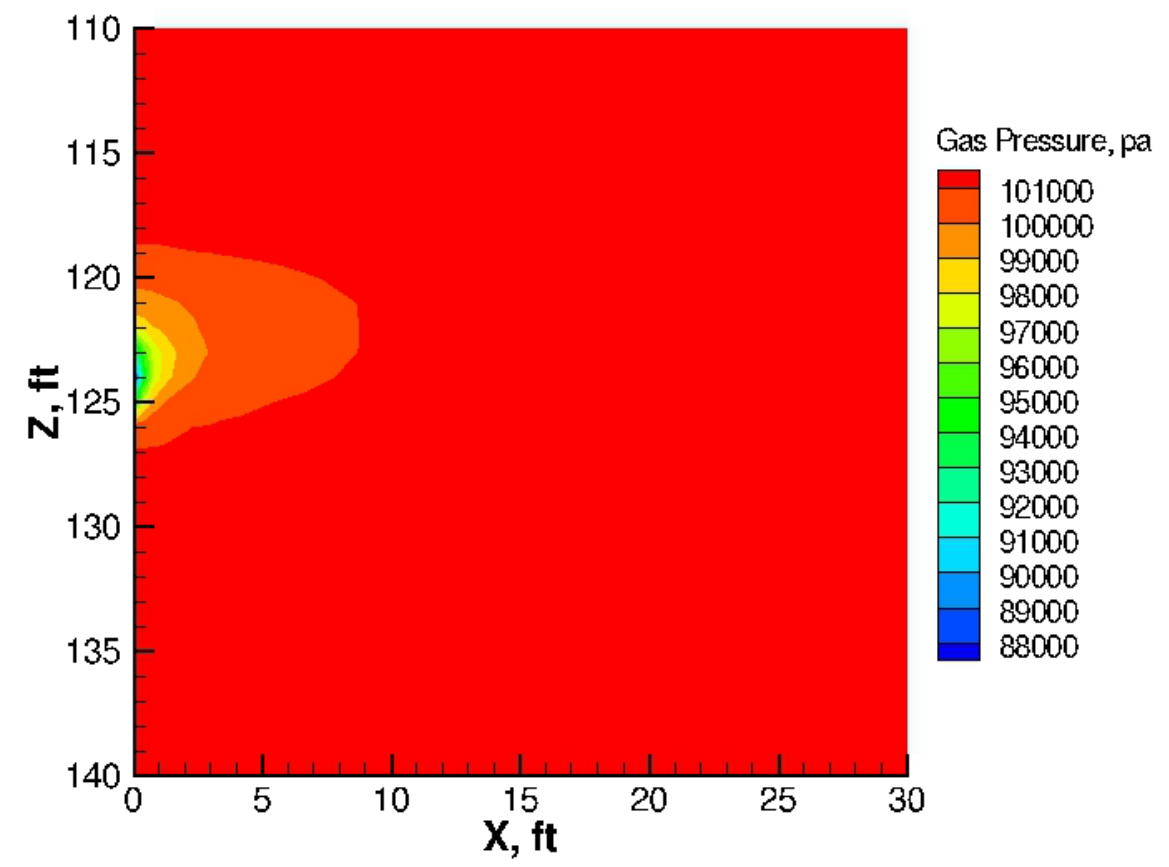

Figure 41. Steady-state gas pressure $(\mathrm{Pa})$ for the simulation with a layered system created using Method 1. 


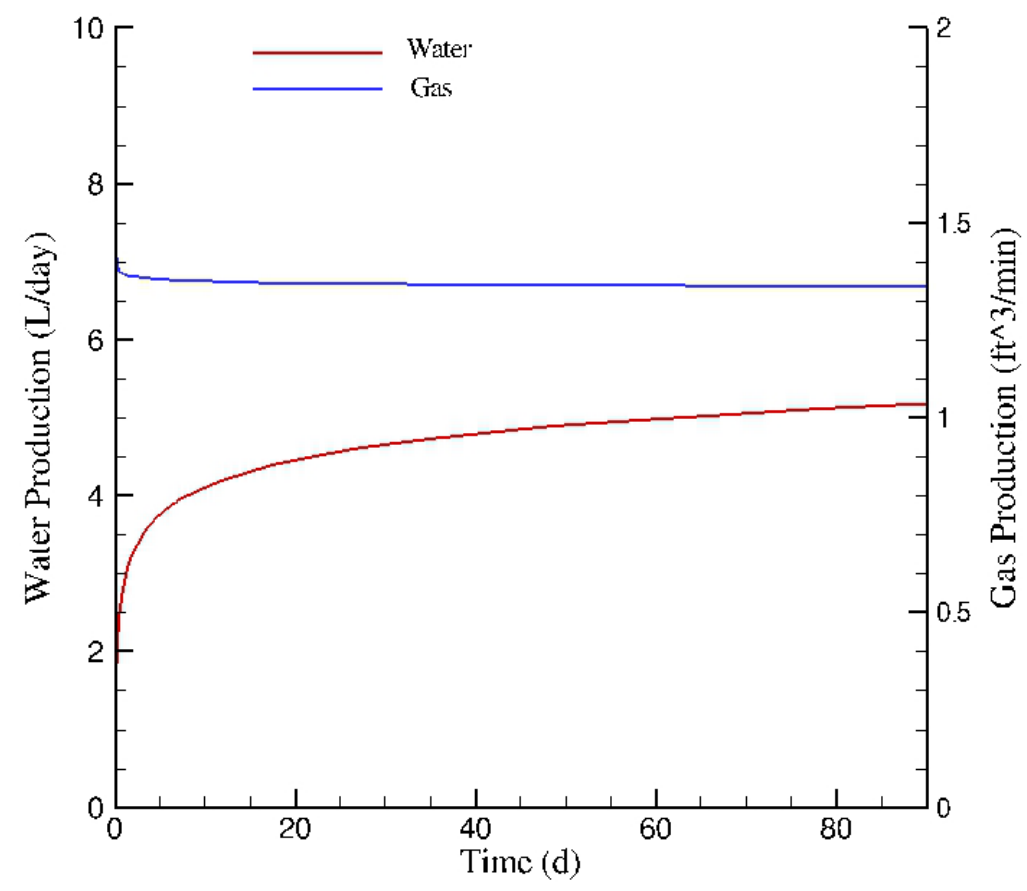

Figure 42. Water and gas extraction rates as a function of time for the simulation with a layered system created using Method 2.

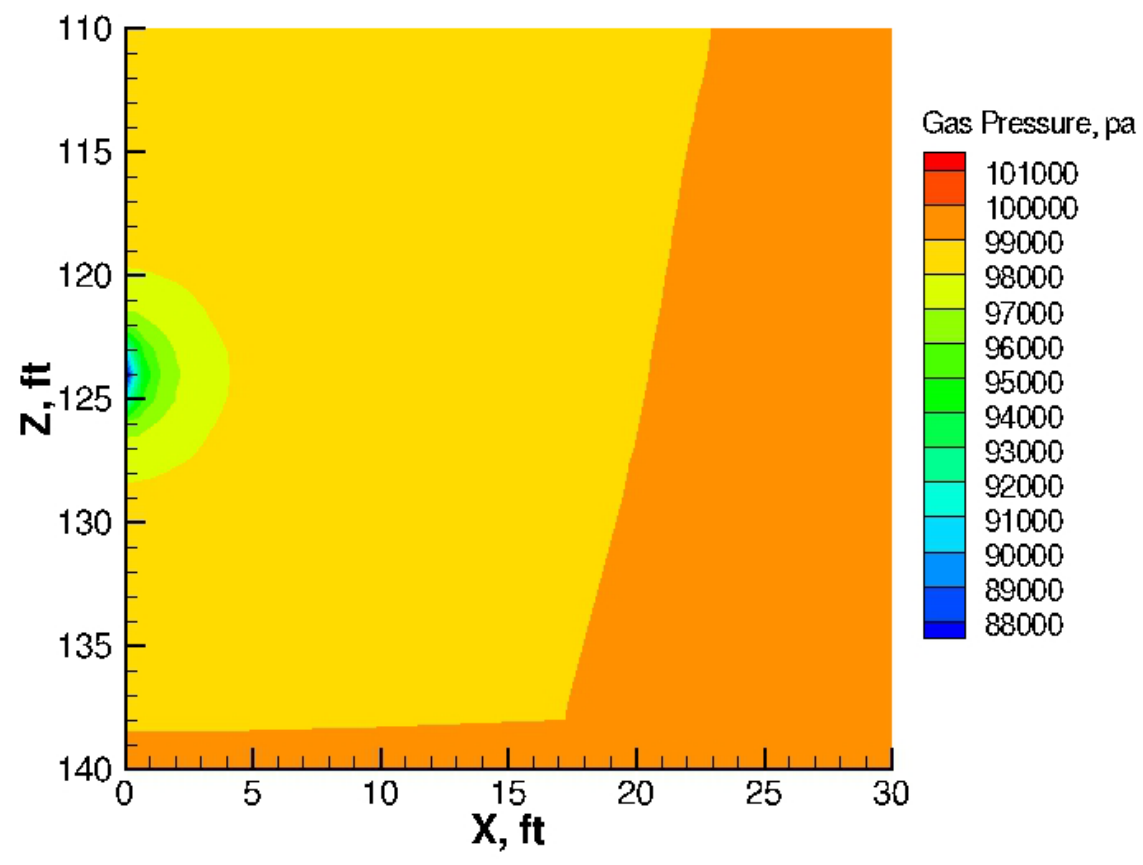

Figure 43. Steady-state gas pressure $(\mathrm{Pa})$ for the simulation with a layered system created using Method 2. 


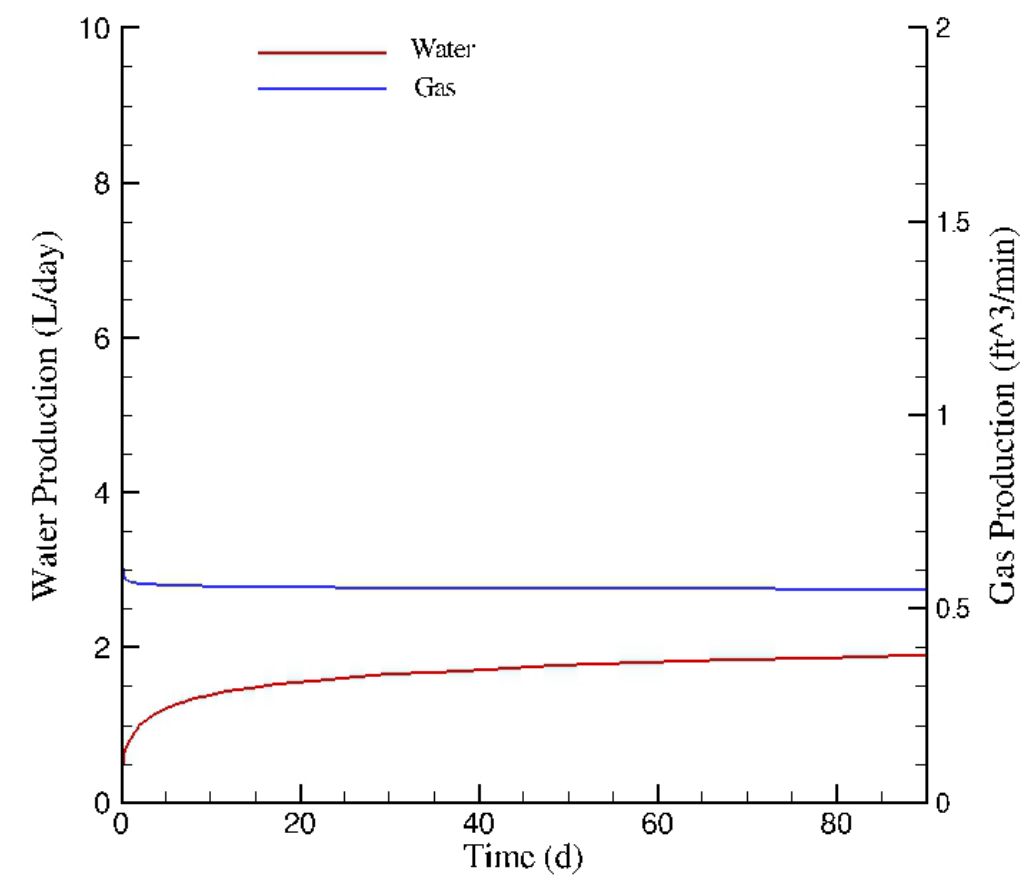

Figure 44. Water and gas extraction rates as a function of time for the simulation with a layered system created using Method 3.

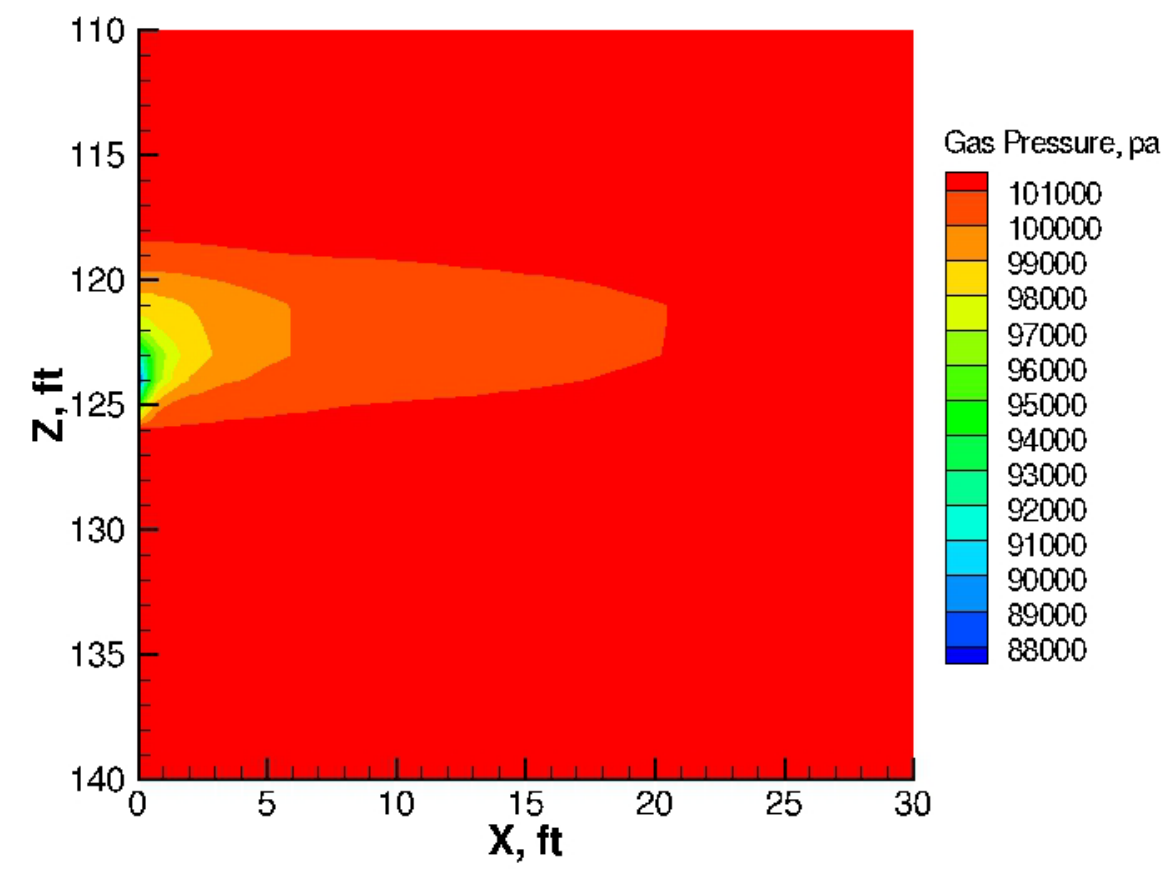

Figure 45. Steady-state gas pressure $(\mathrm{Pa})$ for the simulation with a layered system created using Method 3. 


\subsection{Conclusions}

Two sets of simulations were conducted to evaluate pore-water extraction under conditions relevant to the SX Tank Farm test site. In the first set, the 10-m-thick CCUz layer was assumed to be either 1) homogeneous or 2) heterogeneous with a single $0.3-\mathrm{m}$ (1-ft)-thick high-conductivity layer (at various locations with respect to the screen interval) in an otherwise homogeneous zone. In these simulations, the extraction rates were computed for relatively simple representations of the CCUz layer, but provided an effective configuration to examine the impact of variations in key hydraulic parameters and subsurface configurations (e.g., the position of hypothetical high-permeability layers with respect to the extraction screen). For the second set of simulations, three model configuration approaches were used to represent the observed vertical distribution of moisture content variations in the CCUz layer at the field test site (data from borehole C8761). In all simulations, extraction was from a 0.3-m (1-ft) screened interval.

For a homogeneous CCUz)layer with hydraulic properties obtained in the laboratory (e.g., Base Case simulations), long-term pore-water extraction rates are approximately $15 \mathrm{~L} /$ day. The associated gas extraction rate is about $11.3 \mathrm{~L} / \mathrm{min}\left(0.4 \mathrm{ft}^{3} / \mathrm{min}\right)$. Because of the assumed relatively high initial water saturation (0.8), water extraction at the well is initiated rapidly $(<0.1$ day). However, pore-water extraction rate is highly sensitive to the initial water saturation adjacent to the well screen. A saturation increase to 0.9 more than doubles the rate, while a lower initial saturation of 0.7 reduces the rate by a factor 10. Increasing the vacuum from 2 to $3 \mathrm{~m} \mathrm{H}_{2} \mathrm{O}(\sim 20$ to $30 \mathrm{kPa}, 2.8$ to $4.3 \mathrm{psi})$ almost triples the water extraction rate. Based on experience from laboratory experiments, care must be used in applying higher vacuum levels to avoid creating preferential gas flow pathways that negatively impact the porewater extraction rate.

A limited sensitivity analysis of hydraulic properties identified hydraulic conductivity and the van Genuchten parameters $n$ and $\alpha$ as having the most impact on pore-water extraction performance. Changes in hydraulic conductivity have a nearly linear correlation with water extraction rates. An increase in the pore geometry factor $n$ or a decrease in the air entry pressure factor $\alpha$ both resulted in considerably higher extraction rates, with limited effects on the gas extraction rates. The vertical anisotropy ratio, up to a value of 100 , had only a minor effect on water extraction rate. All the investigated parameter value variations were within the ranges of potential values for the field test site, indicating that a wide range of possible water extraction rates may occur in the field test.

Of importance for equipment design and test operations, the gas extraction rates of most simulations yielded values of less than $28.3 \mathrm{~L} / \mathrm{min}\left(1 \mathrm{ft}^{3} / \mathrm{min}\right)$. Values considerably higher than $28.3 \mathrm{~L} / \mathrm{min}\left(1 \mathrm{ft}^{3} / \mathrm{min}\right)$ were obtained for simulation cases in which (part of) the well screen was located directly adjacent to a high-permeability zone. These high gas extraction rates correlate with low water extraction rates and delayed water arrival times at the extraction well. At the field test site, the combination of these observations (high gas extraction rate, low water extraction rate, delayed water arrival) is a strong indication that a high-permeability zone with low moisture content is negatively affecting the water extraction performance. However, if both relatively high water and gas extraction rates are observed, it is likely that the well screen is located adjacent to a high-moisture zone with a relatively high water permeability. Such conditions are most favorable for water removal using the pore-water extraction technique. 
Near-well compaction occurring during well installation will reduce both water and gas extraction rates but will not reduce these rates to zero. Field indicators of such conditions are relatively low water extraction rates in combination with low gas extraction rates. Based on testing within boreholes recently installed at the field test site, well development through surging and purging with relatively small volumes of water appears to have the ability to reduce near-well compaction and improve pore-water extraction performance. This testing also included use of a falling-head test approach to verify well development success in decreasing near-well compaction and providing an estimate of subsurface permeability adjacent to the screened interval based on an analytical computation. A series of STOMP simulations was completed as an independent evaluation of the falling-head test analysis applied during well development. The analytical computation, using a saturated-zone approach, yielded estimates of near-well permeability on the order of $1.0 \times 10^{-8} \mathrm{~cm}^{2}$. Similar values were obtained using the numerical approach for both saturated and unsaturated conditions. The main conclusion from the numerical analysis is that the analytical computation appears to be valid and can be used to interpret falling-head data during well development in these kinds of unsaturated sediments. A more complex numerical simulator is not needed to produce reliable order-of-magnitude-level permeability estimates.

Modeling was also conducted using configurations with more detailed layering of the CCUz that was based on soil moisture data from the field test site (borehole C8761). Simulations with these configurations resulted in pore-water extraction rates between approximately 2 and $5 \mathrm{~L} /$ day and gas extraction rates of less than $56.6 \mathrm{~L} / \mathrm{min}\left(2 \mathrm{ft}^{3} / \mathrm{min}\right)$. The reduced pore-water extraction rates, compared to the Base Case simulation, are related to the limited thickness of high-moisture zones from which water was extracted. The impact of limited thickness moisture zones will need to be considered when evaluating the field test data.

This modeling study provides estimates of pore-water extraction for a variety of potential conditions in the field. The study builds on the previous efforts to verify and quantify the pore-water extraction process (Oostrom et al. 2011; Truex et al. 2012). The modeling study results can be used to help guide equipment selection, operational strategies and interpretation of the field test results. The following specific recommendations for the field test configuration are based on these modeling results.

- Vacuum monitoring locations will be most effective within $3 \mathrm{~m}(10 \mathrm{ft})$ of the extraction well.

- Test equipment should accommodate pore-water extraction rates of up to $10 \mathrm{~s}$ of $\mathrm{L} /$ day with associated gas extraction rates of between 2.8 and $56.6 \mathrm{~L} / \mathrm{min}\left(0.1\right.$ and $\left.2 \mathrm{ft}^{3} / \mathrm{min}\right)$ for the expected subsurface conditions at the field test site.

- To improve the pore-water extraction rate, extraction well screens should target high-moisture zones and avoid intersecting zones with low moisture content. With the observed variation in moisture content at the field test site, a well screen interval of $0.3 \mathrm{~m}(1 \mathrm{ft})$ is expected to enable effective targeting of a high moisture content zone.

- Well development efforts are recommended to loosen the compacted zone of sediment adjacent to the well bore at the screened interval and improve the permeability of this zone using the techniques previously tested in borehole C8761. 


\subsection{References}

Carsel RF and RS Parrish. 1988 "Developing Joint Probability Distributions of Soil Water Retention Characteristics." Water Resources Research 24(5):755-769.

Ecology, EPA, and DOE (Washington State Department of Ecology, U.S. Environmental Protection Agency, and U.S. Department of Energy). 1989. Hanford Federal Facility Agreement and Consent Order. Document No. 89-10, as amended, Washington State Department of Ecology, U.S. Environmental Protection Agency, and U.S. Department of Energy, Olympia, Washington.

Khaleel R and EJ Freeman. 1995. Variability and Scaling of Hydraulic Properties for 200 Area Soils, Hanford Site. WHC-EP-0883, Westinghouse Hanford Company, Richland, Washington.

Last GV, EJ Freeman, KJ Cantrell, MJ Fayer, GW Gee, WE Nichols, BN Bjornstad, and DG Horton. 2006. Vadose Zone Hydrogeology Data Package for Hanford Assessments. PNNL-14702, Rev. 1, Pacific Northwest National Laboratory, Richland, Washington.

Mualem Y. 1976. "A new model predicting the hydraulic conductivity." Geoderma 65:81-92.

Oostrom M, TW Wietsma, JH Dane, MJ Truex, and AL Ward. 2009. "Desiccation of unsaturated porous media: Intermediate-scale experiments and numerical simulation." Vadose Zone Journal 8:643-650.

Oostrom M, VL Freedman, TW Wietsma, and MJ Truex. 2011. Pore-Water Extraction IntermediateScale Laboratory Experiments and Numerical Simulations. PNNL-20507, Pacific Northwest National Laboratory, Richland, Washington.

RPP-PLAN-53808. 2013. 200 West Area Tank Farms Interim Measures Investigation Work Plan. Rev. 1, Washington River Protection Solutions, LLC, Richland, Washington.

Truex MJ, M Oostrom, TW Wietsma, GV Last, and D Lanigan. 2012. Pore-Water Extraction Scale-Up Study for the SX Tank Farm. PNNL-21882, Pacific Northwest National Laboratory, Richland, Washington.

van Genuchten MT. 1980. "A Closed Form Equation for Predicting the Hydraulic Conductivity of Unsaturated Soils.” Soil Science Society of America Journal 44(5):892-898.

White MD and M Oostrom. 2006. STOMP: Subsurface Transport Over Multiple Phases, Version 4.0, User's Guide. PNNL-15782, Pacific Northwest National Laboratory, Richland, Washington. 


\section{Attachment}

\section{Vadose Zone Falling-Head Test Evaluation}

A copy of the technical memorandum "Vadose Zone Falling Head Test Evaluation," authored by Kevin Lindsey of GSI Water Solutions, Inc., is included here for reference purposes. This attached technical memorandum is independent of the work conducted by Pacific Northwest National Laboratory. 


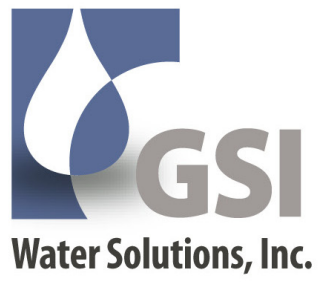

\title{
Technical Memorandum
}

\author{
To: $\quad$ Kent Reynolds, EnergySolutions Government Group \\ From: Kevin Lindsey, $\mathrm{LHg}$ \\ Date: 05 April 2013 \\ Re: $\quad$ Vadose Zone Falling Head Test Evaluation
}

The goal of this technical memorandum (tech memo) is to report on GSI's conclusions from the review and evaluation of data collected from five vadose zone falling head tests conducted in a borehole near the SX Tank Farm. These falling head tests were conducted in a small diameter boring installed by EnergySolutions Government Group (EnergySolutions) staff in the vadose zone at a test site near the SX Tank Farm. The purpose of the falling head tests was to collect data describing the effectiveness of well development techniques used in these borings to break down the compacted material that accumulates on the boring walls as drill rods are pushed into the ground using hydraulic/vibratory push techniques. For the purposes of this tech memo this material is referred to as the compaction skin.

This tech memo includes a brief summary of the data GSI worked with, our interpretations of that data, and recommendations for future work. The work reported on herein was done under EnergySolutions Government Group Purchase Order \#631861.

\section{Data and Interpretations}

The primary data set GSI used for this work consists of pressure data collected by a pressure logging transducer installed in the tested boring during a series of five falling head tests done between 12 March and 20 March 2013. The falling head tests were done, as noted above, to assess the success in breaking down the compaction skin that formed on the borehole wall during installation of the boring. The falling heads tests were done following instructions prepared jointly by GSI and EnergySolutions staff prior to field deployment. Attachment 1 shows the basic configuration of the boring during the tests.

The general timeline for these series of falling head tests, excerpted from EnergySolutions field notes, is summarized below.

1. Test 1, 12 March 2013. Using 1 gallon of water the boring was surged and purged for approximately 1 hour and 15 minutes. At the completion of that activity 1 gallon of

8019 W. Quinault Avenue, Suite 201 Kennewick, WA 99336 P: 509.735.7135 F: 509.735.7067 www.gsiws.com 
water was added to the boring at approximately 1218 . At 1415 an additional 2 gallons was added to the boring and the falling head test commenced. This test ended the following morning with most of the water having drained away.

2. Test 2, 13 March 2013. After adding water to, and surging and bailing the boring for several hours test 2 commenced at approximately 1415 with the addition of 2 gallons of water. This falling head test ended at 0739 the following morning.

3. Test 3, 14 March 2013. After adding water to, and surging and bailing the boring for approximately 1.5 hours test 3 commenced at approximately 1054 with the addition of 2 gallons of water. This falling head test ended at 0707 on 18 March.

4. Test 4, 18 March 2013. After adding water to, and surging and bailing the boring for approximately 1.5 hours test 4 commenced at approximately 1054 with the addition of 2 gallons of water. This falling head test ended at 1103 the following morning.

5. Test 5, 19 March 2013. After adding water to, and surging and bailing the boring for approximately 0.75 hours test 5 commenced at approximately 1232 with the addition of 2 gallons of water. This falling head test ended the following morning.

6. Water bailed from the boring as the test progressed was observed to be progressively less turbid. Field staff reported that water dialed form the boring during Tests 4 and 5 was significantly less turbid that that bailed during Tests 1 and 2 .

During each falling head test a pressure transducer was deployed in the boring to measure head changes in it as the 2 gallon slug of water drained out of the boring. The pressure transducer was programmed by field staff to record data logarithmically. Pressure transducer data was provided to GSI in digital form as a csv file downloaded from the transducer. GSI converted that csv file to an xls file for review and evaluation. Hydrographs of the data from the 5 falling head tests are included with this tech memo as Attachment 2.

Visual examination of Attachment 2 shows that during the first 100 plus seconds of each tests water levels rose. This is interpreted to show the pouring of the 2 gallon test volume into the boring. For that reason this following discussion focuses on the data collected after 100 seconds as that data is interpreted to provide the most information regarding the progress of development and the breaking down of the compaction skin coating the boring wall.

Generally, one sees that in Tests 1 and 2 water levels rose and/or were static between 100 and 500 to 600 seconds into the test. Conversely, in Tests 3, 4, and 5 water levels began to decline between 100 and 200 seconds into each test. Later in the tests both Test 1 and 2 show that the boring took in excess of 60,000 seconds to drain while in Tests 3,4 , and 5 the boring was largely drained by 10,000 to 20,000 seconds into the test.

The decline rates versus time for tests 1 through 4 are plotted on Attachment 3 . This plot shows that water level decline rates per unit time were much lower (less than $-0.002 \mathrm{feet} / \mathrm{sec}$ ) and steady in Tests 1 and 2. Conversely, in Tests 3 and 4 the initial decline rates were much higher (up to $-0.005 \mathrm{ft} / \mathrm{sec}$ ) throughout the tests. Based on the visual examination of this data as portrayed on Attachments 2 and 3, development, in the form of surging and purging, is interpreted to have broken down the compaction skin between Tests 2 and 3, allowing the 2 gallon slug of water introduced into the boring to drain significantly faster. The similarities in the hydrographs for Test 3, 4, and 5 shown in Attachment 2 suggests that the development

8019 W. Quinault Avenue, Suite 201 Kennewick, WA 99336 P: 509.735 .7135 F: 509.735 .7067 www.gsiws.com 
work conducted between Tests 4 and 5 yielded little to no additional improvement in compaction skin breakdown, and that the boring was as developed as this technique could accomplish.

Additional comments and interpretations specific to each falling head test are given below.

Test 1: The hydrograph of Test 1 (Attachment 2) shows increasing water in the boring from the end of pouring in the slug $(\sim 100 \mathrm{sec})$ to approximately 225 seconds. Then the water level in the well begins to fall gradually for the duration of the test. It appears that the slug did not rapidly flush out of the screen but instead seeped out over a long time period. Average rates of change during the first, second, and third log cycles were $-0.00069 \mathrm{ft} / \mathrm{sec},-0.00096 \mathrm{ft} / \mathrm{sec}$, and -0.00042 $\mathrm{ft} / \mathrm{sec}$, respectively (Table 1 ).

Table 1. Average Falling Head Rate of Change for each Log Cycle.

\begin{tabular}{|cccc|}
\hline Test & $100-1000$ seconds & $1000-10000$ seconds & 10000-60000 seconds \\
\hline 1 & $-0.00069 \mathrm{ft} / \mathrm{sec}$ & $-0.00096 \mathrm{ft} / \mathrm{sec}$ & $-0.00042 \mathrm{ft} / \mathrm{sec}$ \\
2 & $0.00271 \mathrm{ft} / \mathrm{sec}$ & $-0.00040 \mathrm{ft} / \mathrm{sec}$ & $-0.00025 \mathrm{ft} / \mathrm{sec}$ \\
3 & $-0.00289 \mathrm{ft} / \mathrm{sec}$ & $-0.00193 \mathrm{ft} / \mathrm{sec}$ & Test complete \\
4 & $-0.00405 \mathrm{ft} / \mathrm{sec}$ & $-0.00207 \mathrm{ft} / \mathrm{sec}$ & Test complete \\
\hline
\end{tabular}

Using Test 1 data a Darcy's Law permeability of approximately $1.0 \mathrm{E}-8 \mathrm{~cm}^{2}$ is estimated (Darcy, 1856; Bear, 1972). Using bulk density data provided by EnergySolutions for silty fine sands such as the boring likely penetrates, natural formation permeability estimated using the Kozeny-Carman method is approximately 3.0 to $4.0 \mathrm{E}-8 \mathrm{~cm}^{2}$ (Carman, 1956; Saar and Manga, 1999). Comparing Test 1 estimated permeability to bulk density estimated permeability suggests that the boring compaction skin has 3 to 4 times less permeability than natural formation materials.

Test 2: The hydrograph of Test 2 (Attachment 2) shows increasing water level in the boring from the end of pouring in the slug $(\sim 100 \mathrm{sec})$ to approximately 530 seconds. Then the water level in the well begins to fall gradually for the duration of the test. It appears that the slug did not rapidly flush out of the screen but instead seeped out over a long time period. The rate of change from 800 to 60,000 seconds in Test 2 is less than the rate of change during the 2,000 to 60,000 second interval in Test 1 . Average rates of change during the first, second, and third log cycles were $0.00271 \mathrm{ft} / \mathrm{sec},-0.00040 \mathrm{ft} / \mathrm{sec}$, and $-0.00025 \mathrm{ft} / \mathrm{sec}$, respectively (Table 1 ).

Using Test 2 data a Darcy's Law permeability of approximately $1.0 \mathrm{E}-8 \mathrm{~cm}^{2}$ is estimated (Darcy, 1856; Bear, 1972). Using bulk density data provided by EnergySolutions for silty fine sands such as the boring likely penetrates, natural formation permeability estimated using the Kozeny-Carman method is approximately 3.0 to $4.0 \mathrm{E}-8 \mathrm{~cm}^{2}$ (Carman, 1956; Saar and Manga, 1999). Comparing Test 2 estimated permeability to bulk density estimated permeability suggests that the boring compaction skin continued to have 3 to 4 times less permeability than natural formation materials at the conclusion of the second test.

8019 W. Quinault Avenue, Suite 201 Kennewick, WA 99336 P: 509.735 .7135 F: 509.735 .7067 www.gsiws.com 
Test 3: The hydrograph for Test 3 shows water level immediately decreasing and at a rapid rate from the end of pouring in the slug $(\sim 100 \mathrm{sec})$ to when the water level reaches approximately just above the top of the well screen at 7560 seconds. At this point the falling head test is interpreted to be complete. Rate of water level change in the boring increased rapidly between approximately 100 and 200 seconds. From approximately 400 seconds to 7560 seconds, rate of change decreased at a moderate but relatively constant rate. Average rates of change during the first and second $\log$ cycles were $-0.00289 \mathrm{ft} / \mathrm{sec}$ and $-0.00193 \mathrm{ft} / \mathrm{sec}$, respectively (Table 1 ). As noted above, the test was interpreted to be complete when the falling slug reached the bottom of the boring casing at 7560 seconds; this is before the start of the third log cycle.

Using Test 3 data a Darcy's Law permeability of approximately $3.6 \mathrm{E}-8 \mathrm{~cm}^{2}$ is estimated (Darcy, 1856; Bear, 1972). Using bulk density data provided by EnergySolutions for silty fine sands such as the boring likely penetrates, natural formation permeability estimated using the Kozeny-Carman method is approximately 3.0 to $4.0 \mathrm{E}-8 \mathrm{~cm}^{2}$ (Carman, 1956; Saar and Manga, 1999). Comparing Test 3 estimated permeability to bulk density estimated permeability suggests that development activities had broken down the compaction skin and that during Test 3 the boring had significant hydrologic connection with formation materials.

Test 4: The results for Test 4 are very similar to Test 3 . The hydrograph for Test 4 shows water level immediately decreasing and at a rapid rate from the end of pouring in the slug ( 100 sec) to when the water level reaches approximately just above the top of the well screen at 6720 seconds. At 6720 seconds Test 4 is interpreted to be complete. Rate of water level change over time in the boring increased rapidly between 100 and 150 seconds at which point it decreased less rapidly to about 350 seconds. From about 350 seconds to about 6720 seconds, rate of change decreased at a moderate but relatively constant rate. Average rates of change during the first and second $\log$ cycles were $-0.00405 \mathrm{ft} / \mathrm{sec}$ and $-0.00207 \mathrm{ft} / \mathrm{sec}$, respectively (Table 1 ). As noted above, the test was interpreted to be complete when the falling slug reached the bottom of the boring casing at 6720 seconds; this is before the start of the third log cycle.

Using Test 4 data a Darcy's Law permeability of approximately $9.8 \mathrm{E}-8 \mathrm{~cm}^{2}$ is estimated (Darcy, 1856; Bear, 1972). Using bulk density data provided by EnergySolutions for silty fine sands such as the boring likely penetrates, natural formation permeability estimated using the Kozeny-Carman method is approximately 3.0 to $4.0 \mathrm{E}-8 \mathrm{~cm}^{2}$ (Carman, 1956; Saar and Manga, 1999). Comparing Test 4 estimated permeability to bulk density estimated permeability shows that the formation material in the vicinity of the boring may have a relatively higher than generally estimated. Given that, development activities are interpreted to have broken down the compaction skin and that during Test 4 the boring had significant hydrologic connection with formation materials.

Test 5: The falling head data collected for Test 5 is very similar to that collected for Test 3 and 4 (Attachment 2). Given that, Test 5 is interpreted to show that further development was not necessary and no additional evaluation was done.

\section{Conclusions and Recommendations}

Conclusions: Based on the data collected during development and falling head tests conducted by EnergySolutions between 12 March and 20 March 2013, the methodology employed is interpreted to have successfully broken down the compaction skin generated during borehole advance. This data is interpreted to show that following several attempts at development using a surge and purge technique the compaction skin broke down, and with purging this material

8019 W. Quinault Avenue, Suite 201 Kennewick, WA 99336 P: 509.735 .7135 F: 509.735 .7067 www.gsiws.com 
was removed from the boring. The falling head rates and permeability estimates seen for Test 3 and 4 versus Test 1 and 2 are interpreted to show successful development.

Based on the data evaluated for this tech memo we conclude that falling head data collected during the first half hour to 1.5 hours of a test can be used to show successful development, as follows:

- In Tests 1 and 2 the first 1000 to 5000 seconds of the tests showed rising, followed by relatively static, to finally slowly decreasing water levels (Attachment 4). This is interpreted to reflect slow drainage of the boring through a relatively undisturbed (undeveloped) compaction skin.

- In Tests 3, 4, and 5 this feature is not seen.

- Instead, in these tests water level immediately begins falling within 100 seconds of it reaching its highest level. In addition, the boring is almost completely drained between 6500 to 7500 seconds (108 to 125 minutes, 2 hours or less) of the start of the test. This is much faster than was seen during Test 1 and 2 where draining was still occurring 50,000 to 60,000 seconds ( 833 to 1000 minutes, up to 16 hours) following the start of the test.

- We conclude that once development succeeds in breaking down the compaction skin falling head tests will show a change from the trend seen in Test 1 and 2, where water level is relatively static before it begins to fall) to that seen in Tests 3,4 , and 5 where water level begins falling from essentially the beginning of the test.

Recommendations: For future well development activities where conditions similar to those tested between 12 March and 20 March are encountered, and based on the data evaluated herein, GSI recommends the following basic method:

1. Once the borehole is ready for development, add a 2 gallon slug of water to it.

2. Leave this slug of water in the borehole for at least 12 hours. The purpose of this is to have water permeate the compaction skin to begin softening and degrading it preparatory to subsequent surge and purge development.

3. At this point begin development activities using 3 to 4 surge and purge events similar to those used in this effort. Each surge and purge would generally include:

a. 30 minutes of surging the 2 gallons of water in the boring.

b. Purging that water from the boring.

c. Repeating until such time as the purge water is visibly less turbid as compared to the initial purge.

4. When the purge water is visibly less turbid conduct a falling head test.

a. In this test one is looking to see if the slug of water stabilizes such as it did in Tests 1 and 2 or quickly begins to fall such as it did in Tests 3,4 , and 5 .

5. If the slug shows the slow rise, stabilization, and slow fall seen in the first 30 minutes of Tests 1 and 2 development of the compaction skin is interpreted to be incomplete bullets 3 and 4 above should be repeated.

8019 W. Quinault Avenue, Suite 201 Kennewick, WA 99336 P:509.735.7135 F: 509.735 .7067 www.gsiws.com 
6. If the slug shows the rapid fall seen in the first 30 minutes of Tests 3,4 , and 5 development is interpreted to be having an effect on the compaction skin. In such a case the final recommended steps are to:

a. Purge the well of the slug.

b. Add a new clean slug.

c. Conduct one 30 minute surge operation followed by purging.

d. Add a new 2 gallon slug and conduct another falling head test.

e. If the slug is seen to be falling at rates similar to the previous falling head test development can be interpreted to be complete.

f. If the slug is seen to be falling at a higher rate, then repeat bullets 6a through $6 f$.

\section{References}

Bear, J., 1972, Dynamics of Fluids in Porous Media: Dover.

Carman, P.C., 1956, Flow of Gases Through Porous Media: Academic, San Diego, 182 pgs.

Darcy, H., 1856, Les Fontaines Publique de la Ville de Dijon: Dalmont, Paris.

Saar, M.O., and Manga, M., 1999, Permeability-porosity relationship in vesicular basalts: Geophysical research Letters, v. 26, n. 1, pgs 111 - 114. 


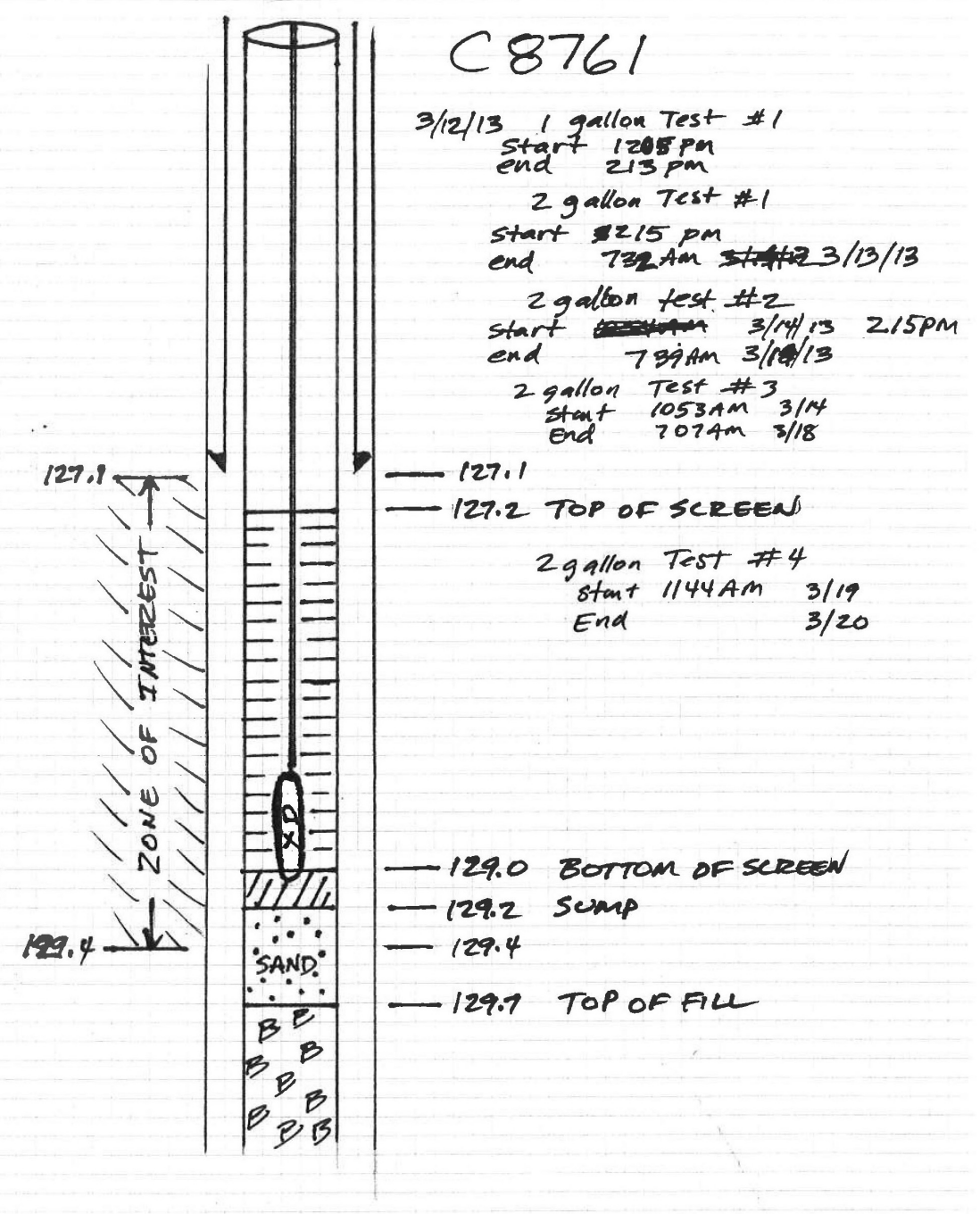

Attachment 1. Basic boring configuration during the falling head tests. 


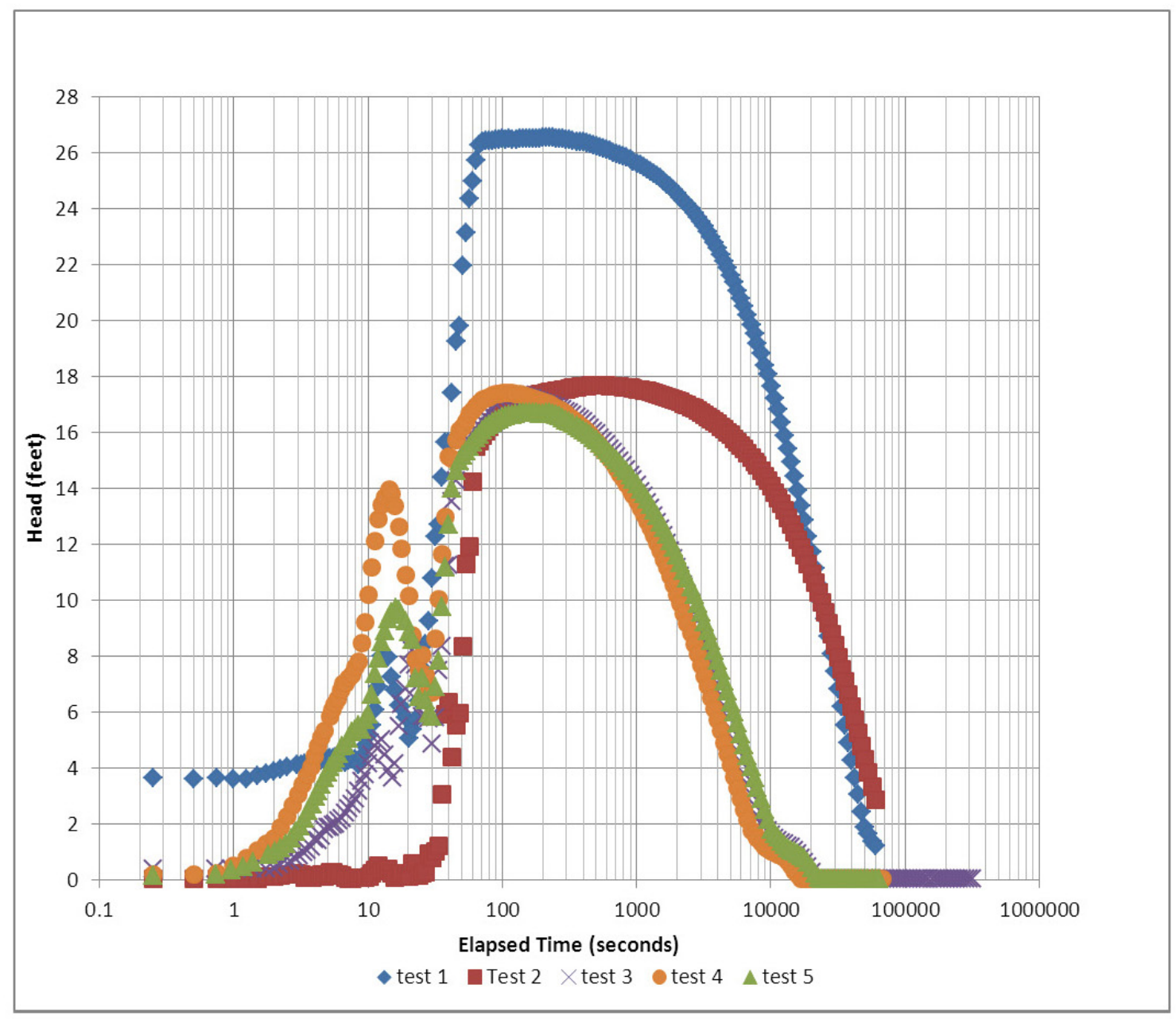

Attachment 2. Falling Head Test Hydrograph.

8019 W. Quinault Avenue, Suite 201 Kennewick, WA 99336 P: 509.735 .7135 F: 509.735 .7067 www.gsiws.com 


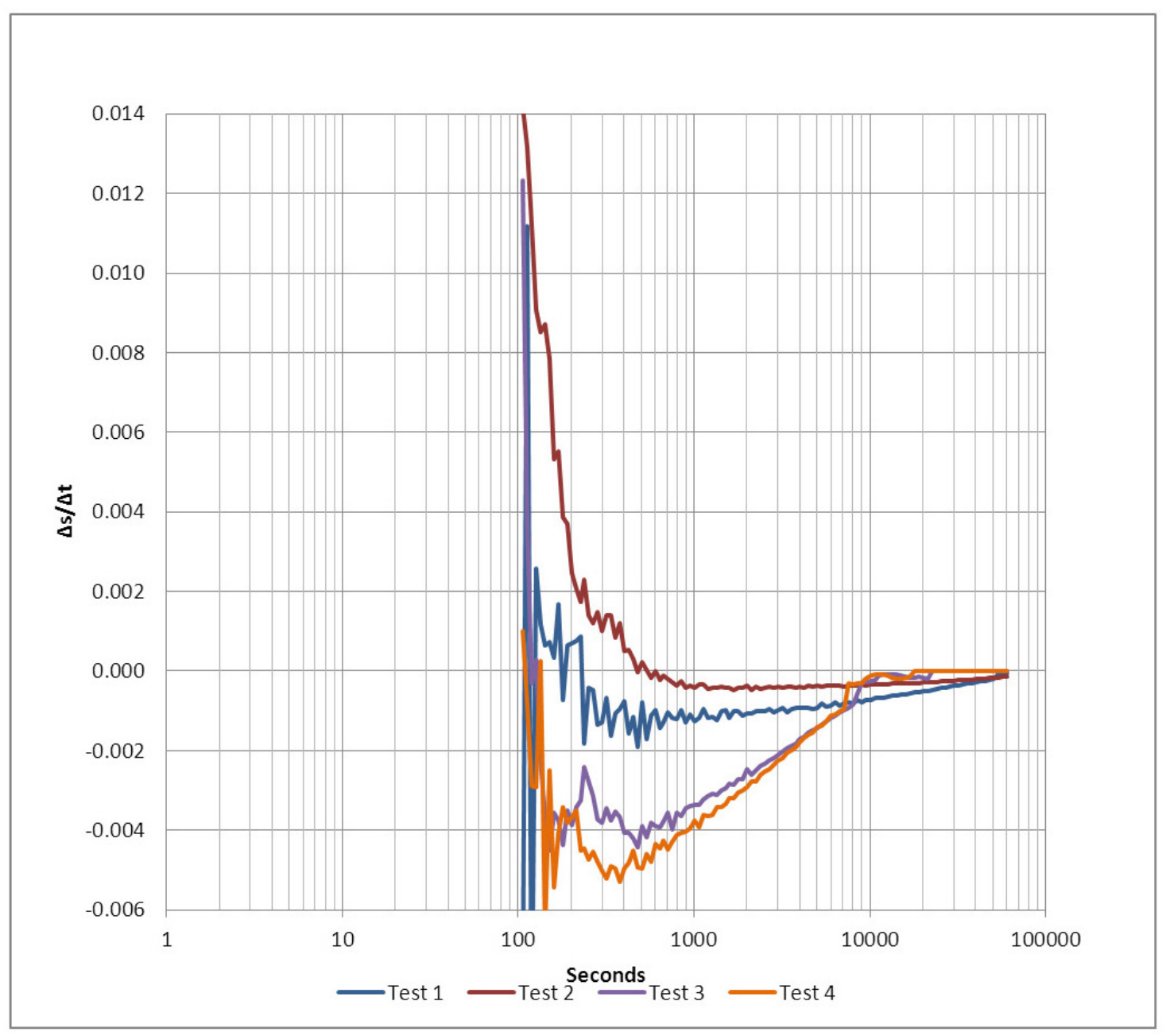

Attachment 3. Calculated Falling Head Test Rates of Change.

8019 W. Quinault Avenue, Suite 201 Kennewick, WA 99336 P: 509.735 .7135 F: 509.735 .7067 www.gsiws.com 


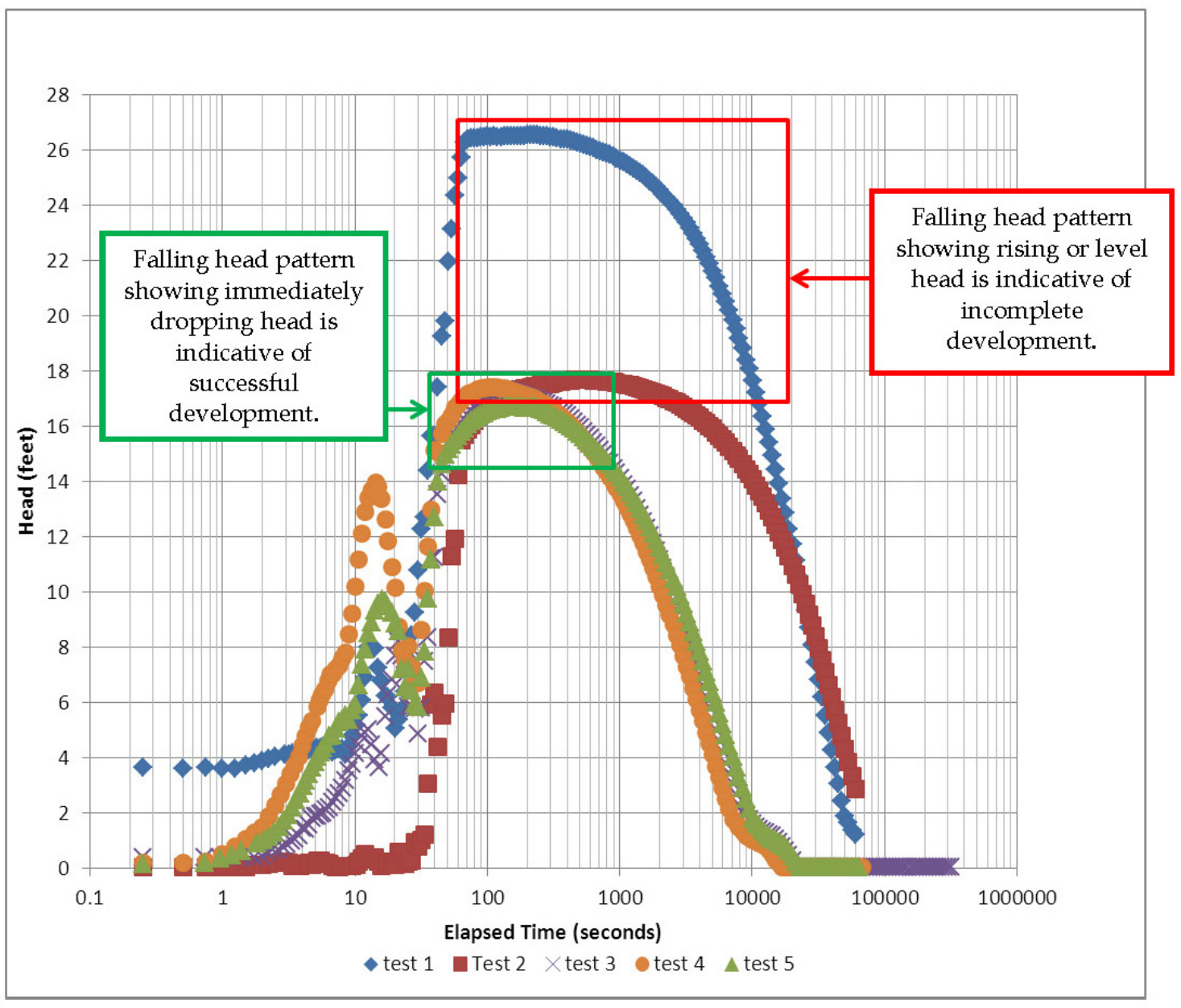

Attachment 4. Falling Head Patterns Indicative of Incomplete and Successful Development. 


\section{Distribution}

No. of

Copies

ONSITE

3 U.S. Department of Energy, Richland Operations Office

BL Charboneau

JG Morse

A6-33

A5-11

$\mathrm{H} 2-53$
No. of

$\underline{\text { Copies }}$

3 Pacific Northwest National Laboratory

M Oostrom

K9-33

MJ Truex

K6-96

DM Wellman

2 U.S. Department of Energy, Office of River Protection

RD Hildebrand

A6-38

CJ Kemp

H6-60

2 Washington River Protection Solutions

LLC

SJ Eberlein

H6-13

D Parker

H6-13 


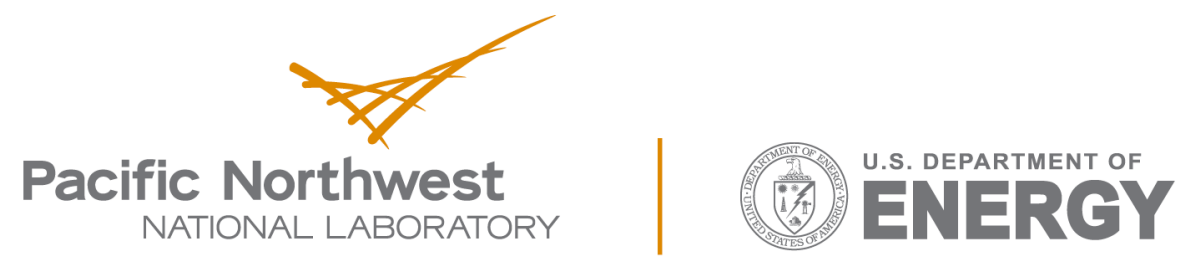

Proudly Operated by Battelle Since 1965

902 Battelle Boulevard

P.O. Box 999

Richland, WA 99352

1-888-375-PNNL (7665)

www.pnnl.gov 